NBSIR 84-2817

\title{
Decision Analysis Model for Passenger-Aircraft Fire Safety With Application to Fire-Blocking of Seats
}

U.S. DEPARTMENT OF COMMERCE

National Bureau of Standards

National Engineering Laboratory

Center for Fire Research

Washington, DC 20234

March 1984

Sponsored by:

U.S. Department of Transportation

Federal Aviation Administration

$Q C-$

Atlantic City, New Jersey 08405 

DECISION ANALYSIS MODEL FOR

PASSENGER-AIRCRAFT FIRE SAFETY

WITH APPLICATION TO FIRE-BLOCKING

OF SEATS

John R. Hall, Jr.

S. Wayne Stiefel

U.S. DEPARTMENT OF COMMERCE

National Bureau of Standards

National Engineering Laboratory

Center for Fire Research

Washington, DC 20234

March 1984

Sponsored by:

U.S. Department of Transportation

Federal Aviation Administration

Atlantic City, New Jersey 08405

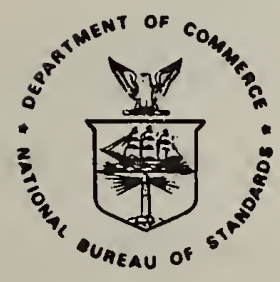

U.S. DEPARTMENT OF COMMERCE, Malcolm Baldrige, Secretary NATIONAL BUREAU OF STANDARDS, Ernest Ambler, Director 



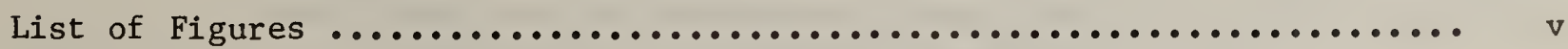

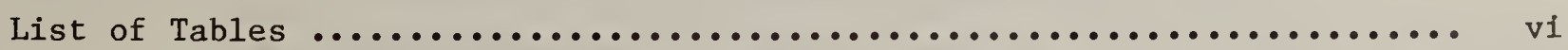

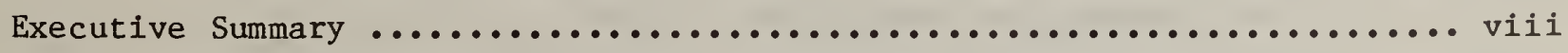

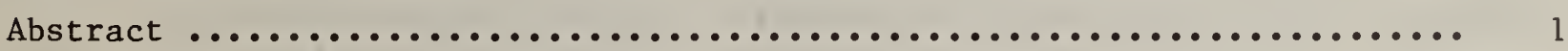

1. INTRODUCTION ....................................... 1

2. GENERIC MODELING FRAMEWORK FOR AIRCRAFT-FIRE DECISION ANALYSIS .....

2.1 Overview of the Parts of the Modeling Framework ............. 3

2.1.1 Aircraft/Activity/Occupant Characteristics and

Fire Scenarios ............................ 3

2.1 .2 Decision Mode1 ................................ 4

2.1.3 Ignition-Initiation Model ....................... 5

2.1.4 Post-Ignition Model ............................. 5

2.1.5 Loss Evaluation Model ............................ 7

2.1 .6 Cost Mode1 ..................................... 8

2. 1.7 Cost-Benefit Comparison Model ...................... 9

2.1.8 Summary of Models to be Discussed in Greater Detail .... 9

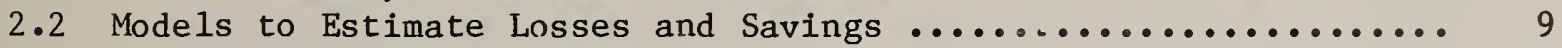

2.2.1 Identifying the Historical Data Base ................. 10

2.2.2 Activity Forecasts Needed to Model Expected Loss ........ 13

2.2.3 Estimating Expected Losses with an Alternative ........ 14

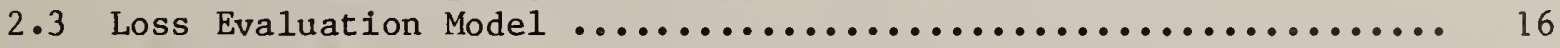

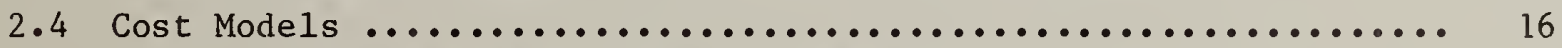

2.4.1 Forecasts Used in the Cost Models ................... 17

2.4.2 Mode1 of Installation and Maintenance Costs .......... 17

2.4.3 Model of Operating Costs .......................... 19

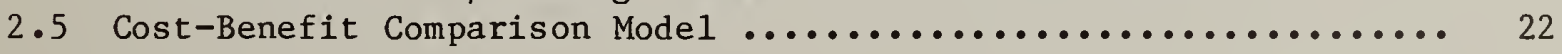

3. REVIEW OF RELATED PROJECTS AND LITERATURE .................... . 23

4. SAMPLE APPLICATION : FIRE-BLOCKING OF SEATS ...................

4.1 Expected Losses and Savings with Seat Blocking .............. 26

4.2 Expected Costs for Seat Blocking ......................... 27

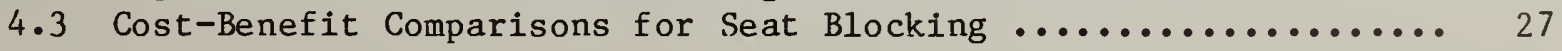

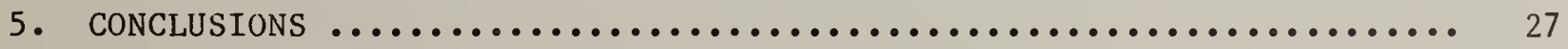

6. ACKNOWLEDGMENTS ....................................... 
Appendix A. Sources and Rationales for Estimated Fire Fatalities -

Total and Estimated Saveable by Seat Blocking .......... A-l

Appendix B. Historical Accidents Involving Fires and Fatalities But

No Fire-Related Fatalities, 1965-82

Appendix C. Historical Major Alrcraft-Fire Property Damage Preventable

by Alternatives Operating in the Alrcraft Interior ...... C-l

Appendix D. Historical Passenger-Exposure Calculations ............. D-1

Appendix E. Forecasts Used in the Cost Models ................... E-l

Appendix F. Annotated Listing of Literature Reviewed .............. F-1

Appendix G. Data Sources and Calculations for Sample Application of

Models to Fire-Blocking of Alrcraft Seats ............ G-1

Appendix H. Formulas for Additional Sensitivity Analysis ............ H-l 


\section{LIST OF FIGURES}

Page

Figure l. Generic Modeling Framework for Aircraft-Fire Decision

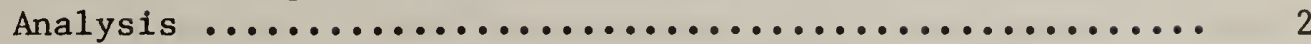

Figure 2. Compact Post-Ignition Display Format for PassengerAircraft Fire Fatalities.

Figure E-l. Sensitivity of Incremental Fuel Consumption to Increased Weight, 1985-2000 
Table 1. Historical Fire Fatalities, 1965-82, U.S. Airlines ....... 11

Table 2. Historical Fire Fatalities, 1965-82, Non-U.S. Airlines Using U.S.-Built Aircraft ...................... 12

Table 3. Historical Fire Fatalities, 1965-82, Non-U.S. Airlines

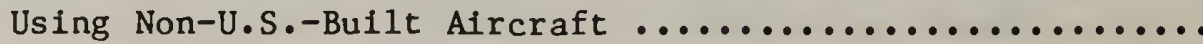

Table 4. Forecast Passenger-Miles as Percentages of Base-Year Figures, Scheduled and Non-Scheduled, Jet and Turboprop, 1983-1997

Table 5. Summary of Characteristics of Seat-Blocking Materials ......

Table 6. Summary of Annualized Costs and Benefits for Seat-Blocking Alternatives

Table 7. Net Annualized Benefits Over Costs for Seat-Blocking Alternatives

Table C-1. Historical Major Aircraft Fire Losses Preventable by Alternatives Operating in the Aircraft Cabin .......... C-2

Table C-2. Summary Estimates of Preventable Property Damage in Aircraft Fires

Table C-3. Bases for Estimating Values of Property Damage to Aircraft

Table D-1. Historical Passenger-Miles (in Billions) for Scheduled and Non-Scheduled Passenger Flights ................ D-2

Table D-2. Estimated Percentage of Passenger-Miles on Piston Aircraft.. D-3

Table D-3. Estimated Percentage of World-Airline, Turbine-Aircraft Traffic in Non-U.S. Airlines Using Non-U.S.-Built Aircraft .................................. D

Table D-4. Total Estimated Passenger-Miles (in Billions), Scheduled and Non-Scheduled, Jet and Turboprop Only, 1965-1982 .... D-5

Table D-5. Assumed Typical Number of Seats Carried on Passenger Flights, by Aircraft Type ..................... D-6

Table E-1. Passenger Aircraft by Generic Class .................. E-2

Table E-2. Historical Projected Passenger-Miles and Available Seat-Miles, 1982-1997 
Table E-3. Inventory, Activity and Descriptive Statistics by Aircraft Model Class, U.S. Airlines Only ................... E-4

Table E-4. Inventory, Activity and Descriptive Statistics by Aircraft Model Class, World Airlines ..................... E-6

Table E-5. Fuel Cost Factors Related to Weight Penalties ........... E-8

Table G-1. Estimated Fire Fatalities Prevented by Seat Blocking,

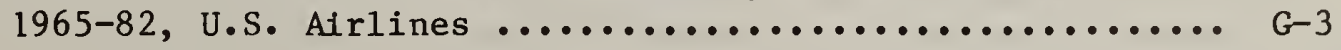

Table G-2. Estimated Fire Fatalities Prevented by Seat Blocking, 1965-82, Non-U.S. Airlines Using U.S.-Built Aircraft ..... G-4

Table G-3. Estimated Fire Fatalities Prevented by Seat Blocking, 1965-82, Non-U.S. Airlines Using Non-U.S.-Built Aircraft G-5

Table G-4. Total Estimated Fatalities Preventable by Seat Blocking in Historical Period ........................... G-6

Table G-5. Estimated Annual Savings From Seat Blocking Given 1982 Exposure Levels .............................. G-7

Table G-6. Estimated Annual Savings Given Five Values of Added Escape Time and 1982 Exposure Levels .................... G-8

Table G-7. Additions to or Reductions in Savings at Limits of Expected Values of Added Escape Time ..................... G-9

Table G-8. Design Characteristics of Seat Blocking Alternatives ....... G-10

Table G-9. Seat Back and Bottom Cushion Incremental Cost and Weight Data .......................................11

Table G-10. High, Middle and Low Cost and Weight per Seat Estimates for Blocking Materials ............................ G-12

Table G-11. Schedule of Seats Blocked for U.S. Fleet Using a Three-Year Refurbishment Cycle ........................... G-12

Table G-12. Schedule of Seats Blocked for World Fleet Using a Three-Year Refurbishment Cycle ............................ G-13

Table G-13. Schedule of Seats Blocked for U.S. Fleet Using a Three-Year Phase-In and Six-Year Reblocking Cycle ................. G-13 
Fire-risk assessment and decision analysis methodologies were developed for the case of major aircraft fires. A generic model has been developed covering fatal passenger-flight fires and fires involving major fire damage. That model has then been applied to the risk-reduction strategy of seat blocking. The model permits not only assessment of the costs (initial and operating) and benefits (lives saved and damage averted) of currently established blocking materials but also rapid calculation of the impact of changes in cost on performance in the face of rapid innovation. Evidence on the sensitivity of overall benefit/cost calculations to changes in one area versus another can be useful in developing priorities for safety research.

The benefits models are organized around a data base of historical fires. Tests and deterministic models are used to assess likely exit speeds, relative contributions of various fire-involved materials to fatalities, projects performance of risk-reduction alternatives, and other factors used in assessing which victims could have been saved by an alternative. Significant uncertainties still remain in these estimates because of uncertainties in some of the models (e.g., models on the role of cyanide in causing fatalities) and even more because of uncertainties in the detail available on circumstances of some accidents. At least in the first sample application, however, these uncertainties did not preclude use of the models to produce useful conclusions.

The cost models use aircraft manufacturers' estimates and forecasts for the project phase-in of new alrcraft, operation and efficiency of the aircraft fleet and fuel costs over the next 15 years, and seat manufacturers' estimates to produce estimated costs for installing the alternative and operating with it. Significant uncertainties exist because these estimates nearly all involve forecasting based on the state of the economy or for products with which manufacturers have very limited experience, but as with benefits models, these uncertainties do not preclude the use of the models to produce useful conclusions.

In the sample application, for example, many key assumptions that were checked for sensitivity proved not to be critical in the assessment of net benefits over costs. Benefits proved less sensitive in general than costs. The relative insensitivity of benefits emphasizes the importance of reducing costs. For the seat-blocking material with the lowest cost and least weight, costs and benefits were closely matched, which meant that conclusions on whether benefits exceed costs or vice versa were sensitive to many of the assumptions used in the analysis. If costs could be reduced even further, sensitivity to these assumptions would be reduced, and the net benefits of seat blocking would be clearly established. Appendix H presents formulas that can be used for quick analysis of the impact of changes in fuel prices, weight penalty per seat, or incremental changes in the costs of fabricating and installing seat blockers.

While no analysis was done on the effects of varying either the discount rate or the speed or timing of the phase-in of seat blocking, it is probably safe to assume that neither would dramatically affect the results. The sizeable contribution of operating costs and the short time between seat refurbishments mean that benefits are incurred at about the same rate as costs. 
This report develops a generic model for analysis of the costs and benefits of fire-risk reducing strategies related to passenger airlines. The model calculates incremental costs for installing and operating these options. It also calculates estimated lives saved and property damage avoided, and it provides rules for combining costs and benefits into a single measure of attractiveness for an alternative. This model is then applied to the strategy of fire-blocking seats on passenger airlines, either on U.S. airlines or on all world airlines.

Key words: aircraft accidents; airlines safety; decision analysis; fire risk; fire statistics; risk analysis.

\section{INTRODUCIIION}

The Federal Aviation Administration (FAA) is concerned about the costs and benefits associated with risk-reduction strategies affecting aircraft accidents, including fires; the National Bureau of Standards' Center for Fire Research (CFR) has an interest in the development of techniques for assessing costs and benefits of fire-risk-reduction strategies. This commonality of interest formed the basis for a project to develop analytic models to assess costs and benefits of candidate risk-reduction strategies targeted at aircraft fire scenarios. This report presents the results of the first year's effort in which the generic model framework was developed and applied in detail to $a$ leading candidate risk-reduction strategy - the use of fire-blocking layers* on passenger-aircraft seats.

The generic model framework and the particular models used in developing estimates of costs and benefits.for risk-reduction strategies are presented in section 2. Section 3 provides a brief discussion of the technical literature reviewed for this project, including sources of models, key assumptions and data; Appendix F contains an annotated listing of that literature. Section 4 contains a sample application of the detailed modeling framework to several versions of the seat-blocking strategy.

\section{GENERIC MODELING FRAMEWORK FOR AIRCRAFT-FIRE DECISION ANALYSIS}

Figure 1 provides an overview of the generic modeling framework. The initial step establishes a structure for the fires to be studied. The analyst identifies aircraft types, activity types, occupant characteristics and fire types of interest, and uses this structure in deciding what data are needed for the other models in the framework. These data are used in parallel by three models: (1) the Ignition-Initiation Model, which provides estimated probabilities of ignition; (2) the Post-Ignition Model, which provides estimated losses (e.g., deaths, injuries and property damage) given ignition; and (3) the Cost Model. The first two models provide the probabilities of accidents and the severities of those accidents, respectively. Together, the measured probabilities and severities give the level of risk, while the third model - the Cost Model - gives the corresponding cost.

\footnotetext{
* This involves the introduction of a layer of material - bonded to, sewn onto or sprayed onto the urethane core - underneath the seat cover in order to delay or prevent involvement of the seats in fire spread.
} 


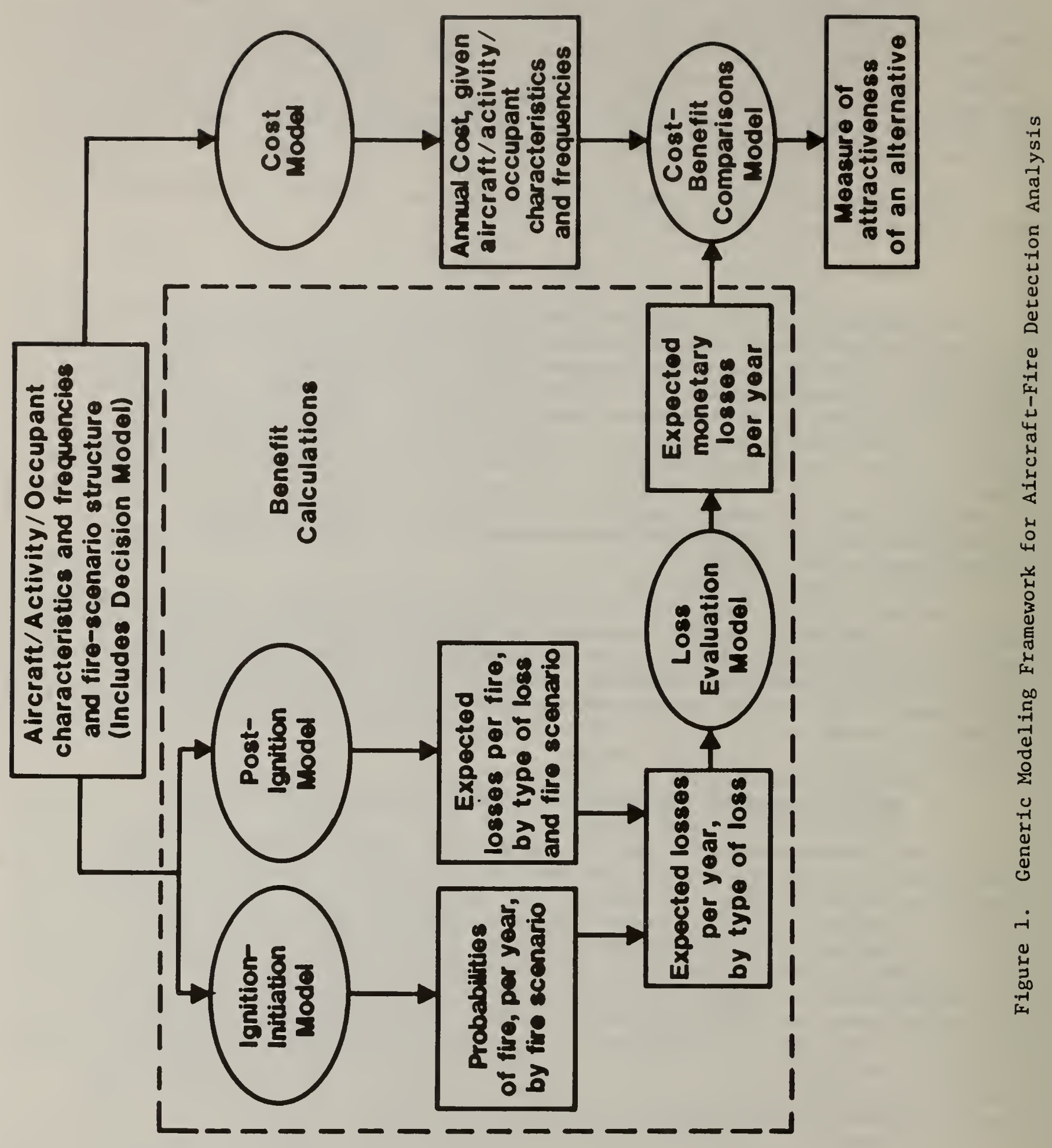


For ease of computation, each of these models is set up to measure risks and costs relative to a base case, which is usually defined as the status quo (and will be so defined in this study). The measured risk, derived from the Ignition-Initiation Model and the Post-Ignition Model, is passed to a Loss Evaluation Mode1, which converts different types of losses (deaths, injuries, property damage) to a common scale. Finally, a Cost-Benefit Comparison Model is used to convert costs and losses into a measure of attractiveness for the alternative.

\subsection{Overview of the Parts of the Modeling Framework}

\subsubsection{Aircraft/Activity/Occupant Characteristics and Fire Scenarios}

The specification of aircraft/activity/occupant characteristics and fire scenarios is intended to (a) bound the problem by excluding flights or fires that are not of interest to the analyst or that would not be affected by the alternative being studied, (b) take account of characteristics that significantly affect either the cost of adopting the alternative or its likely effect, and (c) provide a basis for extrapolating 1ikely future loss and cost experience.

Bounding the aircraft fire problem involved several exclusions. First, flights and accidents involving piston engine or rotary blade aircraft or occurring prior to 1965 were excluded. Jet aircraft dominate air activity today, and 1965 is roughly the start of that period of dominance. Turboprop aircraft are included but constitute a small part of the total. Piston engine and rotary blade aircraft account for a very small share (less than one percent) of commercial passenger flight activity, so they can be safely excluded.

Second, flights other than passenger flights are excluded because this study was directed at alternatives that improve life safety on passenger flights. Cargo flights, training flights, repositioning flights, and flights by military aircraft or privately owned aircraft were excluded from the analysis, even though some of them could be affected by some alternatives. These types of flights would add considerably to the uncertainty in the analysis because data is much less available for such flights. Scheduled and non-scheduled service were both included.

Third, the analysis focused on U.S. airlines, which are FAA's responsibility, but a separate analysis of world airlines (excluding those of the Soviet bloc countries, where data is particularly scarce and U.S. influence is slightest) also was done. One reason is that most non-U.S. airlines use U.S. aircraft, and any change in U.S. airline fleets probably will have ripple effects worldwide. An initial examination of the effect of excluding non-U.S.-built aircraft flown by non-U.S. airlines is briefly discussed in the sample application. The results were so close to those for the world-airline case, however, that there seemed to be little value in pursuing a separate analysis.

To account for effects on either the cost or the likely impact of the alternative, occupant characteristics and fire scenarios had to be spectfied. Occupants were characterized on a fatality-by-fatality basis in terms of both the ability of the alternative to help them (by preventing, moderating or delaying the conditions that killed them) and the victim's own ability to use 
that help if it were provided. An example of the former would be the separating out of persons killed by 1mpact trauma in a crash; they would be unaffected by any measures directed against the post-crash fire. An example of the latter would be the separating out of persons stunned by the crash; they would benefit from any measure that stopped the fire but could not have made use of the extra escape time provided by an alternative that only delayed the fire. The same might be true of small children and very elderly or infirm passengers.

Fire scenarios were set up on the basis of an initial partitioning into in-flight fires, post-crash fires and on-ground or ramp fires. An in-flight fire tends to produce elther minor damage or the destruction of the aircraft and everyone aboard. In such fires, alternatives exert a falrly sharp eitheror effect on both the lives lost and the property damage. Post-crash fires frequently kill some but not all of the occupants, and their contribution to property damage may be large or small, depending on the severity of the crash. Alternatives can have incremental effects on lives lost and property damaged in such fires. Finally, ramp fires generally involve no life risk but can involve serious property damage. In these cases, the problem of unattended fires arises, where the other two scenarios are more involved with hidden or fast-moving fires. Further sub-divisions of these scenarios are then appropriate for analysis of particular alternatives.

Finally, to provide a basis for extrapolating likely future loss and cost experience, the measure of exposure that most closely drives risk - number of flights, aircraft-miles, seat-miles, passenger-miles, hours of flying time, aircraft-departures, or some other measure had to be identified. In aircraft analyses, as with bullding-fire analyses, the cholce of a measure requires a compromise - not necessarily the best measure imaginable, but the best measure obtainable. In home fires, for example, risk is usually assessed relative to numbers of housing units or numbers of occupants because data is readily available on both. Even if one could show that fire risk rises and falls more in relation to square feet of living space than to number of occupants, that would make little practical difference because data on the former is largely unavailable.

Similar data scarcity considerations precluded the use of a fine structure using numerous categories of aircraft types, airline types, activity types, engine types, and fire types. Such a structure would assure that each category is homogeneous with respect to fire probability, likely fire development, likely people movement, and especially the likely effects of any alternatives under consideration. One is then faced, however, with the prospect that many of the categories so created will have had no significant historical fire experience. Instead, this model uses very few categories. Further development of deterministic models or test results may provide more information on relative risk of different types of alrcraft, engines, and the like, permitting more fine structure in the model. Until then, one must use sensitivity analysis by varying assumptions to see how much the results change.

\subsubsection{Decision Model}

As noted in figure 1 , a special part of the Aircraft/Activity/Occupant Characteristics model is the Decision Model, which addresses characteristics of the phasing-in, extent of adoption, rellability, and degradation in use of 
the alternative. One must estimate how many potential users will decide to buy a given alternative, how many of those will be able to buy it, how many of those who buy it will obtain a defective product, and so forth. The speed of introduction of the alternative also is addressed in this model.

The model captures these characteristics through a set of probabilities . For potential users who do not acquire the alternative, probabilities are calculated expressing their share of the total activity/exposure, and both the costs and benefits of the alternative are correspondingly reduced. Users who acquire defective products or products that degrade in use are captured by other probabilities that reduce benefits but not costs.

\subsubsection{Ignition-Initiation Model}

The ignition-initiation model computes differences between the historical baseline probabilities of fire and the probabilities expected if the alternative(s) are present. These differences are calculated per year, given the aircraft/activity/occupant characteristics already specified, for each fire scenario. In other words, the historical probabilities are assumed to continue unchanged if the alternative(s) is not adopted. If past experience is not believed to give a reliable projection in the absence of the alternative, then a more sophisticated model must be used to estimate what the baseline should be. In this model, it has been assumed that, in the absence of specific changes, the probability of ignition will continue to be best estimated by the 1965-82 average probability.

\subsubsection{Post-Ignition Model}

As with the Ignition-Initiation Model, this model begins with historical losses per fire, given a fire scenario and aircraft/activity/occupant characteristics. Therefore it too assumes a fairly stable status quo. The Post-Ignition Model is based on a critical-event sequence or tree. A critical event marks a significant change in the condition of the fire, the status of fire protective features or systems, fire-related activities, or the conditions of persons exposed to the fire.

For analyses of interest to FAA, a more compact display than a criticalevent tree is possible and desirable. Figure 2 shows a two-by-three partitioning of all fatalities in passenger-aircraft fires. This approach can be used to provide an initial sorting of fatal fire victims for all alternatives of interest to FAA, although the actual assignment of victims to one cell versus another will be different for different alternatives. Figure 2 also shows the kinds of fire and victim characteristics that would be assigned to each cell.

An examination of the blocks in figure 2 will show how the type of analysis needed to estimate benefits will vary from block to block. The Limited/Limited block, for example, requires further analysis to determine whether the actual escape time provided will exceed the time required. (It is this block that would create a large number of critical-event branches if a full-critical-event tree were used.) The analysis might involve estimating how long fatal fire effects would have been delayed by an alternative, then analyzing how many of the victims in the Limited/Limited cell could have escaped in that time. For example, test results may show that an alternative 
Note: Persons killed by impact trauma in a crash preceding the fire are not shown.

Extra Escape Time Provided by Alternative

$\left.\begin{array}{l}\text { Extra } \\ \text { Escape } \\ \text { Time } \\ \text { Required } \\ \text { by } \\ \text { Victim }\end{array}\right]$

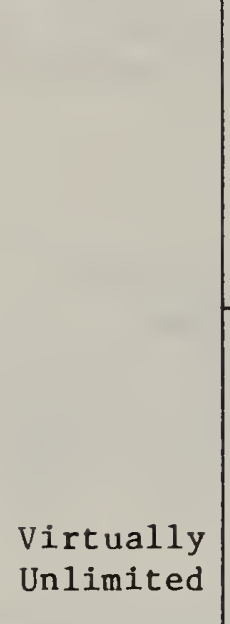

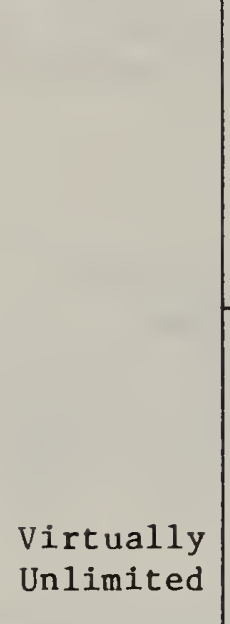

Limited
Limited

None

\begin{tabular}{|c|c|}
\hline $\begin{array}{l}\text { Fatal fire effects } \\
\text { unaffected by } \\
\text { alternative, e.g., } \\
\text { fire spread } \\
\text { primarily along } \\
\text { paths not } \\
\text { covered by } \\
\text { alternative; } \\
\text { fatal fire } \\
\text { effects not } \\
\text { of a kind } \\
\text { affected by }\end{array}$ & $\begin{array}{l}\frac{\text { Fatal fire }}{\text { effects partially }} \\
\frac{\text { affected by }}{\text { alternative, }} \\
\text { e.g., fire } \\
\text { delayed by } \\
\text { alternative. } \\
\text { Victim mobile } \\
\text { and able to } \\
\text { escape given } \\
\text { time. }\end{array}$ \\
\hline
\end{tabular}

alternative.

Victim mobile and able to escape given time

NONE SAVED

Fire effects same as above.

Victim unable to use escape time, e.g., stunned, trapped by debris, blocked by unuseable exits, too young, too sick, etc.

NONE SAVED time.

Fatal fire effects

blocked by

alternative, e.g.,

fire suppressed early, prevented completely, or confined to harmless area for indefinite period of time.

Victim mobile and able to use extra escape time but does not have to.

ALL SAVED

Fire effects same

Fire effects same as above. as above. Victim unable to use extra escape time.

Victim unable to use extra escape time, but that does not matter.

Figure 2. Compact Post-Ignition Display Format for PassengerAircraft Fire Fatalities 
provides 60 extra seconds of escape time. Other tests and data from actual fires may indicate that people can escape at a rate of one per second, given the right sizes and number of useable exits. For such an accident, 60 people could be saved by the alternative. In a particular accident of this type, if 30 victims qualified as Limited/Limited, they would all be saved; if 150 victims fit this description, only 60 would be saved.

The display in figure 2 provides a number of useful insights into the effects of the alternative and its potential for improvement. If the SAVED victims are a large proportion of the total victims, then the alternative is highly effective. If they are not, then one may ask why not. If the SAVED victims in the Limited/Limited cell are a large proportion of the total victims in the Limited/Limited cell, then incremental improvements in the alternative will have little effect. If sizeable numbers of victims fall in the first column (NONE SAVED), then a whole new approach probably will be needed to save them.

Thus far the discussion has focused on post-ignition modeling of fatalities. The procedures for modeling injuries are theoretically the same, but the historical-fire information on injury characteristics - even whether an injury was due to fire or impact trauma - is much thinner than the corresponding information on fatalities. Also, as discussed later, a case may be made that injuries constitute a very small part of the total losses in aircraft fires. For building fires, the lesser severity of injuries as opposed to fatalities is balanced by the far greater frequency of injuries. In aircraft accidents, however, the frequency of injuries is on the same order of magnitude as the frequency of fatalities. For these reasons, injuries receive relatively little attention in our modeling framework.

Property damage also poses modeling difficulties. In post-crash fires, it is rarely possible to identify the incremental effect of fire on the oftensevere damage already caused by the crash impact. (Crashes caused by inflight fires are easier to model if it can be determined whether the alternative would have permitted a safer landing.) Except for crash incidents involving relatively light landings, where impact damage was demonstrably minor, this is a problem. For ramp or ground fires, assessing damage is no longer a problem, but tracking down relevant incidents is. Incidents involving no life risk are not documented as thoroughly or as consistently as incidents involving life risk. Neither government agencies nor industry associations, to our knowledge, have developed summaries of incidents involving only damage to property. Data bases prepared by fire service groups do not go back far enough or are not complete enough to fill the gap. Consequently, some estimation may be necessary.

\subsubsection{Loss Evaluation Model}

The results of the Ignition-Initiation and Post-Ignition models can be combined to produce expected losses per year, by type of loss. The Loss Evaluation Model can then be used to combine these figures into a single scale giving expected losses per year. The most common approach is to monetize the benefits, i.e., convert estimates of lives saved and injuries averted to equivalent dollar values so they can be combined with the dollar values for property damage avoided. This is a controversial procedure which many people object to on several grounds, including the belief that the sanctity of life 
forbids anyone from being asked to put a price on his or her $11 \mathrm{fe}$. It is therefore important to understand that people are not being asked to set a price for which they would be wlling to die. They are instead being asked how much they would pay to further reduce their already low risk of dying. People make such decisions every day, and it is possible for a third party, like FAA or CFR, to infer from studies of such decisions the typical values that express people's wlllingness to pay for reduced risk of death. Over the course of a year, with hundreds of billions of passenger-miles flown, these small risks translate into an expected number of lives lost or saved. For convenience sake, these values are expressed in terms of values per life, but they really reflect an assessments of the value of reduced risk.

\subsubsection{Cost Mode1}

If the analysis has been set up to compare a few we1l-defined alternatives to the status quo, then the Cost Model need only be designed to address the changes in costs due to the alternative(s). The following are the principal sources of cost differences:

1. Equipment costs. The costs of producing the materials and fabricating the products entailed in the alternative(s) need to be estimated. In many analyses, there will be new products which may have been produced only on a test basis. Likely costs under mass-production conditions can be difficult to estimate but need to be addressed.

2. Installation costs. This may include installation of selfcontained devices (like blocked seats) into an otherwise unchanged aircraft, or it could mean the change in construction costs for an aircraft modified in some more fundamental way (e.g., so as to increase compartmentalization of firesusceptible areas of the aircraft). Since some alternatives do not add features but rather modify them (e.g., blocked seats), one needs to estimate the incremental cost of routine installation caused by the modification and the full cost of initial installation if done out of cycle solely to install the modification. Labor costs may vary considerably from place to place, which adds to the uncertainty of these calculations.

3. Operating costs. For aircraft, changes in operating costs arise principally through weight penalties associated with alternatives. In addition, it is conceivable that, for example, changes in fuel composition or procedures could affect operating costs in other ways.

4. Servicing, inspection, testing and maintenance costs. In each case, the cost of concern is the change in the cost relative to the costs of these activities under the status quo.

5. Repair and replacement costs. Under an alternative, repairs may be more or less costly and may be needed more or less frequently. Replacement cycles may be altered or replacement costs (already addressed under installation costs) changed. 
6. Financing costs, salvage value. Implementing the alternative may be covered by time-payment arrangements, adding interest costs. The alternative could add to or subtract from resale value, and it could add to or reduce the likely salvage value of damaged aircraft.

This list is not exhaustive, but it should provide an indication of the diverse ways in which alternatives can affect costs. All of these possibilities need to be identified and worked through to produce overall estimates of cost impacts.

\subsubsection{Cost-Benefit Comparison Mode1}

After deciding on a format for handling non-monetary benefits, as discussed under the Loss Evaluation Model, there remains the need to reduce a time stream of projected costs and benefits into manageable single values of costs and benefits. Discounting is used to reflect opportunity costs and to compensate for deferring consumption. The U.S. Office of Management and Budget has an officially recommended discount rate of 10 percent [72]

\subsubsection{Summary of Models to be Discussed in Greater Detail}

The remainder of section 2 provides additional detail on the major modeling components of the framework. Section 2.2 describes in greater detail the models and data bases that produce estimates of expected loss. Section 2.2.1 presents the historical data base of passenger aircraft fires used in estimating a baseline of expected losses. Section 2.2.2 presents the forecast of future changes in activity/exposure levels; this is used to translate the historical baseline into a projected, status quo baseline of what losses would be in the absence of any alternatives during the period when those alternatives could have been introduced. Section 2.2 .3 describes how the results of sections 2.2 .1 and 2.2 .2 are used to estimate expected losses, by type of loss. Section 2.3 describes the Loss Evaluation model, which translates expected losses, by type of loss, into a single measure of expected loss. Section 2.4 describes the elements of the Cost Model. Section 2.4.1 describes the forecasts needed for the Cost Model, while section 2.4 .2 describes the elements of the model of installation and maintenance costs and section 2.4.3 describes the elements of the model of operating costs. Finally, section 2.5 describes the Cost-Benefit Comparisons model, which combines all the preceding calculations into a measure of the attractiveness of the alternative.

\subsection{Models to Estimate Losses and Savings}

In figure 1 , it was noted that the estimation of expected loss usually is performed by the use of an Initiation of Ignition Model and a Post-Ignition Model. Figure 2, however, showed that a more compact form can be used for the Post-Ignition Model in modeling alternatives of interest to FAA. Note that the last column of Figure 2 - the Virtually Unlimited extra escape time column - shows all victims saved. This column also can be expanded to include all losses avoided through successful prevention of the fire, thereby removing the need for a separate Initiation of Ignition Model. For most alternatives of interest to FAA, this simplified format works well, and it will be used as the basis for modeling expected loss in this report. 


\subsubsection{Identifying the Historical Data Base}

Table 1 lists historical fire incidents involving fire fatalities, 1965-1982, scheduled and non-scheduled passenger flights, U.S. airlines only. Piston-aircraft flights, which accounted for only ten percent of passengermiles in 1965 and no more than two percent from 1970 on, have been excluded because such aircraft are no longer even a moderate-sized factor in passenger travel. Table 2 lists similar incidents for non-U.S. airlines using U.S.built aircraft, and table 3 lists incidents involving non-U.S. airlines using non-U.S.-built aircraft. Each list gives identifying information on the accident, the aircraft and the flight; total passengers on board; total number killed in the accident; and the estimated number killed by fire or smoke. Fires marked as in-flight fires might be preventable. The rest are not preventable short of preventing the crash, which is beyond the scope of FAA's fire research. The latter fires all fall into the first or second column of the stratification given in figure 2. Appendix A gives more details on each incident, including how the number of fire fatalities was calculated. Since most of those estimates involve some uncertainty, appendix B lists all incidents in which people died with fire present but without an apparent fire contribution to any of the deaths. For these cases, all deaths were due to crash trauma or should be excluded for other reasons. The basis for concluding that the deaths were due to fire is given for each of these incidents.

Note that the lists of historical fires exclude some classes of in-flight fires that did not enter storage or passenger-accessible areas. Engine fires and tire fires that caused loss of control and a subsequent fatal crash without ever putting fire products into the interior are excluded because few if any of the alternatives of current interest to FAA will affect such fires.

With these fatality figures in hand, it is possible to consider the effect of fire injuries on total fire loss. The $17 \mathrm{U} . \mathrm{S}$. airline accidents produced 712 estimated fire fatalities. According to Cominsky [5l], the same accidents produced 265 serious injuries, both fire and trauma. Therefore, the serious fire injuries numbered at most 34 percent of the number of fire fatalities, and in view of the likelihood of significant crash-trauma injuries, an upper bound of 20 percent is not unreasonable. According to the FAA [82] and others, people tend to value a given percentage reduction in injury risk three to seven percent as much as the same percentage reduction in the risk of death. Combining these results, it appears that, in equivalent fire fatalities, the serious fire injuries would add at most three percent to the total fire fatalities and more likely only one percent. Assuming that an alternative will at best have no greater effect on injuries than it has on deaths and that a case may be made that prevented injuries will be offset by deaths that are reduced to injuries, then it is reasonable to ignore the effect of any risk-reduction alternative on passenger airline fire injuries.

This argument for ignoring fire injuries was based on serious fire injuries in accidents involving some fire fatalities. Taking the full list of fatal and non-fatal post-crash fires in Cominsky [51] as an example, the nonfatal crashes add very few additional injuries - only 27 serious injuries on U.S.-airline passenger flights and fewer than 100 more on non-U.S. airline passenger flights. Therefore, it still seems appropriate to conclude that serious fire-related injuries are considerably less common than fire 
Table 1. Historical Fire Fatalities, 1965-82

\section{U.S. Airlines}

\begin{tabular}{|c|c|c|c|c|c|}
\hline & Date & Description & $\begin{array}{l}\text { On } \\
\text { Board } \\
\end{array}$ & $\begin{array}{l}\text { Total } \\
\text { Killed } \\
\end{array}$ & $\begin{array}{c}\text { Estimated } \\
\text { Fire Fatalities } \\
\end{array}$ \\
\hline l. & $11 / 8 / 65$ & $\begin{array}{l}\text { American, B727, Jet } \\
\text { Near Constance, KY }\end{array}$ & 62 & 58 & 36 \\
\hline 2. & $11 / 11 / 65$ & $\begin{array}{l}\text { United, } B 727 \text {, Jet } \\
\text { Salt Lake City, UT }\end{array}$ & 91 & 43 & 43 \\
\hline 3. & $4 / 22 / 66$ & $\begin{array}{l}\text { American Flyers, L-188, } \\
\text { Turboprop, Ardmore, OK }\end{array}$ & 98 & 83 & 15 \\
\hline 4. & $6 / 23 / 67$ & $\begin{array}{l}\text { Mohawk, BAC-1ll, Jet } \\
\text { Blossburg, PA (In-Flight) }\end{array}$ & 34 & 34 & 34 \\
\hline 5. & $6 / 12 / 68$ & $\begin{array}{l}\text { Pan American, B707, Jet } \\
\text { India }\end{array}$ & 63 & 6 & 6 \\
\hline 6. & $11 / 27 / 70$ & $\begin{array}{l}\text { Capitol International, DC8, } \\
\text { Jet, Anchorage, AK }\end{array}$ & 229 & 47 & 47 \\
\hline 7. & $12 / 28 / 70$ & $\begin{array}{l}\text { Trans-Caribbean, } B 727 \text {, Jet } \\
\text { St. Thomas, Virgin Is lands }\end{array}$ & 55 & 2 & 2 \\
\hline 8. & $6 / 7 / 71$ & $\begin{array}{l}\text { Allegheny, CV } 580 \text {, Turboprop } \\
\text { New Haven, CT }\end{array}$ & 31 & 28 & 27 \\
\hline 9. & $12 / 8 / 72$ & $\begin{array}{l}\text { United, B7 37, Jet } \\
\text { Chicago, IL }\end{array}$ & 63 & 43 & 30 \\
\hline 10. & $12 / 20 / 72$ & $\begin{array}{l}\text { North Central, DC9, Jet } \\
\text { Chicago, IL }\end{array}$ & 45 & 10 & 10 \\
\hline 11. & $7 / 22 / 73$ & $\begin{array}{l}\text { Pan American, B707, Jet } \\
\text { Tahiti (In-Flight) }\end{array}$ & 79 & 79 & 79 \\
\hline 12. & $1 / 30 / 74$ & $\begin{array}{l}\text { Pan American, B707, Jet } \\
\text { Pago Pago, American Samoa }\end{array}$ & 101 & 96 & 95 \\
\hline 13. & $9 / 11 / 74$ & $\begin{array}{l}\text { Eastern, DC9, Jet } \\
\text { Charlotte, NC }\end{array}$ & 82 & 72 & 36 \\
\hline 14. & $4 / 27 / 76$ & $\begin{array}{l}\text { American, B727, Jet } \\
\text { St. Thomas, V1rgin Islands }\end{array}$ & 89 & 37 & 36 \\
\hline 15. & $3 / 27 / 77$ & $\begin{array}{l}\text { Pan American, } B 747 \text {, Jet } \\
\text { Canary Islands }\end{array}$ & 396 & 335 & 192 \\
\hline 16. & $4 / 4 / 77$ & $\begin{array}{l}\text { Southern, DC9, Jet } \\
\text { Near New Hope, GA }\end{array}$ & 85 & 63 & 20 \\
\hline 17. & $3 / 1 / 78$ & $\begin{array}{l}\text { Continental, DC10, Jet } \\
\text { Los Angeles, CA }\end{array}$ & 202 & 4 & 4 \\
\hline
\end{tabular}


Table 2. Historical Fire Fatalities, 1965-82

Non-U.S. Airlines Using U.S.-Built Aircraft

\begin{tabular}{|c|c|c|c|c|c|}
\hline & Date & Description & $\begin{array}{c}\text { On } \\
\text { Board }\end{array}$ & $\begin{array}{l}\text { Total } \\
\text { Killed }\end{array}$ & $\begin{array}{c}\text { Estimated } \\
\text { Fire Fatalities } \\
\end{array}$ \\
\hline l. & $2 / 16 / 67$ & $\begin{array}{l}\text { Garuda, L-188, Turboprop } \\
\text { Indonesia }\end{array}$ & 92 & 22 & 22 \\
\hline 2. & $3 / 5 / 67$ & $\begin{array}{l}\text { Varig, DC8, Jet } \\
\text { Liberia }\end{array}$ & 95 & 56 & 45 \\
\hline 3. & $4 / 8 / 68$ & $\begin{array}{l}\text { BOAC, B707, Jet } \\
\text { England }\end{array}$ & 127 & 5 & 5 \\
\hline 4. & $9 / 17 / 69$ & $\begin{array}{l}\text { Pacific Western, CV640, } \\
\text { Turboprop, Canada }\end{array}$ & 15 & 4 & 2 \\
\hline 5. & $7 / 5 / 70$ & $\begin{array}{l}\text { Air Canada, DC8, Jet } \\
\text { Canada }\end{array}$ & 109 & 109 & 109 \\
\hline 6. & $1 / 22 / 73$ & $\begin{array}{l}\text { Royal Jordanian, B707, Jet } \\
\text { Nigeria }\end{array}$ & 202 & 176 & 176 \\
\hline 7. & $7 / 11 / 73$ & $\begin{array}{ll}\text { Varig, } & \text { B707, Jet } \\
\text { France } & \text { (In-Flight) }\end{array}$ & 134 & 123 & 123 \\
\hline 8. & $11 / 20 / 74$ & $\begin{array}{l}\text { Luf thansa, B747, Jet } \\
\text { Kenya }\end{array}$ & 157 & 59 & 35 \\
\hline 9. & $6 / 4 / 76$ & $\begin{array}{l}\text { Air Manila, L-188, Turboprop } \\
\text { Guam }\end{array}$ & 45 & 45 & 28 \\
\hline 10. & $3 / 27 / 77$ & $\begin{array}{l}\text { KLM, B747, Jet } \\
\text { Canary Islands }\end{array}$ & 248 & 248 & 192 \\
\hline 11. & $9 / 29 / 77$ & $\begin{array}{l}\text { Japan Air, DC8, Jet } \\
\text { Malaysia }\end{array}$ & 79 & 34 & 25 \\
\hline 12. & $12 / 17 / 78$ & $\begin{array}{l}\text { Indian Airlines, B737, Jet } \\
\text { India }\end{array}$ & 132 & l & 1 \\
\hline 13. & $10 / 7 / 79$ & $\begin{array}{l}\text { Swissair, DC } 8 \text {, Jet } \\
\text { Greece }\end{array}$ & 154 & 14 & $0-14$ \\
\hline 14. & $11 / 26 / 79$ & $\begin{array}{l}\text { Pakistani International, } \\
\text { B707, Jet, Saudi Arabia } \\
\text { (In-Flight) }\end{array}$ & 156 & 156 & 156 \\
\hline 15. & $2 / 27 / 80$ & $\begin{array}{l}\text { China Airlines, B707, Jet } \\
\text { Phillipines }\end{array}$ & 135 & 2 & 2 \\
\hline 16. & $8 / 19 / 80$ & $\begin{array}{l}\text { Saudi Air, L-10ll, Jet } \\
\text { Saudi Arabia (In-Flight) }\end{array}$ & 301 & 301 & 301 \\
\hline 17. & $11 / 19 / 80$ & $\begin{array}{l}\text { Korean Air, B747, Jet } \\
\text { Korea }\end{array}$ & 212 & 14 & 11 \\
\hline 18. & $7 / 27 / 81$ & $\begin{array}{l}\text { Aeromexico, DC9, Jet } \\
\text { Mexico }\end{array}$ & 66 & 32 & $0-32$ \\
\hline 19. & $9 / 13 / 82$ & $\begin{array}{l}\text { Spantax, DC10, Jet } \\
\text { Spain }\end{array}$ & 393 & 51 & 51 \\
\hline
\end{tabular}

\begin{tabular}{clc} 
On & Total & \multicolumn{1}{c}{ Estimated } \\
Board & Killed & Fire Fatalities \\
\hline
\end{tabular}

$92 \quad 22$ 
Table 3. Historical Fire Fatalities, 1965-82

Non-U.S. Airlines Using Non-U.S.-Built Aircraft

\begin{tabular}{|c|c|c|c|c|c|}
\hline & Date & Description & $\begin{array}{l}\text { On } \\
\text { Board } \\
\end{array}$ & $\begin{array}{l}\text { Total } \\
\text { Killed } \\
\end{array}$ & $\begin{array}{l}\text { Estimated } \\
\text { Fire Fatalities } \\
\end{array}$ \\
\hline 1. & $2 / 15 / 66$ & $\begin{array}{l}\text { Indian Airlines, Caravelle, } \\
\text { Jet, India. }\end{array}$ & 80 & 2 & $0-2$ \\
\hline 2. & $9 / 11 / 68$ & $\begin{array}{l}\text { Air France, Caravelle, Jet } \\
\text { France (In-Flight) }\end{array}$ & 95 & 95 & 95 \\
\hline 3. & $7 / 26 / 69$ & $\begin{array}{l}\text { Air Algerie, Caravelle, Jet } \\
\text { Algeria (In-Flight) }\end{array}$ & 37 & 33 & 33 \\
\hline 4. & $5 / 6 / 70$ & $\begin{array}{l}\text { Somali, Viscount, Turboprop } \\
\text { Somalia (In-F1ight) }\end{array}$ & 30 & 5 & $0-5$ \\
\hline 5. & $3 / 15 / 74$ & $\begin{array}{l}\text { Sterling, Caravelle, Jet } \\
\text { Iran }\end{array}$ & 96 & 15 & 15 \\
\hline
\end{tabular}

fatalities in passenger airline accidents. This means that, for any riskreducing alternative having at least as great an effect on risk of death as on risk of injury, the benefits achieved through preventing injuries are so completely dwarfed by the benefits achieved through preventing deaths that the former can be safely ignored in aggregate benefit calculations.

Appendix $C$ describes the identification of property damage due to aircraft fires and potentially preventable by alternatives of interest to FAA. That completes the identification of the historical data base with respect to the direct fire losses of fatalities, injuries and property damage. Indirect losses of potential interest could include lost revenue from out-ofservice aircraft. This study concentrates on fatalities and destroyed or seriously damaged aircraft. Less serious property damage - such as destroyed luggage - adds very little to the total consequences of passenger-aircraft fires.

To analyze a particular alternative, the fire fatalities and property damage cited in tables $1-3$ and appendix $C$ need to be sorted into the categories of relative saveability given by figure 2 .

\subsubsection{Activity Forecasts Needed to Model Expected Loss}

The number of passenger exposures per year can be measured in a number of ways from the most direct (e.g., passenger-departures, pasisengers flown, passenger-miles) to slight1y less direct measures (e.g., ton-miles, which are dominated by passengers) to still less direct measures (e.g•, seats available in the fleet inventory). Passenger-departures seem like the most natural measure of exposure to fatalities since most fatal accidents (even those 
resulting from in-flight fires) occur at or near take-off or landing. But passenger-miles is by far the most available statistic and is the only one with sufficient data to permit ready use as a measure of exposure for the worldwide cases. And, intuitive appeal aside, it is unlikely that the choice of Index would make much difference. For example, worldwide passenger-miles increased at a rate of 4.9 percent a year, compounded annually (see appendix D) from 1970 to 1982, while average miles per aircraft - a factor reflecting the difference between passenger-miles and passenger-departures - was rising only 0.5 percent a year [41].

Table 4 gives the projected 1983-1997 passenger-miles for U.S. and world airlines as percentages of the corresponding base-year (1982) figures, which are calculated in appendix D. These percentages are based on McDonnell Douglas estimates of year-by-year growth rates for total passenger traffic. To compute expected losses for a particular future year, one needs three multiplicative factors: (a) an historical figure, giving historical fatalities and property damage, (b) the number in table 4 corresponding to the future year, and (c) a conversion factor to take account of the fact that the historical losses occurred over an 18-year period, during which the passenger exposure levels were rising toward their base-year (1982) value. The conversion factor then is given by the passenger exposure level in 1982 divided by the total passenger exposures during the historical period. These factors are .080 for U.S. airlines only, .094 for U.S. airlines and/or aircraft, and .093 for world airlines. To summarize, factor (a) gives losses over the historical period, factor (b) converts those to expected losses in the base year, and factor (c) converts expected base-year losses to expected losses in the selected future year. Note that this approach develops the baseline of firedeath risk per passenger-mile flown by combining all years of historical period, so it does not reflect any consistent trends in risk from the beginning to the end of that period. The data actually suggest that risk per passenger-mile was dropping by about five percent a year during the historical period, but because fatal accidents are rare events, the trend is erratic and the pattern of falling risk cannot be established with high statistical confidence. We therefore assumed no downward trend.

\subsubsection{Estimating Expected Losses with an Alternative}

Section 2.2.2 concluded by identifying three multiplicative factors needed to calculate expected losses in any future year, assuming no alternative. The same calculation is used to estimate expected losses with an alternative, but first the historical losses are recalculated to show the effects of that alternative. This process can only be described in general terms because the details depend on the specific performance characteristics of the alternative being studied.

The first step is to resort the fatalities and other losses to reflect those fire effects and scenarios the alternative cannot affect. For example, explosions are generally considered fire-related, but for most explosions that occur while the plane is still in flight, none of the most common pre-ignition or post-ignition alternatives would prevent the explosion or save any of the people killed by it. If the aircraft was broken open by the impact or ground slide, it is much less likely that fire spread could be contained or avoided under any alternative than if the fuselage integrity was relatively undamaged in the crash. If smoke from the burning fuel outside is considered to have 
Table 4. Forecast Passenger-Miles as Percentages of Base-Year Figures, Scheduled and Non-Scheduled, Jet and Turboprop, 1983-1997

\begin{tabular}{lcc} 
Year & U.S. Airlines & World Airlines \\
\cline { 2 - 3 } 1983 & 106 & 105 \\
1984 & 112 & 111 \\
1985 & 119 & 118 \\
1986 & 125 & 124 \\
1987 & 132 & 132 \\
1988 & 139 & 140 \\
1989 & 144 & 147 \\
1990 & 150 & 155 \\
1991 & 156 & 164 \\
1992 & 162 & 172 \\
1993 & 168 & 182 \\
1994 & 175 & 192 \\
1995 & 182 & 203 \\
1996 & 190 & 214 \\
1997 & 198 & 226
\end{tabular}

Source: Douglas Aircraft Company, 1983-1997 Outlook for Commercial Aircraft, Long Beach, California, July 1983, p. 53.

been the cause of death, or to have surrounded the person so he could not find a useable exit, then an alternative that operates to contain fire effects inside would have had no effect, but an alternative that gave that person supplemental lighting to illuminate the escape path might be effective. If fatal injuries were incurred outside the aircraft after a successful escape, then alternatives that operate inside the aircraft would have had no effect. If the alternative provides detection or suppression protection to a part of the aircraft (e.g., lavatory, cargo hold), then fires that originate elsewhere would be unaffected or at least less likely to be affected. All fatalities occurring under circumstances where the fire was not the kind where the alternative would have an effect are considered unsaveable and should be moved to the first column of the figure 2 format display.

After this resorting is done, all losses shown in the first column or the second row of the second column are counted as unaffected by the alternative. The alternative will prevent all the losses in the third column and some of the losses in the second column, first row, if it is present and effective. Therefore, the next step is to calculate what fraction of the losses in the second column, first row, will be saved. By the definition of these losses, this calculation compares the extra escape time needed by these victims to the time provided by the alternative. For any given alternative, this is likely to be a complex calculation, involving deterministic models and test results, which must be done separately for each of a number of historical fires, using the available information on their particular characteristics.

Once this is done, the expected losses under the alternative - and hence the expected savings due to the alternative - will be known, except for any loss of savings occurring because the alternative was not present or was not 
effective when the fire occurred. This is captured by a probability which includes such considerations as the probability that the aircraft or airline or airport will not be equipped with the alternative and the probability that the alternative will be non-operational due to defective construction, improper installation, poor maintenance or degradation of performance in use. For an alternative that is mandated by regulation, completely reliable, and not subject to degradation of performance in use, this probability reflects only the speed of the phasing-in of the alternative, i.e., the proportion of passenger activity/exposures that will occur in alternativeequipped aircraft.

\subsection{Loss Evaluation Mode1}

As stated in section 2.1.5, the Loss Evaluation Model monetizes 1ives saved and injuries averted in order to permit all benefits to be combined into one scale. In CFR risk analyses, benefits are usually calculated for a range of values for a statistical life - $\$ 250,000, \$ 500,000$, and $\$ 1$ million. These values reflect the values implicitly or explicitly developed in most past risk studies of governmental programs [67]. The middle value of $\$ 500,000$ is within $10 \%$ of the value of $\$ 530,000$ specifically recommended by Keech for FAA analyses [82]. The calculations and assumptions used to develop these estimates do not appear highly sensitive to inflation. Therefore, the estimates do not appear to be sensitive to the fact that our analysis uses 1982 as a base year, while Keech published his figures in 1981. Smith [110] assumes inflation should be added and obtains a value of statistical life, stated in 1983 dollars, of $\$ 653,000$, still within the range of values considered in this report.

CFR analyses also use a range of $\$ 5,000$ to $\$ 20,000$ for the value of an injury averted. Keech [82] tends to show higher values, on the order of $\$ 15,000$ for a minor injury and $\$ 38,000$ for a serious injury. Smith [110] shows even higher values, since he adds inflation to the values described by Keech. As already noted, however, injuries can be safely omitted from the model because they represent a negligible share of fire loss in passenger aircraft fires.

\subsection{Cost Models}

A model designed to assess the costs due to the introduction of a fire risk-reduction alternative need only consider the changes in costs attributable to the alternative. The principal sources of cost difference previously mentioned included equipment, installation, operation, service, inspection, testing and maintenance, repair and replacement, and financing. For the case of most, if not all, FAA alternatives one can combine equipment, installation, service, maintenance, repair and replacement into one major cost category the cost of installing and maintaining the alternative. Operation of the fleet equipped with the alternative accounts for the other major cost category.

To model these costs, one must consider a variety of cost elements which may be specific to the aircraft model, airline, or type of flight, specific to the alternative or not specific to either the alternative or the aircraft/ activity/occupant factors. The following are principal examples for these cost-elements: 
1. Aircraft/airline/flight specific. Cost depends upon the performance characteristics, configuration and number of aircraft in the fleet. Examples include fuel efficiency, number of units or quantity of area affected by the fire-risk reduction strategy per aircraft, number of aircraft flying, predicted new delivery and retirement schedules, and forecast activity/exposure levels, defined appropriately for the risk reduction alternative.

2. Fire risk-reduction alternative specific. The characteristics of the fire risk-reduction alternative determine costs not only pertinent to the manufacture and installation of the alternative but also relevant to operation and maintenance. Specific examples include incremental costs of applying the alternative to aircraft while in production versus incremental costs to modify aircraft components through retrofit, incremental weight per component modified or added, and cycles for replacement or refurbishment.

3. Non-specific economic factors. Costs are also driven by factors which are not directly related to a specific aircraft model or mitigation alternative. Economic factors influence the price of fuel and other resources relevant to the alternative; their growth rates over time relative to the price of other commodities; interest, discount and tax rates used in computing present value of costs; and economic assumptions used in predicting prices and demand which in turn affect aircraft activity.

\subsubsection{Forecasts Used in the Cost Models}

The Cost Models use a number of forecasts of aircraft inventory and activity, and these forecasts must be compatible with the forecasts used in the Loss Estimation Models, as described in section 2.2.2. Appendix E presents all needed forecasts.

\subsubsection{Model of Installation and Maintenance Costs}

This model requires the following elements: (a) costs per unit for materials, fabrication and installation costs for the alternative, as an installation in a newly constructed aircraft or as a retrofit in an existing aircraft, (b) costs per unit for servicing, maintaining, repairing or replacing the alternative once it is in place, (c) the number of units of the alternative required per aircraft, by aircraft type, (d) the cycle in which service, maintenance, repair or replacement occurs, and (e) the decision rules for phasing in the alternative, indicating which new and existing aircraft will be equipped with the alternative. A unit of the alternative is simply a measure appropriate to that alternative - an aircraft seat, a lavatory, a square foot of cargo hold, a yard of lighting, and so forth. For simplicity's sake, it is assumed that there is a single cycle for service, maintenance, repair and replacement. If this is not the case, a more sophisticated model is needed, but the extension to the more complex case is straightforward and should be easy to infer from the simpler model used here. It is also assumed 
here that all aircraft are equipped with the alternative at the end of the phase-1n period. If not, the proportions that will not be equipped need to be removed from all cost calculations.

Assuming that the aircraft inventory has been subdivided into a set of classes, with each class requiring the same number of units of the alternative, then the following formulas apply, for each such aircraft class:

Formula l. The cost of introducing the alternative to newly constructed aircraft in any year depends upon the cost per unit of the alternative, the number of units of the alternative required per aircraft and the number of new alrcraft added.

New $_{Y}=C_{\text {new }} \times$ U x N

where New $_{\mathrm{Y}}=$ cost of introducing the alternative to all newly constructed aircraft in year $Y$, where $Y$ equals one in the first year of phase in and is incremented by one to the end of the study period.

$\mathrm{C}_{\text {new }}=$ cost per unit of alternative for materials, fabrication, and installation in newly constructed aircraft.

$\mathrm{U}=$ units of alternative required per aircraft

$\mathrm{N}_{\mathrm{Y}}=$ aircraft added during year $\mathrm{Y}$

Formula 2. The cost of refurbishment in any year depends upon the refurbishment cost per unit, the units of alternative per aircraft, and the number of aircraft scheduled for refurbishment in that year. A different formula is used, depending on (a) whether the year in question comes before or after phase-in is completed, and (b) whether the year in question comes before or after the first aircraft fitted with the alternative are due for refurbishment. If the year comes before the end of the phase-in cycle, then there are refurbishment costs associated with equipping a portion of the original fleet; otherwise, there are no such costs. If the year comes after the first aircraft fitted with the alternative are due for refurbishment, then there are refurbishment costs associated with refurbishing all the aircraft that were refurbished or newly equipped with the alternative one cycle before. If the phase-in and refurbishment cycles have equal length, only one or the other of these costs will apply in a given year. If the cycles have unequal lengths, then there will be years in which both costs occur or years in which no costs occur, depending on which cycle is longer.

$$
\begin{aligned}
\operatorname{Refurb}_{\mathrm{Y}} & =\mathrm{C}_{\text {maint }} \mathrm{x} \mathrm{U} \times\left(\frac{\mathrm{I}}{\mathrm{P}}-\mathrm{RM}_{\mathrm{Y}}+\Delta \mathrm{RM}_{\mathrm{Y}}\right), \mathrm{Y} \leq \mathrm{R}, \mathrm{P} \\
& =\operatorname{Refurb}_{\mathrm{Y}-\mathrm{R}}+\left(\mathrm{C}_{\text {maint }} \mathrm{x} \mathrm{U} \mathrm{x}\left(\frac{\mathrm{I}}{\mathrm{P}}+\mathrm{N}_{\mathrm{Y}-\mathrm{R}}-\mathrm{RM}_{\mathrm{Y}}+\Delta R \mathrm{RM}_{\mathrm{Y}}\right)\right), \mathrm{R}<\mathrm{Y} \leq \mathrm{P} \\
& =0, \mathrm{P}<\mathrm{Y} \leq \mathrm{R} \\
& =\operatorname{Refurb}_{\mathrm{Y}-\mathrm{R}}+\left(\mathrm{C}_{\text {maint }} \mathrm{X} \mathrm{U} \mathrm{x}\left(\mathrm{N}_{\mathrm{Y}-\mathrm{R}}-\mathrm{RM}_{\mathrm{Y}}+\Delta R \mathrm{R}_{\mathrm{Y}}\right)\right), \mathrm{Y}>\mathrm{R}, \mathrm{P}
\end{aligned}
$$


where

Refurb $b_{Y}=$ cost of maintaining, servicing, repairing, or replacing the alternative in all aircraft due for such refurbishment in year $Y$

$\mathrm{C}_{\text {maint }}=\underset{\text { ment }}{\text { mest }}$ per unit of alternative of performing refurbish-

$U=$ units of alternative per aircraft

$I$ = inventory of aircraft flying at the start of the phasing-in of the alternative

$P=$ number of years to be used to phase in the alternative at a constant rate

$\mathrm{RM}_{\mathrm{Y}}=$ aircraft removed from service in year $\mathrm{Y}$

$\mathrm{N}_{\mathrm{Y}}=$ aircraft added during year $\mathrm{Y}$

$\mathrm{R}=$ number of years between refurbishments

$\Delta R M_{Y}=$ a factor that takes account of the fact that, in some years, the number of aircraft removed from service may exceed the number due for refurbishment; in those cases, the number due for refurbishment is set equal to zero and the excess aircraft removed from service are subtracted from those due for refurbishment in the following year.

Formula 2 assumes that aircraft are being retired just prior to their due years for refurbishment. Note that of the four formulas shown in Formula 2 , the second will not apply if $R$ is greater than $P$, the third will not apply if $P$ is greater than $R$, and neither the second nor the third will apply if $P$ is equal to R.

The values of $N_{Y}, R_{Y}$, and $I$ are the same for all alternatives and are given in appendix E. The values of $C_{n e w}, C_{m a i n t}, P, R$ and $U$ are specific to the alternative being analyzed. The values of $\Delta R M_{Y}$ depend on $R$ and therefore are also specific to the analysis of a particular phase-in cycle.

\subsubsection{Model of Operating Costs}

Most, if not all, alternatives of interest to FAA produce added operating costs by increasing the weight of the aircraft. Each unit of the alternative carries a weight penalty, which adds to the fuel costs associated with operating the aircraft. This model therefore requires the following elements: (a) cost of fuel, (b) a formula for computing the marginal fuel required to fly a unit of weight through a unit of distance, (c) weight penalty per unit of the alternative, (d) number of units of the alternative per aircraft, by aircraft type, and (e) number of aircraft-miles flown by the aircraft type.

At the outset of this project it appeared that the formula for marginal fuel would be quite complex. We initially expected these calculations would have to take account of engine fuel efficiency differences and differences in 
stage length, which is the distance between landings and is different, for example, for a two-stop flight compared to a nonstop flight between the same two points. A preliminary analysis showed it was not necessary to include these factors in the formula. This preliminary analysis is worthy of a brief discussion ${ }^{\star}$.

The aircraft classes used in the marginal fuel rate analyses were patterned after the Global Aviation Forecast (GAF) model, an aviation forecasting and simulation computer model developed by SRI International. The GAF model has been used by the FAA for estimating the high altitude atmospheric emissions due to aviation activity and more recently the potential impact of noise certification standards. The GAF model outputs from those recent studies were used because they provided a forecast, by aircraft type, of seatkilometers, stage length frequency and seats per aircraft at five year intervals for 1985 through 2000 [1].

The preliminary project sought to determine the relationship between stage length and gallons of fuel per pound of additional weight, for the range of added weight per aircraft that seemed likely to occur with the FAA alternatives. Combining this information with a forecast of annual aircraft-miles, distributed by trip lengths, would result in a weighted average of the additional gallons of fuel per year per pound of added weight per aircraft for each aircraft class for each year in the forecast. Multiplying by the incremental weight per aircraft would yield an estimate of fuel consumption.

In the process of pursuing this approach, it was discovered that a linear approximation ignoring stage length involved little loss of accuracy. When marginal fuel burn per pound of added weight was plotted against stage length for an aircraft (using values derived from the official performance manuals, assuming normal operation and landing weights characteristic of the stage lengths) for a minor weight increment, a line drawn through the envelope of curves back to the origin served as a good approximation of the relationship throughout the range of stage lengths. Therefore, within the accuracy requirements of this study the slope of the line could be used to relate the marginal fuel burned per additional weight to the distance flown. Furthermore, this linear relationship was found for each of the aircraft types investigated and a remarkable similarity in slope was found between aircrafts of widely varying total weights. Newer aircraft types, however, had a lower marginal fuel consumption rate consistent with their improved design and engine efficiency.

The initial plan to incorporate the forecast distributions of stage and trip lengths into the analysis was not necessary, since for a minor weight increment single relationshlp served as a good approximation regardless of stage or trip length. The values used for marginal fuel burned per added weight are dependent upon aircraft efficiency. As the newer aircraft replace older, less efficient models, this value will continue to improve over time. To adequately reflect this effect and facilitate computation of fuel consumption, it was necessary to develop marginal fuel-burn values for each of the aircraft types in the GAF model and weight each value by the proportion of aircraft-miles predicted each year.

\footnotetext{
* The marginal fuel analysis was performed by Paul Lawrence Hamilton of Technology, Policy, Systems, Germantown, Maryland.
} 
The net result was to produce a single factor for expected marginal fuel sensitivity for each year, shown in appendix $\mathrm{E}$.

Fuel cost was the next element of the operating cost mode1, and the fuel cost computation included a measure of the expected increase in fuel prices over prices of other commodities to reflect fuel costs in constant 1983 dollars. Fuel price values for 1983 were taken as $\$ 0.913$, an average of the domestic and international fuel prices per gallon for U.S. carriers, as reported to the Civil Aeronautics Board (form 41) from January through July 1983, weighted by the quantity of fuel purchased.

Two of the last three elements of the model were the weight per unit of the alternative and the number of units of the alternative per aircraft, by aircraft type. These are both specific to the particular alternative being analyzed; the latter is given by formulas, shown below, for each aircraft type. The last model element is the number of aircraft-miles flown, by aircraft type. The data for this calculation are given in appendix $\mathrm{E}$. The formulas are as follows:

Formula 3. The number of units of an alternative flying in any year depends upon the number of units of an alternative per aircraft and the number of aircraft having the alternative installed. During the phase-in cycle, the number of aircraft flying and equipped with the alternative in any year equals the proportion of the initial inventory fitted with the alternative plus the number of new aircraft added during the phase-in period less the number of aircraft removed from service during the phase-in period up to the year of interest. An adjustment is made for one-half of the aircraft either fitted with the alternative or removed from service during the year of interest (because on the average only half the aircraft will be fitted with the alternative or removed during the year of interest). Afte the phase-in cycle, the same formula applies except that all of the initial inventory still flying has been fitted with the alternative.

$$
\begin{aligned}
\text { Units }_{Y}= & U x\left(\frac{Y x I}{P}+\sum_{X=1}^{Y}\left[N_{X}-R M_{X}\right]-\frac{1}{2}\left[\frac{I}{P}+N_{Y}-R M_{Y}\right]\right), Y \leq P \\
& =U x\left(I+\sum_{X=1}^{Y}\left[N_{X}-R M_{X}\right]-\frac{1}{2}\left[N_{Y}-R M_{Y}\right]\right), Y>P
\end{aligned}
$$

where Units Un $_{\mathrm{Y}}=\begin{aligned} & \text { number of units of the alternative in aircraft flying } \\ & \text { in year } \mathrm{Y}\end{aligned}$

$U=$ number of units of the alternative per aircraft

$I=$ inventory of aircraft flying at the start of the phase-in of the alternative

$\mathrm{P}=$ number of years to be used to phase in the alternative at a constant rate

$\mathrm{N}_{\mathrm{Y}}=$ number of aircraft added during year $\mathrm{Y}$ 


$$
\mathrm{RM}_{\mathrm{Y}}=\text { number of aircraft removed during year } \mathrm{Y}
$$

NOTE: This formula assumes aircraft added are added at a constant rate during the year and aircraft removed are removed at a constant rate during the year.

The formula for the operating cost, then, is as follows:

Formula 4. For each aircraft model, the operating fuel costs attributable to weight penalties associated with an alternative depends upon the unit cost of fuel, the amount of fuel required to fly an aircraft with an additional increment of weight over a unit of distance, the weight increment per unit of the alternative, the number of units of alternative per aircraft flying and finally, the distance flown per aircraft flying with the alternative. Summing over the various aircraft models gives the total operating costs for fuel.

$O C_{Y}=$ Fuel $_{Y} \times \mathrm{MF}_{\mathrm{Y}} \times \mathrm{W} \times\left[\sum_{1=1}^{\mathrm{M}}\left(\right.\right.$ Units $\left.\left._{\mathrm{Y}, 1}\right) \times\left(\mathrm{MPA}_{\mathrm{Y}, 1}\right)\right]$

where $\quad$ Fue $l_{Y}=$ cost per gallon of fuel in year $Y$

$$
\begin{aligned}
\mathrm{MF}_{\mathrm{Y}}= & \text { gallons of fuel per added pound per aircraft-mile } \\
& \text { flown } 1 \text { n year } \mathrm{Y} \\
\mathrm{W}= & \text { weight penalty per unit of the alternative } \\
\text { Units }_{\mathrm{Y}, 1}= & \text { units of the alternative in all alrcraft of model type } \\
& 1 \text { flying in year } \mathrm{Y} \\
\mathrm{MPA}_{\mathrm{Y}, 1}= & \text { miles flown per aircraft of type } 1 \text { in year } \mathrm{Y} \\
\mathrm{M}= & \text { number of aircraft model types }
\end{aligned}
$$

\subsection{Cost-Benefit Comparison Mode1}

This model brings together the time stream of costs, the time stream of benefits, and the discount rate, which allows the two time streams to be collapsed into single values for ease of comparison. As noted earlier, the U.S. Office of Management and Budget recommends use of a discount rate of 10 percent [72].

The values computed in this section are expressed in terms of annualized costs and benefits. These values are calculated in two steps. First, the costs and benefits for each year are converted to present values and summed. After the present values by year have been summed to obtain a total present value, they are converted to an annualized cost or benefit. This is calculated analogously to a mortgage payment: it produces a flat annual dollar amount whose present value (again taking account of discounting) is the same as the present value of the cost or benefit we are examining.

The formula to perform these steps is as follows: 
Formula 5. The annualized cost or benefits discounts each year's cost or benefit according to the year it occurs, sums these terms to produce a present value, then computes a single annual cost or benefit value which would, if repeated over the same period, produce the same present value.

$\begin{aligned} \text { (Annualized Cost or Benefit) } & =\left[\frac{d(1+d)^{N}}{(1+d)^{N}-1}\right] \times \sum_{Y=1}^{N} \frac{(\text { Cost or Benefit in year } Y)}{(1+d)^{Y}}, d \neq 0 \\ & \left.=\frac{1}{N} \times \sum_{Y=1}^{N} \text { (Cost or Benefit in Year } Y\right), d=0\end{aligned}$

where $d=$ discount rate (assumed to be 0.10 )

$\mathrm{N}=$ number of years in study period

\section{REVIEW OF RELATED PROJECTS AND LITERATURE}

Reports and data sources were examined in such areas as hazard characterization, fire management and suppression studies, models of fatal levels of cyanide and carboxyhemoglobin, product performance, human behavior as it relates to survivability, and cost analysis. A brief description of major findings and sources used is given below. An annotated list of references is given in appendix $F$ and provides additional information on the materials reviewed and their contributions to the structure and data base of the decision analysis model.

The review of hazard characterization literature centered on the creation of a workable data base of historical accidents involving fire fatalities and aircraft destroyed or seriously damaged by fire. The World Airline Accident Summary [3] provided the principal listing of fatal accidents, with several previous studies, particularly Cominsky [51], providing information on fire development, the role of fire versus crash trauma as a cause of fatalities, exit availability, occupant mobility, escape routes used, and similar key characteristics of individual incidents. For accidents occurring within U.S. territory, unpublished reports by the National Transportation Safety Board's Human Factors Division usually were available as supplements to the published accident reports.

Several reports, notably Quintiere and Tanaka [102], were examined to identify physical factors that strongly influence fire development. The one dominant exogenous factor identified in those studies was wind - both speed and direction. Unfortunately, neither the existing models nor the available data on historical accidents would have provided adequate information to support a model capable of examining fire development under different assumptions regarding wind speed and direction. Instead, the effect of wind was addressed implicitly through its historic variations in actual fires. Incident reports showed that some fires were made worse by wind blowing a separate fire toward the cabin while others, where the wind was not so strong, were less severe. 
Fire management and suppression studies, beyond those already addressed as sources of information on hazard characterization, consist chiefly of studies of possible safety alternatives. Enders and Wood [63], in particular, provide a consensus of experts on promising technological possibilities and their likely impacts.

Several studies $[30,88,106]$ cited blood cyanide as a key indicator of the involvement of interior materials and suggested formulas for assessing the relative contribution of cyanide and carbon monoxide to a fatality. These were the only toxicity studies examined.

Product performance studies examined dealt primarily with seat blocking, the particular alternative chosen to demonstrate the decision analysis methodology. Sarkos and Hill [107] provided the estimates of additional escape time provided by two seat blocking materials.

In addition to the NTSB Human Factors Division reports on individual accidents, the principal source on human behavior related to survivability was Snow [111]. It provided the basis for estimates of exit speeds as one per second for main doors, one every two seconds for overwing exits and fuselage breaks, and something slower than one per second for partially obstructed exits. The Snow report also provided evidence in support of other modeling assumptions needed to estimate likely escapes per second of additional escape time - the forms of occupant immobility (too young, stunned, trapped, chronically ill, etc.), the propensity to use closer exits even if others would be faster, and so forth.

Cost analyses included sources addressing the initial costs, maintenance costs, replacement cycles, and fuel-cost penalties related to added weight for various seat blocking alternatives $[31,56,65,84,115]$. Also of interest were sources suggesting values for the discount rate to use in comparing current costs with future costs and benefits [72] and for the value of a statistical life, i.e., a figure reflecting people's willingness to pay to reduce their risk of death $[67,82]$. The dollar value attributable to destroyed aircraft was developed from sources in the literature giving market values of used aircraft $[36,103,104]$.

Finally, a number of data sources were identified giving past and projected future activity levels, which could then be related to fire fatality frequencies. These sources, when combined, permitted the identification of activity levels by the desired flight types (scheduled and non-scheduled passenger flights), aircraft types (U.S. or non-U.S. built), airline types (U.S. or non-U.S.), and engine types (jet and turboprop but not piston).

\section{SAMPLE APPLICATION: FIRE-BLOCKING OF SEATS}

Fire-blocking of passenger airline seats can be accomplished in many ways, and recent screening tests by the FAA Technical Center have produced a list of over 100 materials that have passed the proposed test. Table 5 lists the materials analyzed in the sample application of the decision analytic modeling framework. Materials 2 and 4 (each of which can be manufactured in two versions, labeled $A$ and $B$ ) are existing materials that have received fullscale testings. Material 3 is an existing material that has received more limited testing. Materials 1, 5 and 6 are hypothetical materials that were analyzed to examine the sensitivity of the results on the existing materials. 


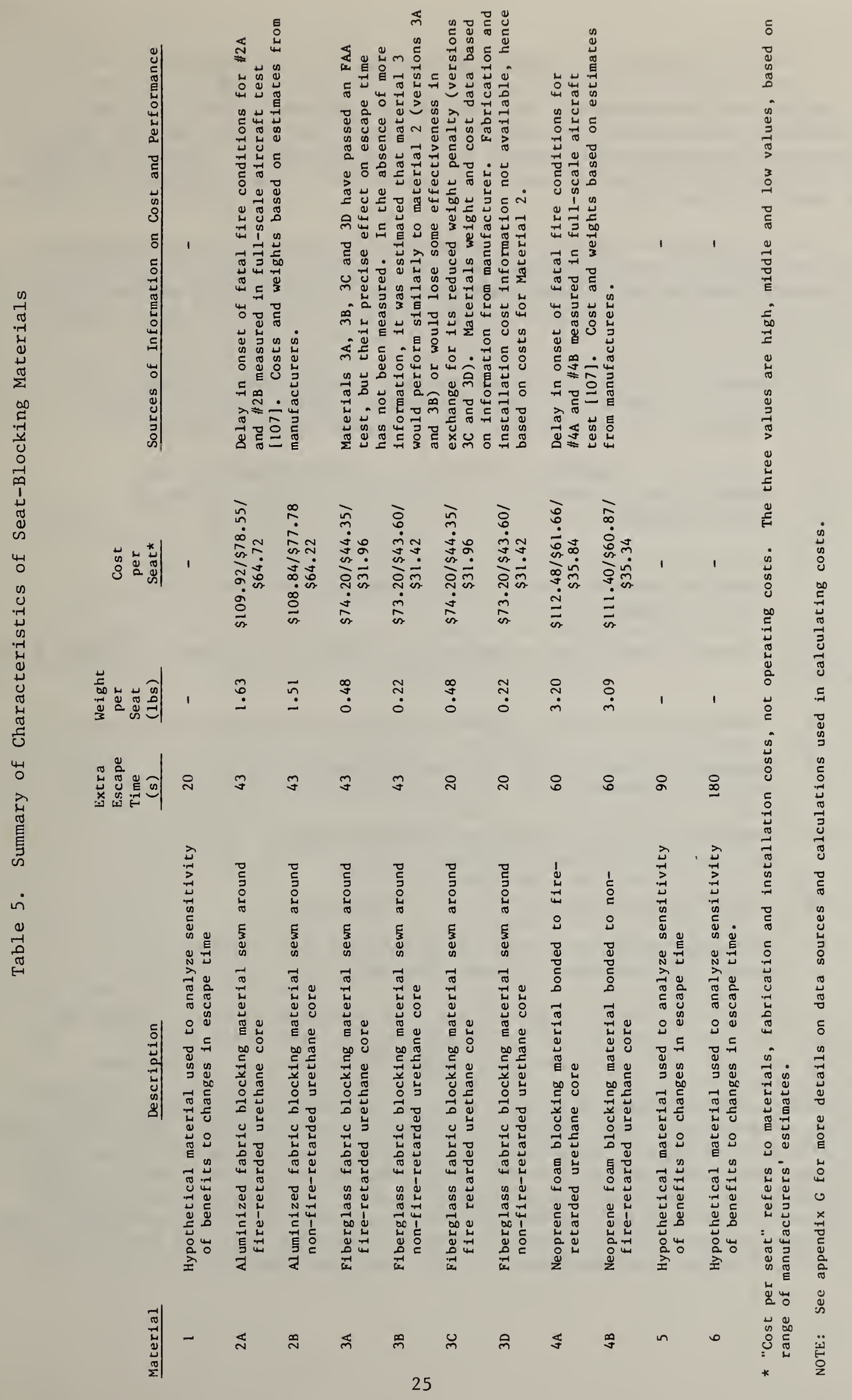




\section{4.l Expected Losses and Savings with Seat Blocking}

Appendix $G$ documents the expected lives saved for each of the fatal accidents cited in tables $1-3$ and combines them into overall savings as functions of extra escape time provided by the seat blockers. Expected savings for the particular values of escape time provided by the alternatives analyzed are shown in table G-6.

The savings are calculated in terms of high, middle and low estimates, reflecting the uncertainty involved in many of the reconstructions of the accidents. The following groups comprise most of the victims who were deemed unsaveable, even if seat blocking provided several minutes of extra escape time:

(a) Passengers killed by an in-flight fire that never involved the seats. (This is also a major source of uncertainty in the estimates, because of the 1979 accident in Saudi Arabia.)

(b) Passengers killed by a fast-moving, fuel-driven fire with numerous entry points into the aircraft because of severe crash damage.

(c) Passengers killed by smoke generated by items other than passenger seats. (This also is a major source of uncertainty in the estimates.)

The following additional categories accounted for far fewer unsaveable passengers:

(d) Passengers stunned by impact, unable to use extra escape time.

(e) Passengers immobile for reasons not related to accident (e.g., in wheelchair).

(f) Passengers unable to use extra time because of panic or because all exits were blocked.

(g) Passengers killed by fire outside aircraft.

(h) Passengers unable to find exits because they were lost in smoke not generated by burning seats.

It is useful to consider what proportion of the total fire fatalities prevented by seat blocking would have occurred in only a few accidents. For the low estimate, U.S. airlines only, nearly two-thirds of the maximum possible total saves come from the 1965 Salt Lake City accident. For the low estimates, world airlines with or without non-U.S. aircraft, nearly three fourths of the saves come from the 1980 Saudi Arabia accident. For the middle estimate, U.S. airlines only, nearly two-thirds of all saves come from the 1974 Pago Pago accident and the 1965 Salt Lake City accident. For the middle estimates, world airlines with or without non-U.S. aircraft, over half the total saves came from the two Saudi Arabia accidents, and over two-thirds came from those two accidents plus the 1973. Nigeria accident and the 1982 Spain accident. Similar concentrations hold for the high estimates. 
This means that most of the life-saving benefits of seat blocking are likely to come in the one or two accidents per decade where conditions are ideal for seat blocking to have an effect. It also means any estimate of the likely benefits of seat blocking is very dependent on an assessment of 1ikely seat-blocking effects in those few accidents. Uncertainties in assessment of the dozens of other accidents involving fire fatalities are not critical to the overall conclusions.

As noted in appendix $G$, further increases in the extra escape time provided by seat blocking over those available with Material 4 would produce further reductions in total loss of at most $10-15$ percent (if a high estimate of saves were used) and more likely 2-6 percent. For U.S. airlines only, no improvements in performance are possible except for the high saves estimates. Reductions in savings as a result of cutting the extra escape time are only slightly more sensitive; a 53 percent cut in escape time over that provided by Material 2 yields at most a 21 percent reduction in lives saved and a slightly smaller reduction in total loss avoided.

\subsection{Expected Costs for Seat Blocking}

Appendix $G$ also provides the data and calculations used to estimate costs for the various seat-blocking alternatives.

\subsection{Cost-Benefit Comparisons for Seat Blocking}

Table 6 summarizes the annualized costs and benefits for Materials 2A-4B. Table 7 provides a range of cost-benefit estimates, based on different combinations of the high, middle, and low estimates in table 6 .

Table 7 indicates that, for most alternatives, the results on whether benefits exceed costs or vice versa are not sensitive to (a) the use of fireretarded versus non-fire-retarded urethane (A vs. B and C vs. D options, respectively), or (b) the use of high, middle or low estimates (unless a best case of low costs and high benefits is assumed). The results also are not sensitive, in most cases, to the addition or reduction of extra escape time or the use of a higher value for life saved, within the range of $\$ 250,000$ to $\$ 1$ million discussed earlier. All these assumptions can make a difference, however, for Material 3, where costs and benefits are so closely matched that even small changes can change the difference between them from positive to negative or vice versa. Material 3 does much better than Materials 2 and 4 for the U.S.-airlines-only case because its costs are significantly lower. The cost side of the calculation, therefore, appears to offer more room for improvement than the benefits side.

\section{CONCLUSIONS}

This report has demonstrated that the fire-risk assessment and decision analysis methodologies developed by the Center for Fire Research can be successfully applied to the case of major aircraft fires. A generic model has been developed covering fatal passenger-flight fires and fires involving major fire damage. That model has then been applied to the risk-reduction strategy of seat blocking. The model permits not only assessment of the costs (initial and operating) and benefits (1ives saved and damage averted) of currently established blocking materials but also rapid calculation of the impact of 

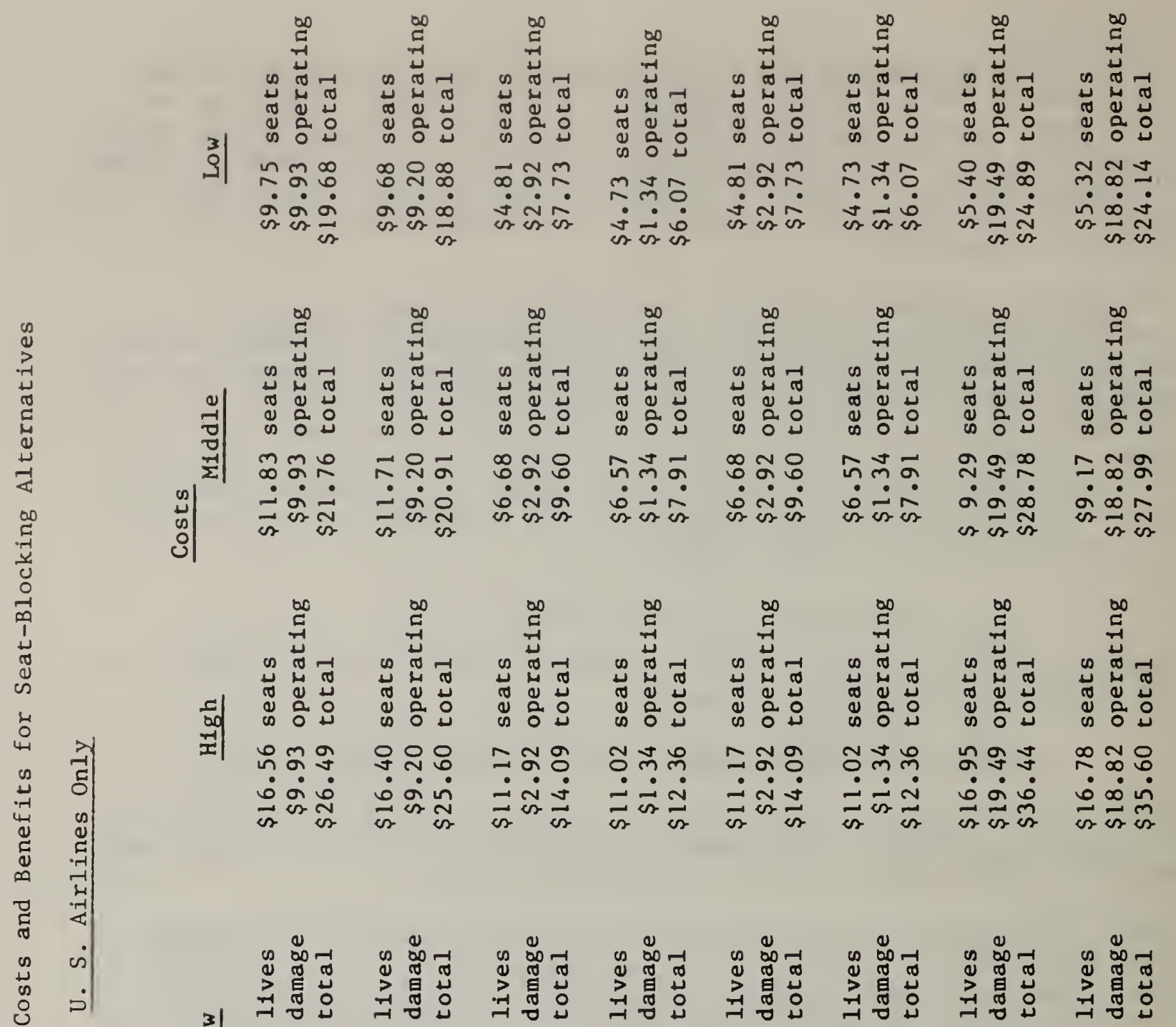

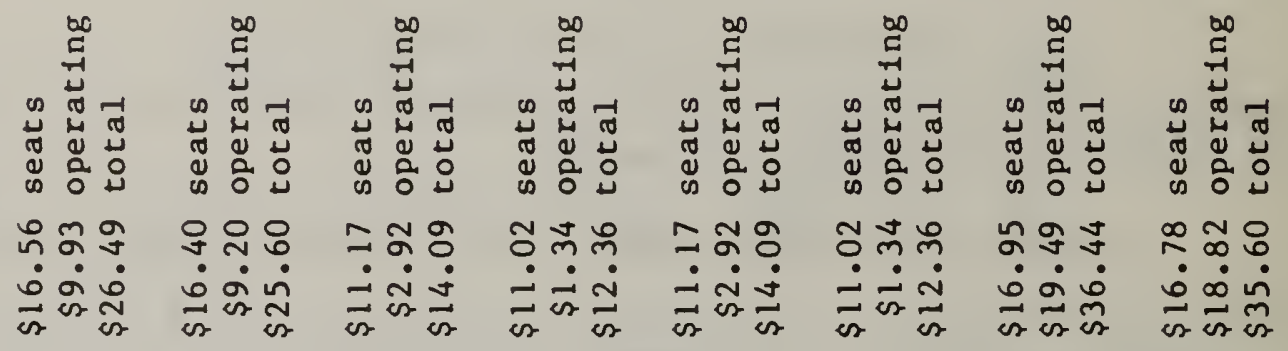
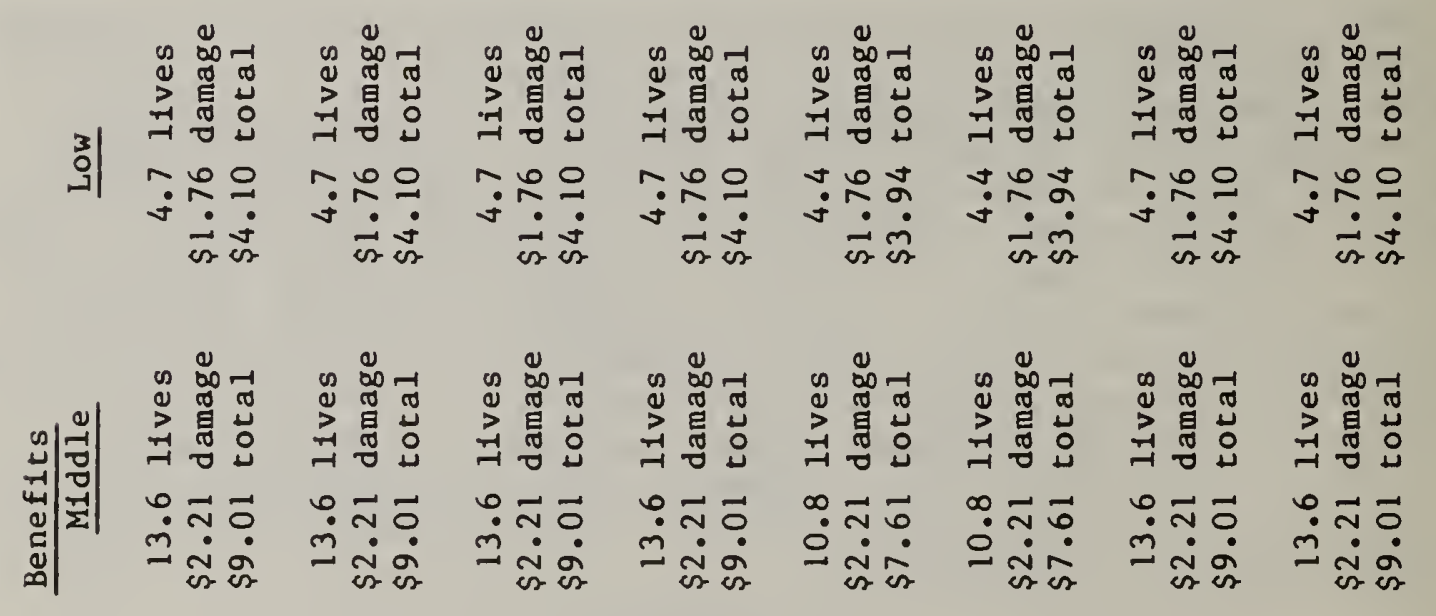

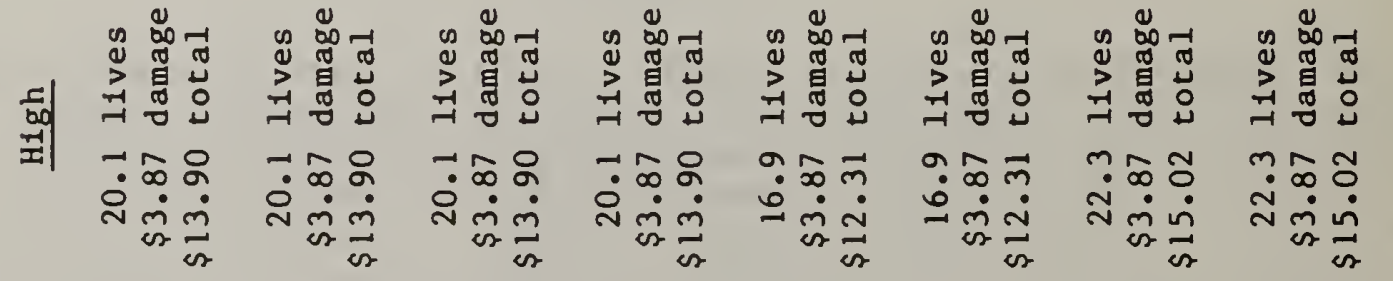

สุ

m

ले

4

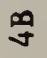




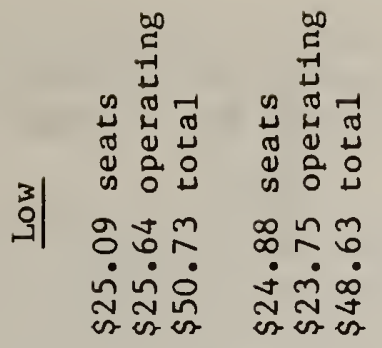

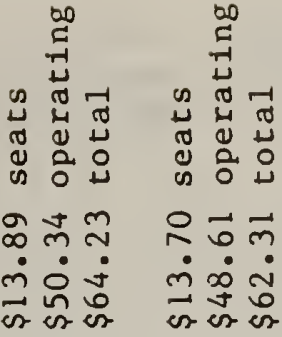

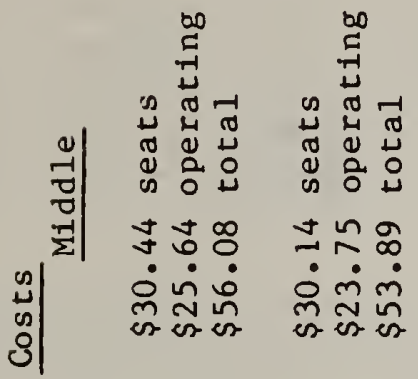

茎

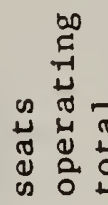

क्षे जิ

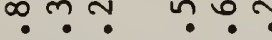

$\dot{~} \dot{0} \dot{\sim} \dot{\infty} \dot{0}$

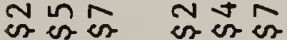

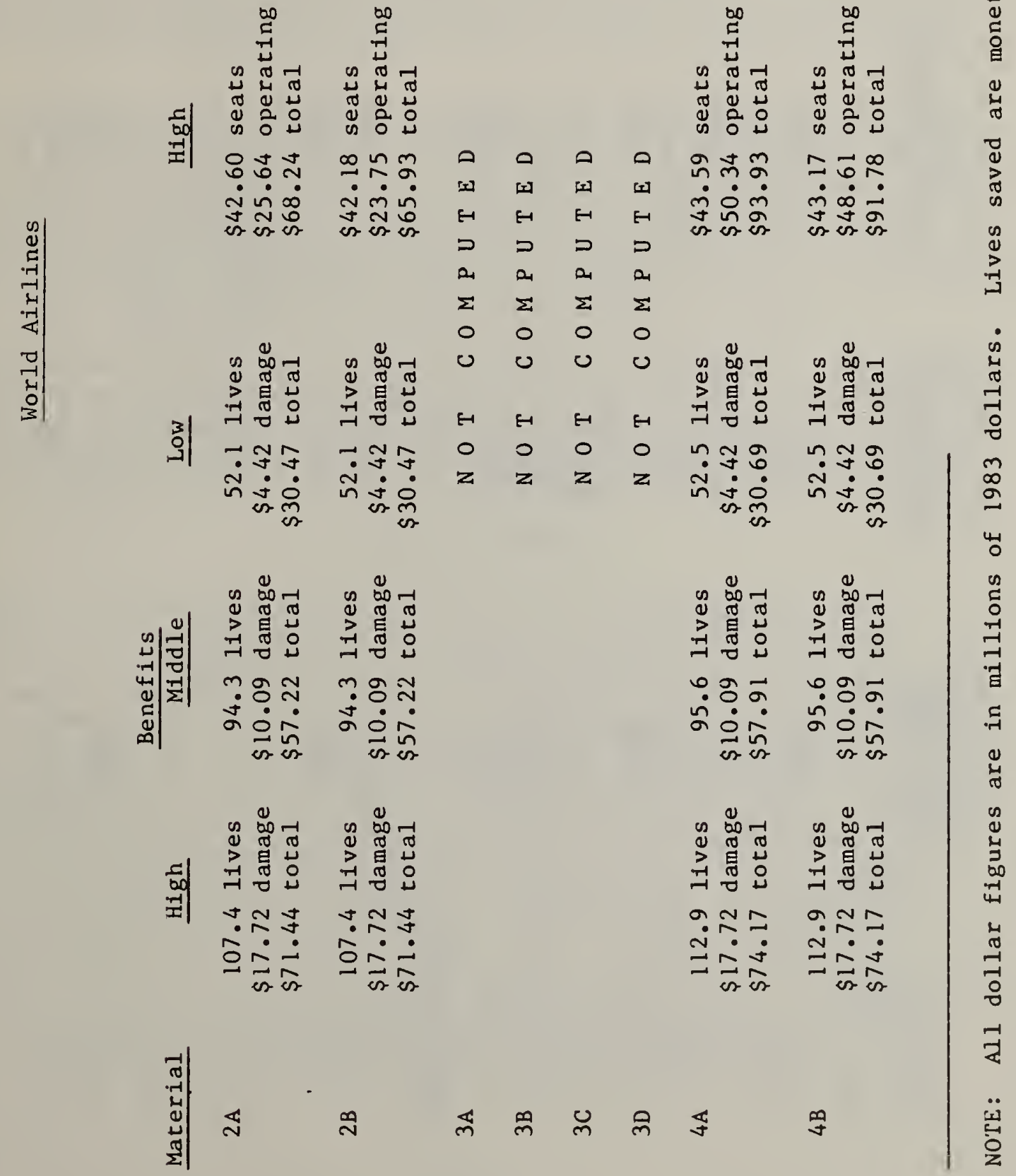

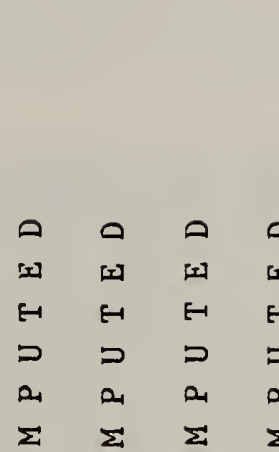

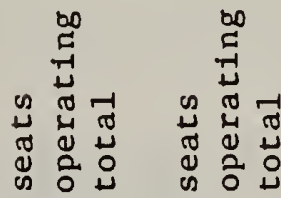

ที่ॅू =

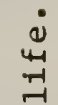


$$
\square \square \square \square
$$$$
\text { a. D م a }
$$$$
\Sigma \Sigma \Sigma \Sigma \Sigma
$$$$
\begin{array}{llll}
0 & 0 & 0 & 0
\end{array}
$$ 
changes in cost on performance in the face of rapid innovation. Evidence on the sensitivity of overall benefit/cost calculations to changes in one area versus another can be useful in developing priorities for safety research.

The benefits models are organized around a data base of historical fires. Tests and deterministic models are used to assess likely exit speeds, relative contributions of various fire-involved materials to fatalities, projected performances of risk-reduction alternatives, and other factors used in assessing which victims could have been saved by an alternative. Significant uncertainties still remain in these estimates because of uncertainties in some of the models (e.g., models on the role of cyanide in causing fatalities) and even more because of uncertainties in the detail available on circumstances of some accidents. At least in the first sample application, however, these uncertainties did not preclude use of the models to produce useful conclusions.

The cost models use manufacturers' estimates and forecasts to produce estimated costs for installing the alternative and operating with it. Significant uncertainties exist because these estimates nearly all involve forecasting from very limited experience, but as with benefits models, these uncertainties do not preclude the use of the models to produce useful conclusions.

In the sample application, for example, many key assumptions that were checked for sensitivity proved not to be critical in the assessment of net benefits over costs. Benefits proved less sensitive in general than costs. The relative insensitivity of benefits emphasizes the importance of reducing costs. Appendix $\mathrm{H}$ presents formulas that can be used for quick analysis of the impact of changes in fuel prices, weight penalty per seat, or incremental changes in the costs of fabricating and installing seat blockers.

While no analysis was done on the effects of varying either the discount rate or the speed or timing of the phase-in of seat blocking, it is probably safe to assume that neither would dramatically affect the results. The sizeable contribution of operating costs and the short time between seat refurbishments mean that benefits are incurred at about the same rate as costs.

\section{ACKNOWLEDGMENTS}

We want to express our appreciation to the many individuals who contributed to the development of the models and data used in this analysis. A special note of appreciation is due Constantine Sarkos, Richard Hill, and Peter Versage of the FAA Technical Center and Alan Gomberg of Firepro, Inc., who were instrumental in the initiation of the project and offered suggestions and critique based on their valuable experience. Other individuals at the FAA who helped us included Wayne Smoot, Richard Soper, Peter Boyle, Thor Eklund, Brian Colamasca and Jack Smith. Gerald Walhaut, of the National Transportation Safety Baord, John Enders and Edward Wood of the Flight Safety Foundation and R.L. Sears of the Boeing Commercial Alrplane Company helped us with detailed descriptions of some accidents. Paul Hamilton, a private consultant, helped with operating cost calculations. John N. Feren of the Douglas Aircraft Company helped with forecasts of aircraft inventory, activity and fuel burn data. G.W. Morrow of the Aerospace Division of UOP Inc., William Downey, $\mathrm{Jr}$. of Fairchild Burns Company and Jack Putman of Weber Aircraft Company provided incremental cost and weight data for fire blocked seats. 
Sources and Rationales for Estimated Fire Fatalities Total and Estimated Saveable by Seat Blocking

U.S. Airlines

1. $11 / 8 / 65 \quad$ American, B727, near Constance, KY

NTSB reports did not suffice to indicate the split of fire versus crash trauma fatalities, but seven of the ten passengers checked (70 percent) had carboxyhemoglobin levels over $10 \%$. This 70 percent result was used as an estimate of the percentage of total fatalities felled by fire, so 70 percent of 58 total fatalities gives 36 fire fatalities. Because there was a violent explosion only seconds after the aircraft struck the hill, all fire victims were deemed unsaveable by seat blocking. Either they were killed by the explosion or they were stunned by it and unable to use extra escape time.

\section{2. $11 / 11 / 65 \quad$ United, B727, Salt Lake City, UT}

NTSB reports indicate all fatalities were due to fire. Snow [111] provides an unusually thorough examination of victim conditions and escape activities. The high estimate of saves assumes that only three passengers - one wheelchair-bound invalid (unable to act) and two persons near the tail who would not have been able to follow others to useable exits (1ost/isolated in. smoke) - would have been killed regardless of the escape time provided by seat-blocking. The other 40 passengers would escape (including two who escaped and died later; they probably would not have been fatally injured before escaping) - nine through window exits near them and 29 through the main door. Escape rates are estimated at one per second for the main door and one per two seconds for the window exits. The middle estimate differs from the high estimate only in the assumption that two more ailing passengers - one with emphysema, one with arthritis - would have been fatally injured regardless of the extra escape time available; they are also classed as unable to act. The low estimate differs from the middle estimate in assuming that (1) the two passengers who escaped or were rescued but died later still would have died, (2) the two small children (aged two and six) would not have been carried out but would have died, and (3) four of the passengers closest to the flame-blocked galley door would have been killed trying to escape through that door rather than turning around and waiting in line to go out the main door. The children are classed as unable to act and the others as blocked by fire.

\section{4/22/66 American F1yers, L-188, Ardmore, OK}

NTSB reports do not suffice to split fatalities as fire versus crash trauma. A11 five crew fatalities were caused by crash trauma. Of the 78 passengers killed, 63 were tested for carboxyhemoglobin levels and 12 had levels over 10 percent. On this basis, Lucha [90] attributed 12 fatalities to fire. Instead, we prorated these 12 of 63 cases to the full group of 78 passengers killed and attribute 15 to fire. 
The high- and middle-save estimates assume all of those fire fatalities were mobile and likely to be able to escape within 20 seconds. (There was no information on the conditions of exits.) The low-save estimate assumes all the fatalities were either stunned by the crash (hence, unable to act) or blocked from the exits, possibly by the fact that most passenger seats separated during the slide down the mountain and may therefore have been blocking the aisles and exits.

$$
\text { 4. 6/23/67 Mohawk, BAC } 111, \text { Blossburg, PA }
$$

NTSB reports state that this in-flight fire produced a non-survivable crash. Since the fire originated in the airframe plenum chamber and did not use the cabin as an avenue of spread, seat blocking would have had no effect.

$$
\text { 5. 6/12/68 Pan American, B707, India }
$$

Lucha [90] attributed all six fatalities to fire. Information from Boeing [86] confirms this and attributes all deaths to smoke from burning fuel outside the aircraft. This meant that no one could have been saved by seat blocking, and all three estimates therefore assume no one could have been saved.

\section{11/27/70 Capitol Internationa1, DC8, Anchorage, AK}

NTSB reports indicate all fatalities were due to fire. The high estimate of saves assumes that all fatalities were felled by cabin material gases and that, with seat blocking and numerous useable doors and breaks in the fuselage to escape through, everyone on board could have escaped with an additional 20 seconds. The middle estimate and low estimate assume that only those fatalities killed by cyanide were killed by burning materials inside the cabin; hence, only those would have been saved by seat blocking. Tests were done on 19 of the 47 fatalities. Sarkos [106] estimated cyanide as a factor in four cases (which prorates to 10 for the full group of fatalities), based on a cyanide level of 0.55 . Kirkham and Lacefield [88] estimate that incapacitation will occur whenever cyanide (as a percentage of 0.75 ) plus carboxyhemoglobin (as a percentage of $46.5 \%$ ) equals or exceeds 1.00 . There are six such cases here where removal of the cyanide would change an incapacitating combination to a non-incapacitating one; these six cases prorate to 15 for the full group of fatalities. The higher Kirkham-Lacefield estimate of fatalities due to cabin materials is used for the middle-save estimate; the lower Sarkos estimate is used for the low-save estimate.

$$
\text { 7. 12/28/70 Trans-Caribbean, B727, Virgin Islands }
$$

NTSB reports indicate both fatalities were due to fire and both were unable to use extra escape time - one trapped under debris, the other knocked unconscious in the crash. 
NTSB reports indicated all fatalities but one were due to fire. The high estimate assumes that all fire fatalities were due to gases or flames attributable in large part to seat involvement. Without seat involvement, and with no evidence that anyone was unable to act, all passengers could have exited via the overwing exit (the only useable exit) at a rate of one every two seconds.

The middle estimate uses the Kirkham-Lacefield formula cited in case 非 to determine which fire fatalities would have been prevented if cyanide had not been a factor. (The Sarkos formula gives four killed by cyanide, almost the same.)

The low estimate then takes account of the fact that most people saveable by seat blocking would have found their paths to the one useable exit blocked by other fatalities not saveable by seat blocking. Only one person was next to the only useable exit - the window exit.

$$
\text { 9. } 12 / 8 / 72 \quad \text { United, B737, Chicago, IL }
$$

The estimate of fire fatalities is based on our review of the causes of death listed by the coroner in his report attached to the NTSB Human Factors Division report.

The high and middle saves estimates are based on a Sarkos estimate [106] that seven deaths were due to cyanide, hence avoidable with seat blocking. This is backed by an Aviation Daily article [30] quoting the Cook County coroner as saying that seven deaths were attributable to cyanide. The low estimate is based on the assumption that the coroner's analyses, strongly disputed at the time, were correct in finding that carboxyhemoglobin levels alone were fatal in all cases; this estimate also assumes that those levels were produced by smoke from outside, i.e., probably smoke from burning fuel.

10. $12 / 20 / 72$ North Centra1, DC9, Chicago, IL

NTSB reports indicate all fatalities were due to fire. The high estimate assumes that all fire fatalities were caused by gases attributable to seat involvement and that only one invalid (unable to act) would die. The middle estimate assumes that the invalid and two other passengers who were lost in smoke in the rear - one in the tail cone and one in a rest room - would die, the latter because they would not be able to find useable exits even with extra escape time. Alternatively, there were three fatalities with lethal carboxyhemoglobin levels alone. It was not possible to tell whether the two groups of three fatalities overlapped, so it is assumed a total of three would die. The low estimate assumes that the two people isolated in the rear and the five who never left their seats (including the invalid) were lost in smoke, then killed by smoke from the outside.

ll. 7/22/73 Pan American, B707, Tahiti

Lucha [90] cites this accident, which began as an in-flight fire outside the cabin area. There were four in-air explosions which killed everyone on board. Seat blocking would have had no effect. 
NTSB reports indicate all fatalities but one were killed by fire. The highsave estimate assumes that if seat blocking had been present, then the six persons who escaped but died later would not have received fatal injuries, that the one person killed by the fire outside the aircraft still would have died, and that the other 88 fatalities were killed by gases from seat involvement and would have survived longer with seat blocking and been able to escape. It is further assumed that the apparent panic, cited in the NTSB reports, would not have occurred if seat blocking had delayed the spread of the fire, permitting one of the two unused main doors to be opened and occupants to escape at a rate of one per second.

The middle-saves estimate assumes that only persons killed by cyanide would be saved by seat blocking. The Sarkos formula (cited in case 非) produces a maximum of 47 killed by cyanide and hence saveable; this is the number used here. (The Kirkham-Lacefleld formula, cited in case \#6, produces an estimate of 50 potential saves, almost the same.) Both estimates are prorated from blood gas analyses done on 49 of the 95 fire fatalities.

The low estimate assumes that the added escape time failed to prevent the panic on board. Therefore, neither main door was opened and the useable overwing exit was not discovered by anyone other than the four passengers who used it. (The investigators said that even without seat blocking, more passengers should have been able to escape via the overwing exits if they had been noticed.)

\section{3. $9 / 11 / 74$ Eastern, DC9, Charlotte, NC}

The split of fire versus trauma fatalities is our estimate based on the partial information provided in the NTSB reports. Using the same information, Cominsky [51] estimated 39 fire fatalities. Cominsky counted as fire fatalities all six passengers killed by "combined factors" - fire and crash trauma; that report also excluded one fatality who died some time after the accident. Our study counted the fire and smoke fatalities (33) and half the combined-factors fatalities (3) to get the estimated 36 fire fatalities.

NTSB reports say the effects of fire were fatal before cyanide gas from interior materials could become a factor. All normal exits appear to have been jammed or blocked, and the fire appears to have rapidly blocked the holes in the fuselage. Seat blocking, therefore, probably would have had no effect.

\section{4/27/76 American, B727, Virgin Islands}

NTSB reports suggest all fatalities but one died of fire. The fire itself seems to have been a fast-moving, fuel-driven fire that could have overwhelmed the passengers through the numerous fuselage breaks even if seat blocking had been present; this argument underlies the low- and middle-saves estimates. If not, then the 11 people the NTSB reports say were killed by cyanide could have escaped through those fuselage breaks and the overwing exits at an estimated rate of one escape every two seconds; this provides the high-saves estimate. 
Cominsky [5l] provided the estimated split of fire versus crash trauma fatalities. Survivors exited primarily through a left-side door and a hole in the left wall. Evacuation time was limited to about one minute. With the top of the fuselage torn of $f$ and exposed to flame, it is unlikely that seat blocking would have helped.

16. 4/4/77 Southern, DC9, near New Hope, GA

The estimate of crash trauma versus fire fatalities was based on our review of the NTSB report material on each fatality. Cominsky [51] counted all 20 fire fatalities and half the nine combined fire-trauma fatalities. This study counted only the fire fatalities because the trauma part of the combinedfactor fatalities seemed too severe. Three victims had lethal levels of cyanide and probably would have been able to escape if seat blocking had delayed involvement of interior materials. The others had non-incapacitating levels of gases and were probably killed by burns, since there was a fireball in the aircraft before it stopped sliding.

\section{3/1/78 Continental, DC10, Los Angeles, CA}

NTSB reports indicate there were four fire fatalities - two succumbing quite a while after the accident and therefore not captured by some overview studies like Cominsky [51]. All four were killed by fire outside the aircraft and would not have been helped by seat blocking.

Non-U.S. Airlines Using U.S.-Built Aircraft

$$
\text { 1. 2/16/67 Garuda, L-188, Indonesia }
$$

The World Airline Accident Summary attributed deaths primarily to fire so this study estimated a11 22 were due to fire. The crew and passengers were unable to open the forward main entrance door or the rear service door. Many died near those doors. Survivors went out the right hand forward emergency exit and cockpit sliding windows. There was no mention of breaks in the fuselage. Smoke and fumes in the cabin were mentioned only after the aircraft stopped.

The high- and middle-save estimates assume that everyone killed could have escaped but at a rate of only one every two seconds because of the limited exits available. The low-estimate assumes that some passengers were killed by crash trauma or would have continued to attempt to escape through main doors until overcome by smoke, even after seat-blocking delayed smoke, with the net effect that no one would have been saved.

$$
\text { 2. } 3 / 5 / 67 \quad \text { Varig, DC8, Liberia }
$$

The reports examined estimated 56 total fatalities, while Cominsky [51] estimated 51 total fatalities. Cominsky's estimate of 11 trauma fatalities was applied to the higher total to give 45 fire fatalities (versus Cominsky's estimate of 40 ). 
The aircraft caught fire from a wing fuel spill during ground slide after crash. Fire entered the fuselage during the slide through an overwing exit. Fire spread faster toward the rear than the front, and most fatalities were found in the rear headed back toward the exits. Access to the rear exits was partially obstructed by broken seats, a fallen $11 \mathrm{fe}$ raft and other items. The high- and middle-saves estimates assume everyone could escape, given time, and the two estimates differ only on the likely speed of escape - one per second versus one every two seconds - in light of the obstructions. The low-save estimate assumes the obstructions cut escape speed to one every five seconds, that the crew still would have stopped helping passengers escape at 90 seconds of extra time (in the actual accident, the crew did stop helping passengers escape before they had to, according to the investigators), and that passengers could not have escaped without help from the crew.

\section{4/8/68 BOAC, B707, England}

Reports state all fatalities were killed by heat or explosion. All were queued to escape through the rear exit (galley door) when it was blocked by spreading flames from under the fuselage. Before they could move all the way forward to another exit, an explosion breached the integrity of the aircraft and exposed them to the flames. Seat blocking would not have helped, in all likelihood.

\section{9/17/69 Pac1f1c Western, CV640, Canada}

The cockpit area was destroyed in the crash so it is assumed the two crew fatalities were due to crash trauma and the two passenger fatalities, since that area remained intact, were due to fire. Survivors escaped through the rear exits before fire consumed the aircraft. The high- and middle-saves estimates assume the two passenger fatalities simply ran out of time and would have escaped with seat blocking. The low-save estimate assumes that either they were unable to act (e.g., stunned) or they were killed by a fire that did not involve cabin materials.

\section{7/5/70 Air Canada, DC8, Canada}

The aircraft's first landing attempt ruptured an engine and pylon, spiling fuel. Three explosions followed, apparently killing everyone before the aircraft came to a stop. Seat blocking would not have helped. All fatalities were due to the explosions, hence were related to fire not crash trauma.

$$
\text { 6. 1/22/73 Royal Jordanian, B707, Nigeria }
$$

The aircraft landed in an undershoot, fire broke out, and the runway surface collapsed. According to information from Boeing [86], the aircraft came to rest over a drainage ditch so that burning fuel ran under the fuselage. Flames and smoke entered when the first exit door was opened, but it is not clear which killed the passengers. Escape was possible through some exits, but in some cases it required running through the fire. The high-save estimate assumes all 176 fatalities were killed by fire, hence would have had extra time with seat blocking, would have been able to act if given extra escape time, and could have escaped at a rate of one per second. The middlesave estimate assumes that half the fatalities were killed by smoke from outside or were unable to act and that the other half could escape but only at 
a rate of one every two seconds. The low-save estimate assumes everyone was killed by smoke from outside, unable to act, blocked by unuseable exits, or otherwise unable to benefit from seat blocking.

\section{7/11/73 Varig, B707, France}

This stemmed from an in-flight fire that began in the rear lavatories during approach. Fire extinguishers were used but were ineffective because the crew could not find the start of the fire. At touchdown, fire was still confined to the rear toilet, according to the reports, but the passengers were already immobilized. Polyvinyl chloride materials in the lavatory construction were deemed the source of the gases that killed most people. It is unlikely that seat blocking would have helped because the deaths occurred before the seats became involved.

\section{8. $11 / 20 / 74 \quad$ Lufthansa, B747, Kenya}

The brief descriptions say the aircraft lost height on its takeoff. After the crash, fire broke out in the left wing and separated tail section. Information from Boeing [86] suggests 35 fatalities were due to fire. All but four of those were considered stunned by impact and unable to act. Survivors left through two right-side doors or breaks in the fuselage or were thrown clear, with the crews assisting evacuation until the fire became too fierce. All estimates assume the four mobile victims would have been saved by seat blocking.

\section{6/4/76 Air Manila, L-188, Guam}

NTSB reports indicate that 28 of the 45 fatalities were due to fire. The fire moved rapidly and the occupiable area was compromised. The description suggests everyone would have been stunned by debris or trapped by a fastmoving, fuel-driven fire with multiple access points to the fuselage, even if seat blocking had been present.

10. $3 / 27 / 77$

KLM, B747, Canary Islands

The estimated split between fire and crash-trauma fatalities is taken from Cominsky [51]. Fire enveloped the aircraft completely and immediately, presumably blocking all exits. The saves estimates assume seat blocking would have had no effect on this situation.

11. $9 / 29 / 77$ Japan Air, DC8, Malaysia

Cominsky [51] attributed 34 of the 45 fatalities to fire, based on an unpublished McDonnell Douglas file report. The aircraft hit some trees and then a hill. The aft fuselage broke off, and the front section exploded in flames. Because of the breakup of the aircraft, affording a wide area of access to the cabin for the fire, it is estimated that seat blocking would have had no effect.

12. $12 / 17 / 78$ Indian Airlines, B737, India

The one fatality died of burns incurred after evacuating the aircraft. All estimates assume seat blocking would not have made a difference in the death. 
The reports say only that fire was present but not whether any fatalities were due to fire. In the absence of more information, the high-saves estimate assumes all the fatalities were fire-related and preventable by seat blocking; the middle-saves estimate assumes half were; and the low-saves estimate assumes none were.

\section{1l/26/79 Pakistani International, B707, Saudi Arabia}

The crash was caused by an in-flight cabin fire for which the investigators never found conclusive evidence of cause. Since seat blocking would either have controlled the fire, saving everyone, or not controlled it, saving no one, it makes no sense to split the difference for a middle-saves estimate. Therefore, since the speculations as to cause seem to include more scenarios that would have been controlled by seat blocking than scenarios that would not, the middle-saves and high-saves estimates both assume all 156 would have been saved. The low-saves estimate assumes none of them would have been saved.

\section{2/27/80 China Airlines, B707, Phillipines}

There were two fatalities, both killed by fire. Jack Enders of the Flight Safety Foundation indicated in a conversation with us that both were killed outside the aircraft. This means seat blocking would have had no effect.

\section{6. $8 / 19 / 80$ Saudi Air, L-1011, Saudi Arabia}

This crash was caused by an in-flight fire originating in the cargo hold. With seat blocking, the fire probably would not have established itself in the cabin but would have cycled in the cargo hold, permitting a safe landing and evacuation of all on board. All three saves estimates therefore show all 301 passengers being saved.

\section{7. $11 / 19 / 80 \quad$ Korean Air, B747, Korea}

Richard Hill of the FAA provided site-observer estimates that all fatalities but three were probably due to fire and all of those would have been saved with seat blocking. Therefore, the saves estimates all show 11 of the 14 victims saved.

18. $7 / 27 / 81 \quad$ Aeromexico, DC9, Mexico

The aircraft crashed and burst into flames. All or none of the fatalities may have been due to fire. The saves estimates, with the absence of better information, assume that all, half, and none of the fatalities were saveable.

19. $9 / 13 / 82 \quad$ Spantax, DCl0, Spain

All 51 fatalities were due to fire, according to the reports. Richard Hill of the FAA, who observed the crash site, estimates that all victims were saveable by seat blocking. Because all doors were useable, it is estimated that all 51 victims could have been saved, even with only 20 extra seconds of escape time. 
Non-U.S. Airlines Using Non-U.S. Aircraft

\section{2/15/66 Indian Airlines, Carave1le, India}

The two fatalities died after evacuation. The reports do not indicate whether the cause was fire or crash trauma. The high-saves estimate assumes both would have received non-fatal injuries if seat blocking was present; the lowand middle-saves estimates assume no seat blocking effect.

\section{2. $9 / 11 / 68$ \\ Air France, Carave11e, France}

Al1 95 occupants were killed by a crash caused by an in-flight cabin fire. The only location fire ever reached, according to those reports, is the rear of the cabin, presumably behind the last row of seats, and it is therefore assumed that seat blocking would have had no effect.

\section{3. $7 / 26 / 69$ Air Algerie, Caravelle, Algeria}

The 33 fatalities were killed by a crash caused by an in-flight fire in electrical components. There is no mention of spread into the cabin, so it is assumed seat blocking would have had no effect.

$$
\text { 4. 5/16/70 Somali, Viscount, Somalia }
$$

The five fatalities followed a crash caused by loss of control, which in turn was caused by an inflight fire of unidentified nature and origin that was seen burning through the floor (from below) near the sixth row of seats. Since the critical damage apparently occurred in the concealed spaces, seat blocking would have had no effect.

\section{5. $3 / 15 / 74 \quad$ Sterling, Caravelle, Iran}

A heavy fire resulted from a fuel spill after the right landing gear collapsed causing the right wing to strike the ground. From the description, it appears that all fatalities probably were due to fire, and it is more 1ikely than not that seat blocking would have helped. Therefore, the high- and middle-saves estimates assume everyone saved; the low-saves estimate assumes no one saved. 



\section{Historical Accidents Involving Fires and Fatalities But No Fire-Related Fatalities, 1965-82}

The following list describes historical fatal passenger-flight incidents in which fire was present but which were estimated to have no fatalities attributable to the fire.

The list is not comprehensive but concentrates on incidents where there were uncertainties as to whether any fatalities were due to fire. Incidents involving fire following a clearly non-survivable crash are omitted. The rationales for excluding these accidents are provided. All descriptions not otherwise labeled are from the NTSB Aircraft Accident Reports (for U.S.-site crashes) or the World Airline Accident Summary [3].

\section{Description}

1. 4/10/65 Alia, Herald, Turboprop, Syria
On

Board

Total

Killed

Fuselage failed structurally in flight and aircraft crashed on a mountain slope. The facts that everyone was killed and that the fuselage failed suggest, in the absence of more detail, that all fatalities were due to crash trauma. There were witness reports, unconfirmed by investigation of the wreckage, that the aircraft had caught fire in flight.

2. 10/27/65 British European, Vanguard, Turboprop, England

Aircraft crashed in overshoot and fire followed impact. The report says that everyone was killed due to crash trauma.

$$
\text { 3. 3/4/66 Canadian Pacific, DC8, Jet, Japan }
$$

The aircraft slid, hit lights, hit seawall, spilled fuel, and fuel caught fire. Survivors escaped through holes in fuselage. Reports say only that deaths were due to impact trauma or fire or both. The aircraft was thrown over and destroyed, then caught fire. This sounds like a nonsurvivable crash. Cominsky [51] attributed half of all fatalities to fire in the absence of more information. Wayne Smoot of FAA also reviewed this case for the purpose of creating a fire-fatality data base; he concluded that none of the facalities were due to fire.

$$
\text { 4. 11/6/67 TWA, B707, Jet, Erlanger, KY }
$$

The only fatality was due to crash trauma. This was cited in Mniszewski [95]. 
The accounts, including Cominsky [51], agree that this was a high-impact, non-survivable crash in which the survivors were lucky. All carboxyhemoglobin tests were under 10 percent, consistent with fire not being a cause of death.

\section{2/16/68 Civil Air Transport, B727, Jet, Taiwan}

The aircraft hit a farm house while taking off after an aborted landing. During the ensuing ground slide, the nose and landing gears collapsed and the tail section, left wing and three engines separated. This degree of ground-slide damage tends to mean that all fatalities are due to crash trauma. Taylor [114] attributes all fatalities to fire, but that study tends to resolve doubts in favor of fire being the cause.

\section{4/20/68 South African Atrways, B707, Jet,} Southwest Africa

At impact, the aircraft was descending at a rate of 1500-2000 feet per minute. On impact, the hull and all four engine pods gouged deep trenches in the ground. The aircraft then began to break up. Two separate fuel fires broke out. Wreckage and bodies were strewn over an area 1400 meters long and 200 meters wide. This crash severity suggests that all fatalities were due to crash trauma.

While NTSB reports are unsure, they say there was "no indication of fire until after impact and breakup which caused deaths". All carboxyhemoglobin tests were at or below 7 percent. Cited in Mniszewski [95].

$$
\begin{aligned}
& \text { 9. 12/27/68 North Central Atrways, CV-580, Turboprop, } \\
& \text { Chicago, IL }
\end{aligned}
$$

The NTSB and Human Factors reports both suggest all fatalities were due to impact, although reports are far from conclusive. All crew fatalities, at least, were attributed to impact. The cabin area had extensive impact damage but "was virtually free of fire damage". Mniszewski [95] attributed all deaths to fire and estimated 16 would be saved by reducing flammability of interior finish and combustibility of seating. 


\section{Description}

10. 1/5/69 Ariana, B727, Jet, England
On Total

Board Killed

$64-65 \quad 48-50$

The two citations - Taylor [114] and the World Airline Accident Summary [3] - differ on the number of fatalities and the total number on board. Taylor attributes 41 fatalities to fire, but the World Summary says "crash destroyed aircraft ... and set the wreckage on fire". In the absence of more information or a rationale from Taylor, who tends to resolve doubts in favor of attributing cause to fire, the World Summary description suggests all fatalities were due to crash trauma.

11. 9/12/69 PAL, BAC-111, Jet, Phillipines

The aircraft struck a hill. The accident description mentions fire only in saying that the wreckage was consumed by fire. That, and the fact that nearly everyone died, suggests that all fatalities were due to crash trauma.

12. $11 / 20 / 69$ Nigerian, VC-10, Jet, Nigeria

The aircraft broke up on impact. That, and the fact that everyone died, suggests that all fatalities were due to crash trauma.

13. 1/25/70 Royal Nepal, F27, Turboprop, India

The description cites a "localized minor fire", which seems a less likely cause for the one fatality than the also-cited "extensive damage by impact".

14. 12/31/70 PIA, F27, Turboprop

The only information is that it "crashed and burnt out on landing". With so little information, it is more likely that the fatalities were due to crash trauma than to fire.

15. 9/4/71 Alaska Airlines, B727, Jet, Near Juneau, AK

The NTSB report termed this a non-survivable crash, which indicates all fatalities were attributable to crash trauma.

16. Pan Internationa1, BAC-111, Jet, Germany

The aircraft struck a bridge over the autobahn during an emergency landing. Both wings and the tail unit separated, then fire broke out. The severity of the crash damage suggests that all fatalities were due to crash trauma. 
The aircraft crashed 13 miles short of the airfield, then caught fire. In the absence of other information and since almost everyone was killed, it seems most 11 kely that all fatalities were due to crash trauma.

18. $8 / 11 / 72$ Indian Airways, F27, Turboprop, India

The aircraft collided with the terrain, then caught fire. In the absence of other information and since everyone was killed, it seems most likely that all fatallties were due to crash trauma.

19. 11/28/72 Japan Alrlines, DC8, Jet, USSR

The left wing and tall touched ground on landing. The alrcraft broke up and caught fire. The aircraft is described as "rolling", which sounds like a non-survivable crash, with all fatalities attributed to crash trauma.

20. 12/29/72 Eastern Airlines, L-1011, Jet, Miami, FL

Reports are unclear but seem to suggest that all fatalities were due to impact. There were burns, but the Human Factors Group report seems to say they were on $1 y$ suffered by survivors near an open window where flames briefly blew 1n. This suggests all fatalitles were due to crash trauma.

21. 5/31/73 Ind1a, B737, Jet, India

The aircraft flew into wires, collided with the terrain, then crashed in flames. In the absence of other information, this sounds like a severe crash in which all

fatalities would have been due to crash trauma. The government report (cited in [86]) is self-contradictory on the question of flre involvement in any of the deaths.

22. $7 / 31 / 73$ Delta, DC9, Jet, Boston, MA

The coroner said all fatalities were due to impact.

23. 1/1/74 Itavia, F28, Jet, Ita1y

The aircraft crashed two miles short of the runway and caught fire. In the absence of other information and since almost everyone was killed, it is most likely that all fatalities were due to crash trauma. 
The report said the airplane disintegrated and the crash was non-survivable. This indicates all fatalities were due to crash trauma.

25. 6/27/74 Cambodia Air, B307, Piston, Cambodia

This aircraft was incorrectly 1isted in the World Summary as a B707. Boeing [86] says it was a B307, hence not one of the aircraft types being studied.

26. 6/24/75 Eastern, B727, Jet, Jamaica, NY

While not conclusive, the NTSB and Human Factors Group reports suggest all fatalities were due to impact. The only examples were impact fatalities, and the sampled carboxyhemoglobin levels were all under $20 \%$. There was a fastmoving fire, however, that caused serious burns to the survivors.

27. $7 / 15 / 75$ National, DC10, Jet, enroute to Jacksonvi11e, FL

The one fatality committed suicide by fire while the aircraft was in flight. The fire had gone out by the time it was discovered. As a suicide, it should not be counted with other fire fatalities.

28. 11/23/76 01ympic, YS-11, Turboprop, Greece

The report says the aircraft disintegrated. This indicates al1 fatalities were due to crash trauma.

29. $11 / 19 / 77$ TAP, B727, Jet, Spain

The aircraft went off the end of the runway, hit some lights, plunged over a steep bank, and exploded on impact. This suggests a non-survivable incident with all fatalities due to crash trauma.

30. 12/4/77 Garuda, B737, Jet, Malaysia

The aircraft crashed due to an inflight fire, which was hijacking-related and therefore probably caused by a bomb. For this reason, the fatalities are probably attributable to an explosive device rather than a fire. 
The alrcraft bounced four times, then hit a building. A fire began sometime in that sequence, but the crash severity suggests that all fatalities were due to crash trauma.

32. 5/25/79 American, DC10, Jet, Chicago, IL

The NTSB report says all were killed by impact.

33. 10/31/79 Western, DC10, Jet, Mexico

The aircraft broke into several pieces and the front end hit a bullding while traveling at 180 knots, according to Richard Hill, FAA, who was an official observer at the crash site. This crash severity suggests that all fatalities were due to crash trauma.

34. 12/23/79 Turkish, F28, Jet, Turkey

The aircraft struck a hill; then there was a post-impact fire. In the absence of other information and since almost everyone was killed, it seems likely that all fatalities were due to crash trauma.

35. $7 / 20 / 81 \quad$ Somali, F27, Turboprop, Somalia

The only information is that the aircraft crashed and burnt out. Since everyone was killed, it seems likely that all fatalities were due to crash trauma.

36. 3/20/82 Garuda, F28, Jet, Indonesia

The aircraft overshot the runway, crashed in a field in heavy rain, and then burst into flames. In the absence of other information and since almost everyone was killed, it seems likely that all fatalities were due to crash trauma.

37. 6/8/82 Varig, B727, Jet, Brazil

The aircraft crashed into a hillside. There was fire, but the crash description suggests it was not a factor in the deaths. 
Historical Major Aircraft-Fire Property Damage Preventable by Alternatives Operating in the Aircraft Interior

Table C-1 1ists seven cases of major property damage attributable to aircraft fires for which some effective alternatives operating in the aircraft interior could have prevented all or nearly all damage. The limitation to alternatives located in the aircraft interior covers most alternatives of interest to FAA but excludes most large-loss aircraft fires. Accidents during refueling or servicing of systems like the oxygen system, in-flight engine fires, and tire fires while landing are among the more common causes of largeloss aircraft fires.

of the incidents listed in table $\mathrm{C}-1$, 非 1 and 2 involved U.S. airlines, while the others all involved non-U.S. airlines using U.S.-built aircraft.

Table C-2 provides summary estimates of preventable property damage. The Middle Estimate given in table $\mathrm{C}-2$ is based on all the incidents in table $\mathrm{C}-1$ and uses the loss figure for 非 1 that was based on the standardized approach cited in table $\mathrm{C}-3$.

The Low Estimate in table C-2 includes only incidents $\|_{1} 1,2$ and 5 - the two ramp fires and the Saudi in-flight fire - because they are the three incidents where the evidence for effect of interior alternatives is strongest. The others were external fires that might have caused extensive damage without involving the interior $\left(\$ k_{4}, 6\right)$ and fires where very little is known about what happened $(\equiv 3,7)$. Also the loss figure actually reported $(\$ 14.5$ million) is used for the 1974 accident rather than the higher figure based on the standardized approach.

The High Estimate in table $\mathrm{C}-2$ assumes that the list of incidents in table C-1 represents under-reporting of all relevant incidents. Most citations are based on recollections of experts whose associations with this problem go back only to 1978. Therefore, it is assumed that the incidents in table C-1 (excluding 非) should be taken as the 1978-82 portion of a true, longer list of incidents. The estimated total loss is estimated by prorating the 1978-82 losses over 1965-82, using passenger-miles as the basis for weighting. (See table D-4 for the passenger-mile figures.) This means the 1978-82 losses in table $\mathrm{C}-1$ were estimated to have been 44 percent of the true total for flights involving U.S. airlines and/or U.S.-built aircraft and for al1 world flights. For U.S. airlines only, incident 非 was the only incident to come after 1977, which would make the High Estimate lower than the Low Estimate. The High Estimate is therefore calculated so that the Middle Estimate for U.S. airlines only will be 44 percent of it; this is the same percentage relationship characteristic of the other two rows. 
Table C-1. Historical Major Aircraft Fire Losses Preventable by Alternatives Operating in the Aircraft Cabin

Date

1. $4 / 19 / 74$

2. $10 / 26 / 79$

3. $11 / 26 / 79$

4. $2 / 27 / 80$

5. $8 / 19 / 80$

6. $11 / 19 / 80$

7. Unknown
Description

TWA, L-1011, Jet A fire began in the cabin and did not break out unt1l the alrcraft was on the ground, parked and unattended. Some alternatives could have blocked the growth of the fire to selfsustaining size. The first loss figure is the one cited in [97]; it probably reflects a usedalrcraft valuation of the alrcraft and the value of salvage. The second loss figure is the "value of alrcraft" figure cited in the original article on the accident in [37]. The third loss figure is based on a standardized approach (see table C-3).

United, B727, Jet

Discarded smoking materials ignited cabin seats. With some alternatives no selfsustaining fire probably would have occurred. Accident cited and described in [38].

Pakistani International, B707, Jet This 1 -filght fire of undetermined origin also is listed under fatalities. Richard Hill, FAA, estimated that of the possible scenarios leading to the fire, more than half of them could have been blocked by some alternatives. The loss value assumes the alrcraft was a B707-300 serles alrcraft because only those B707s were "disposed of" in 1979, according to the International Civil Aviation Organization's Fleet and Personnel for 1979. The loss figure 1s based on a standardized approach (see table $(-3)$.

China Airlines, B707, Jet

This post-crash fire, also c1ted in the list of fatal fires, involved rapid spread to the seats and had a similar fire damage pattern to the Korean Air incident cited below. It is therefore assumed to be susceptable to sharply reduced loss through some cabin alterantives. The loss figure is based on a standardized approach (see table $\mathrm{C}-3$ ).

Saud1 Afr, L-101l, Jet

This in-flight fire also was c1ted in the list of fatal fires. The loss figure is based on a standardized approach (see table $\mathrm{C}-3$ ).

Korean Air, B747, Jet

This post-crash fire involved very $11 t$ tle Impact damage to the alrcraft, and RIchard H111, FAA, estimates there would have been only minor flre damage if some effective alternative operating in the cabin had been present. The loss figure 1 s based on a standardized approach (see table $\mathrm{C}-3$ ).

Pakistan1 International, DC10, Jet This incident was cited by Richard H111, FAA, as an incident in which an effective cabin alternative would have prevented most damage. The loss figure is based on a standardized approach (see table C-3).
Estimated Loss (1n m11110ns)

$\$ 14.5 / \$ 22.5 / \$ 19.0$

$\$ 3.2$

$\$ 1.0$

$\$ 1.0$

$\$ 19.0$

$\$ 24.0$

$\$ 16.6$ 
Table C-2. Summary Estimates of Preventable Property

Damage in Aircraft Fires

High Estimate Middle Estimate Low Estimate

U.S. Airlines

$\$ 39.0$ million $\$ 22.2$ million

$\$ 17.7$ million

U.S Airlines

and/or Aircraft

$\$ 147.3$ million $\quad \$ 83.8$ million

$\$ 36.7$ million

World Airlines

$\$ 147.3 \mathrm{mil11}$ on

$\$ 83.8$ mil1ion

$\$ 36.7$ mi11ion 
Table C-3. Bases for Estimating Values of Property Damage to Aircraft

Used aircraft prices have been surveyed and summarized at several points during 1970-1980, and the results are summarized below. Prices have proven extremely volatile so any attempt to use simple inflation or depreciation indices is likely to produce results quite at variance with the actual costs faced by the airlines that lost the aircraft. Instead, an attempt has been made to set damage values at 80 percent of the midpoint of the 1979-80 range of used aircraft prices. The 80 percent adjustment is used to account for value received for salvage and damage (impact or fire) that would not have been prevented by seat blocking. Even with this formula, some of the aircraft of interest are missing price data from 1979, 1980 or both. After the source tables are shown, therefore, the method used to calculate a price figure for each aircraft type of interest is described.

\begin{tabular}{|c|c|c|c|}
\hline Alrcraft type & $\begin{array}{c}1970-75 \text { Values } \\
\text { (millions) } \\
\end{array}$ & $\begin{array}{l}1979 \text { Values } \\
\text { (millions) } \\
\end{array}$ & $\begin{array}{l}1980 \text { Values } \\
\text { (millions) } \\
\end{array}$ \\
\hline B7 $07-100 / 200$ & $\$ 0.742$ & -- & - \\
\hline B7 $07-100 B$ & $\$ 1.921$ & -- & -- \\
\hline B707-300 & $\$ 1.086$ & -- & -- \\
\hline B7 07-320B & $\$ 3.408$ & $\$ 4.2-6.0$ & $\$ 2.5$ \\
\hline B707-320C & $\$ 5.515$ & $\$ 7.5+$ & $\$ 3.0$ \\
\hline B747-100 & - & $\$ 28.0-30 \cdot 0$ & $\$ 25 \cdot 0-35 \cdot 0$ \\
\hline $\mathrm{B} 747-200 \mathrm{~B}, \mathrm{~F}, \mathrm{C}, \& \mathrm{SP}$ & - & $\$ 45.0+$ & $\$ 27.0-40 \cdot 0$ \\
\hline B747 (not further split) & $\$ 18.188$ & -- & -- \\
\hline$L-1011-1$ & -- & -- & $\$ 19.0$ \\
\hline$L-1011-100 / 200$ & -- & $\$ 22.5+$ & $\$ 25.0$ \\
\hline $\mathrm{DC} 10-10$ & -- & $\$ 21.5$ & $\$ 20.0$ \\
\hline $\mathrm{DC} 10-30 / 40$ & - & $\$ 38.0-43.0$ & $\$ 32.0$ \\
\hline
\end{tabular}


Incidents $\|_{1}$ and 5 from table C-1 are L-1011s, series not specified. It is assumed both are part of the $100 / 200$ series. Eighty percent of the 1979 and 1980 used aircraft prices is $\$ 18$ and $\$ 20$ million, respectively, so the midpoint is $\$ 19.0$ million. (Harris and Thorpe [69] cite much lower prices for used L-1011s - \$12 to \$15 million, probably reflecting the depressant effect of the 1982-83 recession.)

Incident $\# 2$ is a $B 727$, series not specified, but the loss figure provided indicates the damage, while severe, was far from total. Therefore, that loss figure is used.

Incidents $\$ 3$ and 4 are $B 707$ s, series not specified, but information on the Pakistani International fleet indicates its aircraft were from the 300 series so it was assumed both aircraft were from the 300 series. No 1979-80 data were available for 300 series aircraft, but data were available for the $320 \mathrm{~B}$ and $320 \mathrm{C}$ series. The $320 \mathrm{~B}$ series prices went down about $5 \%$ from $1970-76$ to the midpoint of $1979-80$, while the $320 \mathrm{C}$ series went up about $25 \%$. This suggests the 300 series prices should be estimated as rising about $15 \%$ to $\$ 1.25$ million. Eighty percent of that price is $\$ 1.0$ million.

Incident $\left.\right|_{6} 6$ is a $B 747$, series not specified. It is assumed the aircraft was from series 100 , and the midpoint of the 1979-80 price range is $\$ 30.0$ million. Eighty percent of that is $\$ 24.0$ million.

Incident $\#_{7}$ is a $\mathrm{DC} 10$, series not specified. It is assumed the aircraft was from series 10. Eighty percent of the midpoint of the 1979-80 price range, then, is $\$ 16.6$ million. (Donoghue [57] give a slightly lower price $\$ 18$ million - for used DCl0s, probably reflecting the depressant effect of the 1982-83 recession.)

Sources were:

1970-75 data: Avmark, Inc., Used Aircraft: Who They Came From - Where They Went, Miami, Florida, December 22, 1975.

1979 data: Bron Rek, Would you buy a second-hand jet?, Flight Internationa1, Vo1. 115, March 24, 1979.

1980 data: Bron Rek, "Airliner price guide", Flight International, Vol. 116, September 27, 1980. 



\section{Appendix D}

\section{Historical Passenger-Exposure Calculations}

Table D-1 shows historical passenger-miles on scheduled and non-scheduled passenger flights for U.S. and worldwide airlines. (As with accidents, "worldwide" excludes flights and aircraft of the U.S.S.R. and China.) Table D-2 shows adjustment factors to remove passenger flights in piston aircraft. Table D-3 shows factors to estimate the percentage of passenger airline activity in non-U.S. airlines using non-U.S.-built aircraft. And table D-4 shows the estimated totals of scheduled and non-scheduled passenger-miles in turbine aircraft for flights involving any world airlines, for flights involving U.S. airlines or U.S.-built aircraft or both, and for flights involving U.S. airlines only. 
Table D-1. Historical Passenger-Miles (in Billions) for Scheduled and Nonscheduled Passenger Flights

\begin{tabular}{|c|c|c|c|c|c|}
\hline Year & U.S. Airlines & World Airlines & Year & U.S. Airlines & World Airlines \\
\hline 1965 & 76 & 137 & 1974 & 188 & 409 \\
\hline 1966 & 93 & 172 & 1975 & 185 & 428 \\
\hline 1967 & 118 & 210 & 1976 & 203 & 466 \\
\hline 1968 & 139 & 245 & 1977 & 220 & 512 \\
\hline 1969 & 154 & 270 & 1978 & 252 & 580 \\
\hline 1970 & 160 & 288 & 1979 & 278 & 643 \\
\hline 1971 & 162 & 311 & 1980 & 267 & 645 \\
\hline 1972 & 177 & 355 & 1981 & 260 & 657 \\
\hline 1973 & 189 & 397 & 1982 & 268 & 678 \\
\hline
\end{tabular}

Sources: 1965, 1970-82: Boeing Company, Dimensions of Airline Growth, Seattle, WA, March, 1983.

1966-69, World: International Civil Aviation Organization, Annual Report to the Council, Montreal, Quebec, Canada, 1966-76. The formula used multiplies scheduledflight passenger miles times an adjustment factor for non-scheduled flights. That non-scheduledflight factor is itself calculated as a percentage adjustment factor for non-scheduled-flight tonmiles plus a further adjustment for the difference between passenger-mile and ton-mile adjustment factors. The difference ( 4.5 percentage points) is calculated from 1971-76 data, the only years for which ICAO estimated both percentages.

1966-69, U.S. Civil Aeronautics Board, Reports to Congress: Fiscal Year 1971, Washington, DC, 1971, Table 1. 
Table D-2. Estimated Percentage of Passenger-Miles on Piston Aircraft

$\underline{\text { Year }}$

1965

1966

1967

1968

1969

$1970-72$

1973-80

1981-82
Percentage

10

7

5

4

3

2

1

Sources: International Civil Aviation Organization, Annual Report to the Council, Montreal, Quebec, Canada, 1965-82

Air Transport Association of America, Air Transport Facts and Figures, Washington, DC, Vols. 27-30, 1966-69.

Note: Percentages of world air traffic by type of engine were estimated only through 1969 and only for ton-miles available on scheduled flights, not for passenger-miles performed on scheduled plus nonscheduled flights. Using these percentages and statistics on aircraft fleet size by engine type, a least-squares model was solved to provide estimated ton-miles available on scheduled flights per aircraft for 1965-69. These indices were then applied to 1970-82 data on fleet sizes to give 1970-82 estimates of the desired percentages of flight activity by engine type. Figures from the ATAA, covering U.S. passenger-miles in scheduled aircraft, either available $(1967)$ or performed $(1965,1966,1968)$, are almost identical with the world figures for that period, suggesting the same percentages can be used for both cases. 
Table D-3. Estimated Percentage of World-Airline, Turbine-Aircraft Traffic in Non-U.S. Airlines Using Non-U.S.-Bullt Aircraft

\begin{tabular}{|c|c|c|c|c|c|}
\hline Year & $\begin{array}{l}\text { Estimated } \\
\text { Percentage } \\
\text { for Jets } \\
\end{array}$ & $\begin{array}{l}\text { Percentage } \\
\text { of Activity } \\
\text { in Jets } \star \\
\end{array}$ & $\begin{array}{c}\text { Estimated } \\
\text { Percentage } \\
\text { for Turboprop } \\
\end{array}$ & $\begin{array}{c}\text { Percentage } \\
\text { of Activity } \\
\text { in Turboprop * } \\
\end{array}$ & $\begin{array}{c}\text { Combined } \\
\text { Percentage }\end{array}$ \\
\hline 1965 & 12 & 77 & 48 & 13 & 17 \\
\hline 1966 & 11 & 81 & 48 & 12 & 16 \\
\hline 1967 & 10 & 84 & 48 & 11 & 14 \\
\hline 1968 & 9 & 87 & 48 & 9 & 13 \\
\hline 1969 & 8 & 89 & 48 & 8 & 11 \\
\hline 1970 & 7 & 90 & 48 & 8 & 10 \\
\hline 1971 & 6 & 90 & 48 & 8 & 9 \\
\hline 1972 & 6 & 91 & 48 & 7 & 9 \\
\hline 1973 & 6 & 92 & 48 & 7 & 9 \\
\hline $1974-77$ & 6 & 93 & 48 & 6 & 9 \\
\hline $1978-80$ & 6 & 94 & 48 & 5 & 8 \\
\hline 1981 & 6 & 95 & 48 & 5 & 8 \\
\hline 1982 & 6 & 96 & 48 & 4 & $\cdots=8$ \\
\hline
\end{tabular}

* These percentages are based on total passenger aircraft activity, including piston aircraft, so the percentages may not add to 100 in the earlier years.

Sources: Benchmark percentages of seats available by aircraft engine type were developed for 1966, 1968, 1972, and 1980, using Air Transport World's annual listing of fleet inventories by airline and estimated seats per aircraft, based in part on International Civil Aviation Organization, Fleet and Personnel, Series FP, November 14, 1980. The actual percentages were smoothed to produce these estimates but do not differ by more than five percentage points in any of the years checked. (See table D-5 for assumptions on typical number of seats per aircraft.) 
Table D-4. Total Estimated Passenger-Miles (in Billions), Scheduled and Non-Scheduled, Jet and Turboprop On1y, 1965-1982

\begin{tabular}{|c|c|c|c|c|}
\hline Year & U.S. Airlines & Only & $\begin{array}{l}\text { U.S. Airlines or } \\
\text { U.S.-Built Aircraft }\end{array}$ & World Airlines \\
\hline 1965 & 68 & & 102 & 123 \\
\hline 1966 & 86 & & 134 & 160 \\
\hline 1967 & 112 & & 172 & 200 \\
\hline 1968 & 133 & & 205 & 235 \\
\hline 1969 & 149 & & 233 & 262 \\
\hline 1970 & 157 & & 254 & 282 \\
\hline 1971 & 159 & & 277 & 305 \\
\hline 1972 & 173 & & 317 & 348 \\
\hline 1973 & 187 & & 358 & 393 \\
\hline 1974 & 186 & & 368 & 405 \\
\hline 1975 & 183 & & 386 & 424 \\
\hline 1976 & 201 & & 420 & 461 \\
\hline 1977 & 218 & & 461 & 507 \\
\hline 1978 & 249 & & 528 & 574 \\
\hline 1979 & 275 & & 586 & 637 \\
\hline 1980 & 264 & & 587 & 639 \\
\hline 1981. & 260 & & 604 & 657 \\
\hline \multirow[t]{2}{*}{1982} & 268 & & 624 & 678 \\
\hline & 3,328 & & 6,616 & 7,290 \\
\hline per Year & 185 & & 368 & 405 \\
\hline ure as & & & & \\
\hline $\begin{array}{l}\text { ge of } \\
\text { per Year }\end{array}$ & 145 & & 170 & 167 \\
\hline
\end{tabular}


Table D-5. Assumed Typical Number of Seats Carried on Passenger Flights, by Alrcraft Type

\section{Number of Seats}

20

40

50

65

90

100

110

125

130

200

250

340

\section{Aircraft Types}

DHC-6, EMB 110, Nord 262, Skyvan

F27, FH227, HS748, Mystere, al1 turboprops not explicitly shown on this list

CV580, CV600, CV640

F28, Viscount, YS11

BAC 111, Caravelle, DC9, L-188, all jets not explicitly shown on this list

Concorde, CV880, CV990

B737, Comet 4

B7 27

$\mathrm{B} 707, \mathrm{~B} 720, \mathrm{VClO}$

DC8

Airbus $\mathrm{A}-300, \mathrm{DC} 10, \mathrm{~L}-1011$

B747

Source: Estimates based primarily on range of figures on reported seats flown, by aircraft type, in International Civil Aviation Organization, Fleet and Personnel, Series FP, Montreal, Quebec, Canada, November 14, 1980. 
Forecasts Used in the Cost Models

Table E-l lists the aircraft models covered by each of the nine generic classes used in the Cost Models. Table E-2 lists the 1982-1997 passenger-mile and available seat-mile projections used in the analysis, for world and U.S. airlines. Tables E-3 and E-4 list the statistics, by model class and U.S. versus world airlines, that were used with the formulas presented in section 2.4. Specifically, the variable in the cost formulas that corresponds to the aircraft inventory operating at the initiation of 1984 , is given by the Original Fleet Size figure. The first row gives the aircraft removed from service each year. The second row gives the aircraft added each year; it combines figures on aircraft already ordered or optioned, used aircraft scheduled to be reintroduced, and other aircraft needed to meet projected demand. The third row of the table gives the available miles projected per aircraft for that model class in each year. The fourth row gives the seats per aircraft.

The operating cost formulas presented in section 2.4 .3 require year-byyear forecasts of marginal fuel consumption rates. These will change over time with the gradual introduction of more efficient aircraft. These forecasts were developed and tested so as to incorporate relationships valid for minor weight increments of the order of 0.5 percent of total landing weight or less. Alternatives involving weight penalties outside this range would require additional fuel burn analyses and possibly more complicated marginal fuel consumption formulas.

Figure $E-1$ is a plot from Hamilton's study of the weighted averages of marginal fuel consumption (pounds of fuel per pound of added weight per distance flown) at five-year increments from 1985 to 2000. This relationship was used in table E-5 to estimate appropriate annual values for the study period from 1984 to 1997.

Table E-5 provides fuel cost factors needed to calculate the effect of weight penalties on operating costs. These figures can be combined, for each aircraft model type, with figures on millions of aircraft-miles flown (based on miles flown per aircraft and aircraft flying, both given or inferable from tables E-3 and E-4) and added pounds per aircraft (based on an assessment specific to the alternative being analyzed). The resulting products can then be summed to give the changes in operating costs. 
Table E-1. Passenger Aircraft by Generic Class

Short-Range 110

BA-1 $146-200$
BAC- $111-200$
BAC- $111-300$
BAC- $111-400$
BAC- $111-475$
BAC- $111-500$
B7 $27-100$
B727-100C
B7 27-100QC
B7 37-100
B737-200
B7 37-200C
B7 $37-200 Q C$

\section{B7 37-300}

Caravelle 10B

Caravelle IOR

Caravelle $11 R$

Caravelle 12B

Caravelle 3

Caravelle $6 \mathrm{~N}$

Caravelle 6R

DC-9-10

DC-9-1 OMC

DC-9-1 ORC

DC-9-20

DC-9-30

DC-9-30CF
Short-Range 160

DC-9-30RC
$D C-9-40$
DC-9-50
$F-28-1000$
$F-28-2000$
F-28-3000
F-28-4000
F-28-6000
Trident $1 C$
Trident $1 E$
Trident $2 E$
TU-104
TU-134

B727 200

Super 80

Mercure

Trident 3B

Medium-Range 200

\begin{tabular}{lll}
\hline & & \\
A-310-100 & B7 20 & DC-8-30 \\
A-310-200 & B7 20B & DC-8-40 \\
B707-120 & B757-200 & DC-8-50 \\
B707-120B & B767-200 & DC-8-50CF \\
B707-138B & Comet 4 & DC-8-62 \\
B707-220 & Comet 4B & DC-8-62CF \\
B707-320 & Comet 4C & IL-62 \\
B707-320B & Concorde & Super VC-10 \\
B707-320C & CV-880 & TU-154 \\
B707-420 & CV-990A & VC-10 \\
& DC-8-20 &
\end{tabular}

Medium-Range 270

\begin{tabular}{lll}
\hline & & \\
$A-300 B-1$ & $D C-10-10$ & $D C-8-63 P F$ \\
$A-300 B-2$ & $D C-10-10 C F$ & DC-8-71 \\
$A-300 B-2 K$ & $D C-10-15$ & DC-8-71CF \\
$A-300 B-4$ & DC-10-30CF & DC-8-73 \\
A-300B-600 & DC-10-30 & DC-8-73CF \\
A-300C-4 & DC-10-40 & L-1011-1 \\
B747-SP & DC-8-61 & L- $1011-100$ \\
B747-200CSCD & DC-8-61CF & L-1011-200 \\
B747-200SCD & DC-8-63 & L- $1011-500$ \\
& DC-8-63CF &
\end{tabular}

\begin{tabular}{lll}
\multicolumn{3}{c}{ Long-Range 270} \\
\hline A-300B-600 & DC-10-30 & DC-8-63PF \\
B747-SP & DC-10-30CF & DC-8-73 \\
B747-200CSCD & DC-10-30ER & DC-8-73CF \\
B747-200F SCD & DC-10-40 & IL-86 \\
B747-200SCD & DC-8-63 & L-1011-500 \\
& DC-8-63CF & \\
& & \\
& &
\end{tabular}

Med1um-Range 400

B7 $47-100$

B747-100RF

B747-100SR

B747-200C

B7 47-200

Medium-Range 600

B7 47-300

B747-300C

\section{Long-Range 400}

$$
\begin{aligned}
& \text { B7 } 47-100 \\
& \text { B747-100RF } \\
& \text { B747-200 } \\
& \text { B747-200C } \\
& \text { B747-200R }
\end{aligned}
$$

\section{Long-Range 600}

B747-300

B747-300C

Source: Douglas Alrcraft Company, 1983-1997 Outlook for Commerc1al Alrcraft, Long Beach, California, July 1983 
Table E-2. Historical and Projected Passenger-Miles and Available Seat-Miles, 1982-1997

U.S. Airlines only

$\begin{array}{cc}\begin{array}{c}\text { Passenger- } \\ \text { Miles }\end{array} & \begin{array}{c}\text { Available } \\ \text { Seat-Miles }\end{array} \\ 267.8 & 448.5 \\ 285.1 & 470.1 \\ 301.3 & 488.9 \\ 320.2 & 507.1 \\ 335.8 & 525.8 \\ 355.3 & 550.8 \\ 373.7 & 575.8 \\ 387.7 & 594.4 \\ 402.5 & 613.7 \\ 419.9 & 635.6 \\ 436.4 & 658.4 \\ 453.7 & 681.0 \\ 471.9 & 704.7 \\ 491.1 & 730.8 \\ 511.3 & 757.9 \\ 533.0 & 786.2\end{array}$

World Airlines

$\begin{array}{cc}\begin{array}{c}\text { Passenger- } \\ \text { Miles }\end{array} & \begin{array}{c}\text { Available } \\ \text { Seat-Miles }\end{array} \\ 657.9 & 1,066.5 \\ 687.7 & 1,104.5 \\ 730.9 & 1,162.1 \\ 777.2 & 1,218.5 \\ 819.6 & 1,275.2 \\ 871.3 & 1,343.4 \\ 923.8 & 1,414.2 \\ 971.7 & 1,483.0 \\ 1,022.4 & 1,549.7 \\ 1,079.7 & 1,627.4 \\ 1,138.7 & 1,714.0 \\ 1,201.6 & 1,803.0 \\ 1,268.5 & 1,899.8 \\ 1,339.8 & 2,003.5 \\ 1,415.8 & 2,114.4 \\ 1,497.2 & 2,232.1\end{array}$

Source: Adapted from figures appearing in Douglas Aircraft Company, 1983-1997 Outlook for Commercial Aircraft, Long Beach, California, July 1983.

Note: All figures are in billions. 


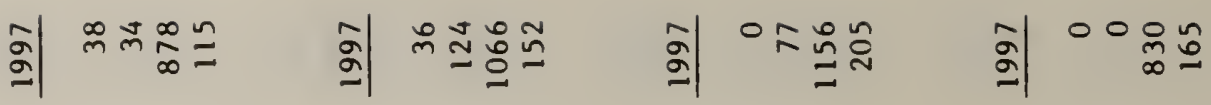

: ํำ

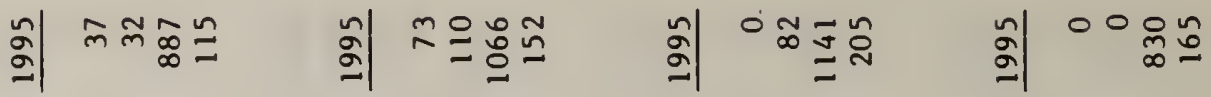

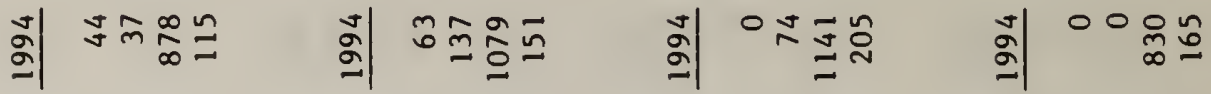

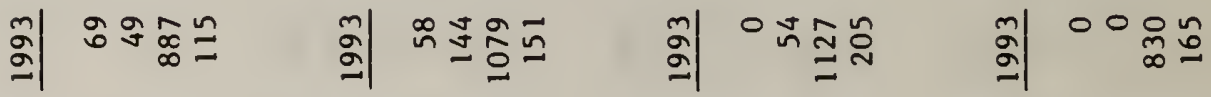

亲

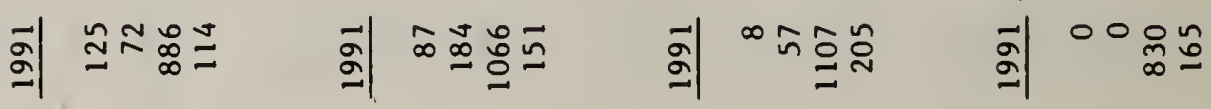

일 웅

인

品

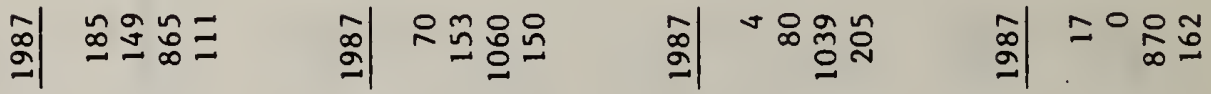

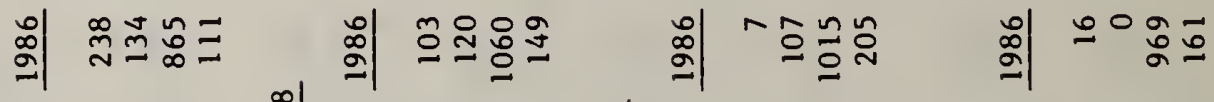

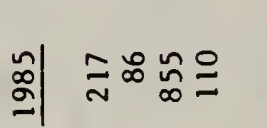

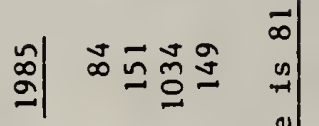

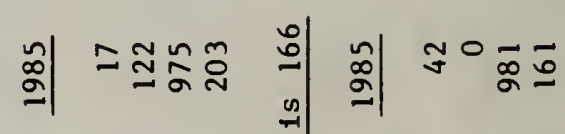

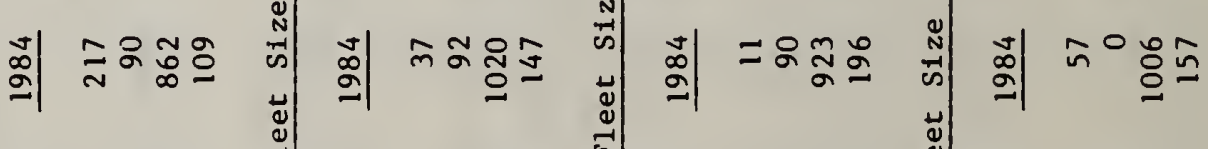

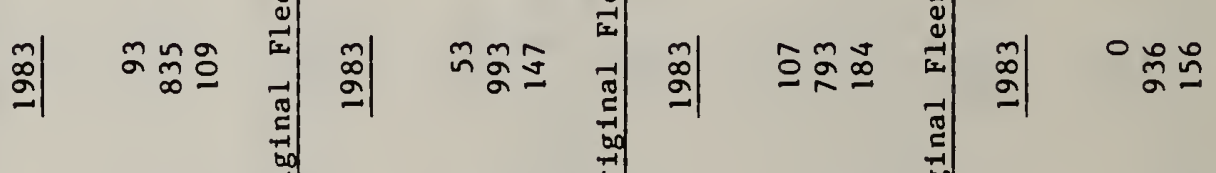
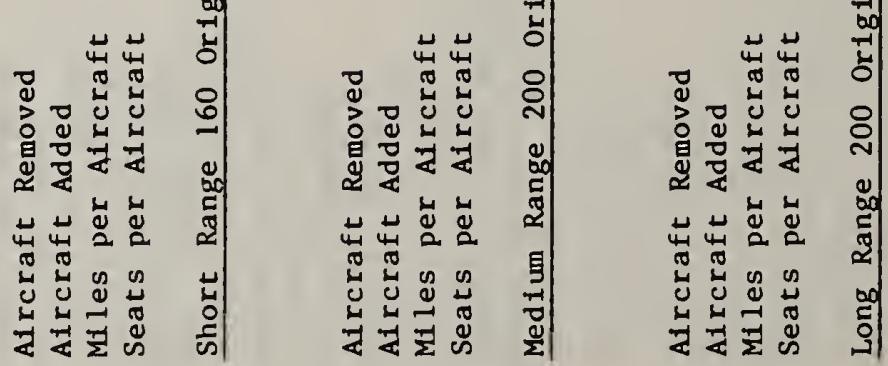

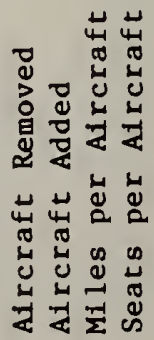




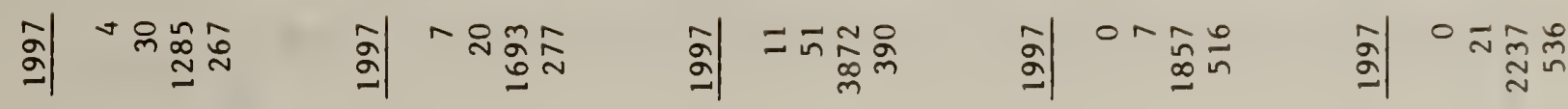

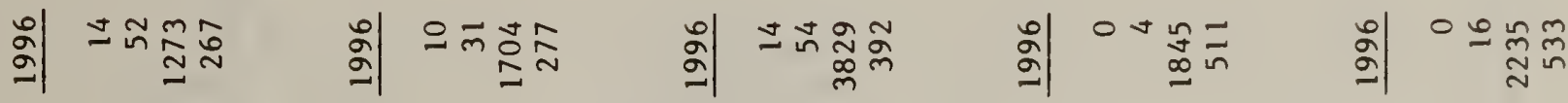

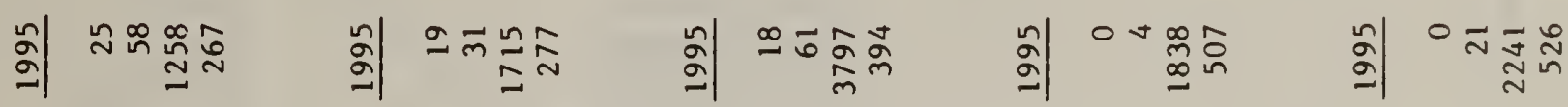

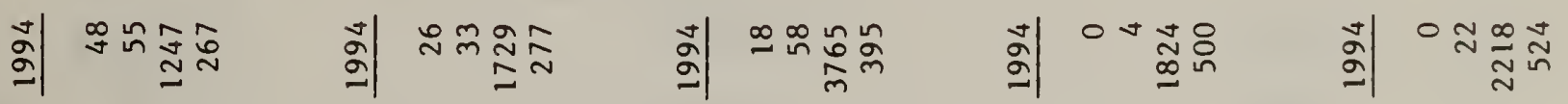

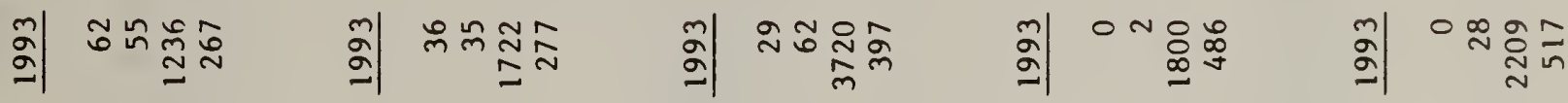

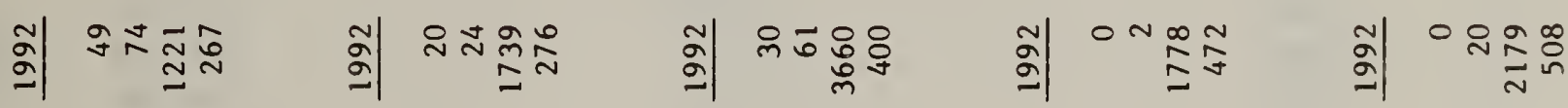

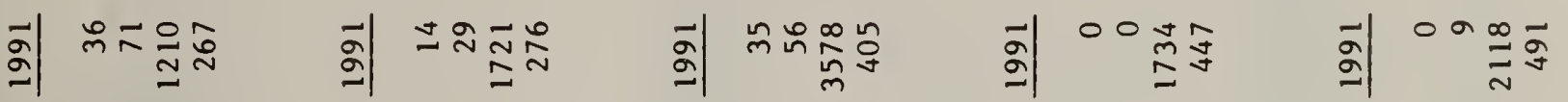

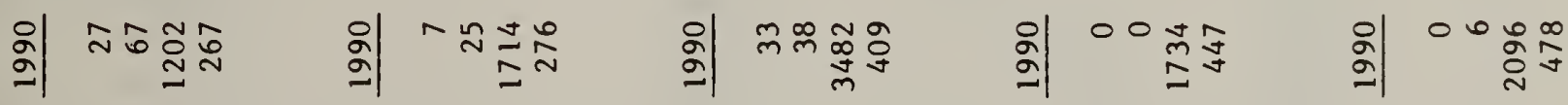

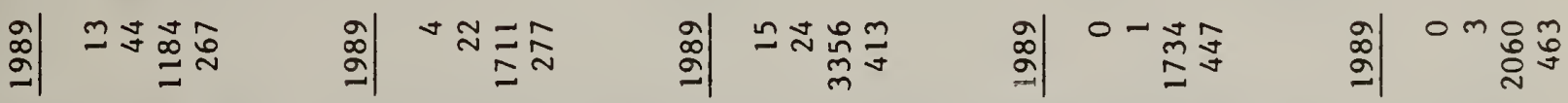

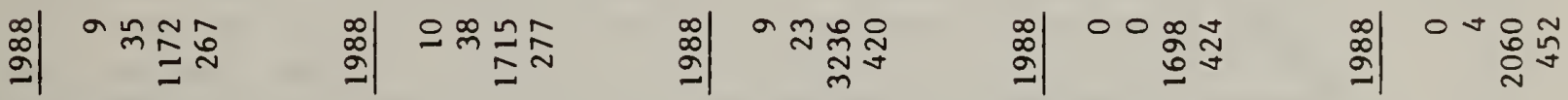

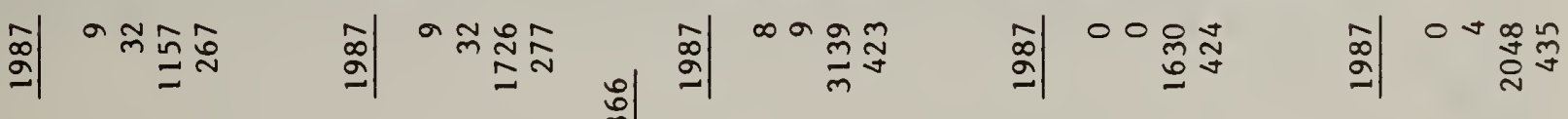

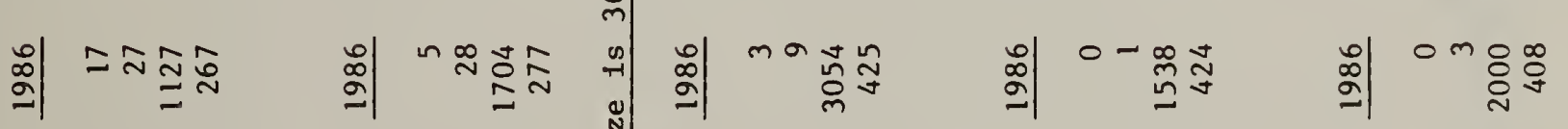

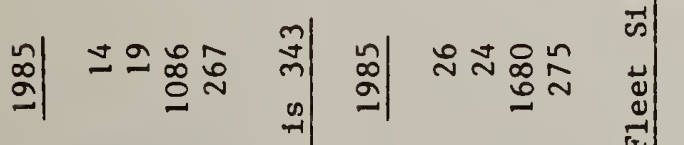

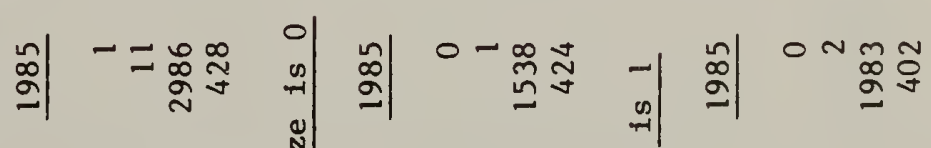

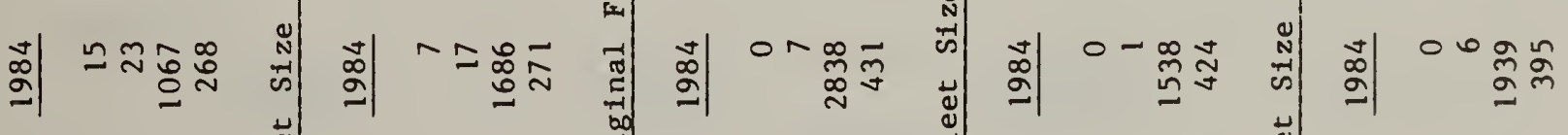

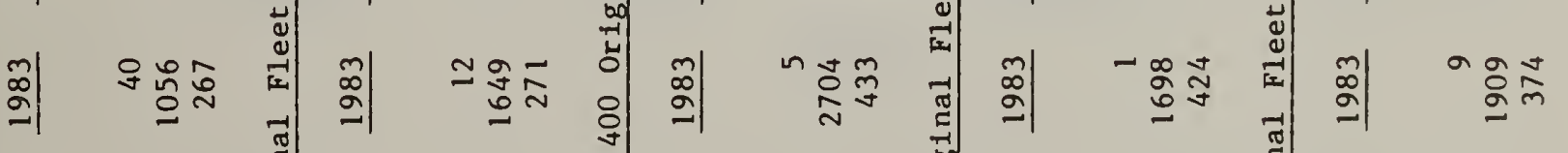

告


Table E-5. Fuel Cost Factors Related to Weight Penalties

$\begin{array}{lll} & \begin{array}{l}\text { Gallons of } \\ \text { Fuel per } \\ \text { Added Pounds } \\ \text { per Aircraft, } \\ \text { per Million } \\ \text { Aircraft-Miles } \\ \text { Flown }\end{array} & \begin{array}{l}\text { Fue } \\ \text { Price } \\ \text { per }\end{array} \\ \text { Year } & \text { Gallon } \\ 1984 & 12.92 & \text { in } 1983 \\ 1985 & 12.79 & \text { Dollars } \\ 1986 & 12.66 & \$ 0.915 \\ 1987 & 12.53 & \$ 0.929 \\ 1988 & 12.40 & \$ 0.960 \\ 1989 & 12.27 & \$ 0.979 \\ 1990 & 12.15 & \$ 0.990 \\ 1991 & 12.02 & \$ 0.974 \\ 1992 & 11.85 & \$ 0.982 \\ 1993 & 11.71 & \$ 0.992 \\ 1994 & 11.56 & \$ 1.014 \\ 1995 & 11.44 & \$ 1.020 \\ 1996 & 11.31 & \$ 1.037 \\ 1997 & 11.18 & \$ 1.056 \\ & & \$ 1.055 \\ & & \end{array}$

Sources: The second-column figures are based on figure E-1, with nautical miles converted to statute miles and pounds of fuel converted to gallons of fuel. The fuel price is a product of two indexes from Wharton Econometrics projections $[120,121]$, applied to a 1983 fuel price per gallon of $\$ 0.913$, based on Civil Aeronautic Board Form 41 . 


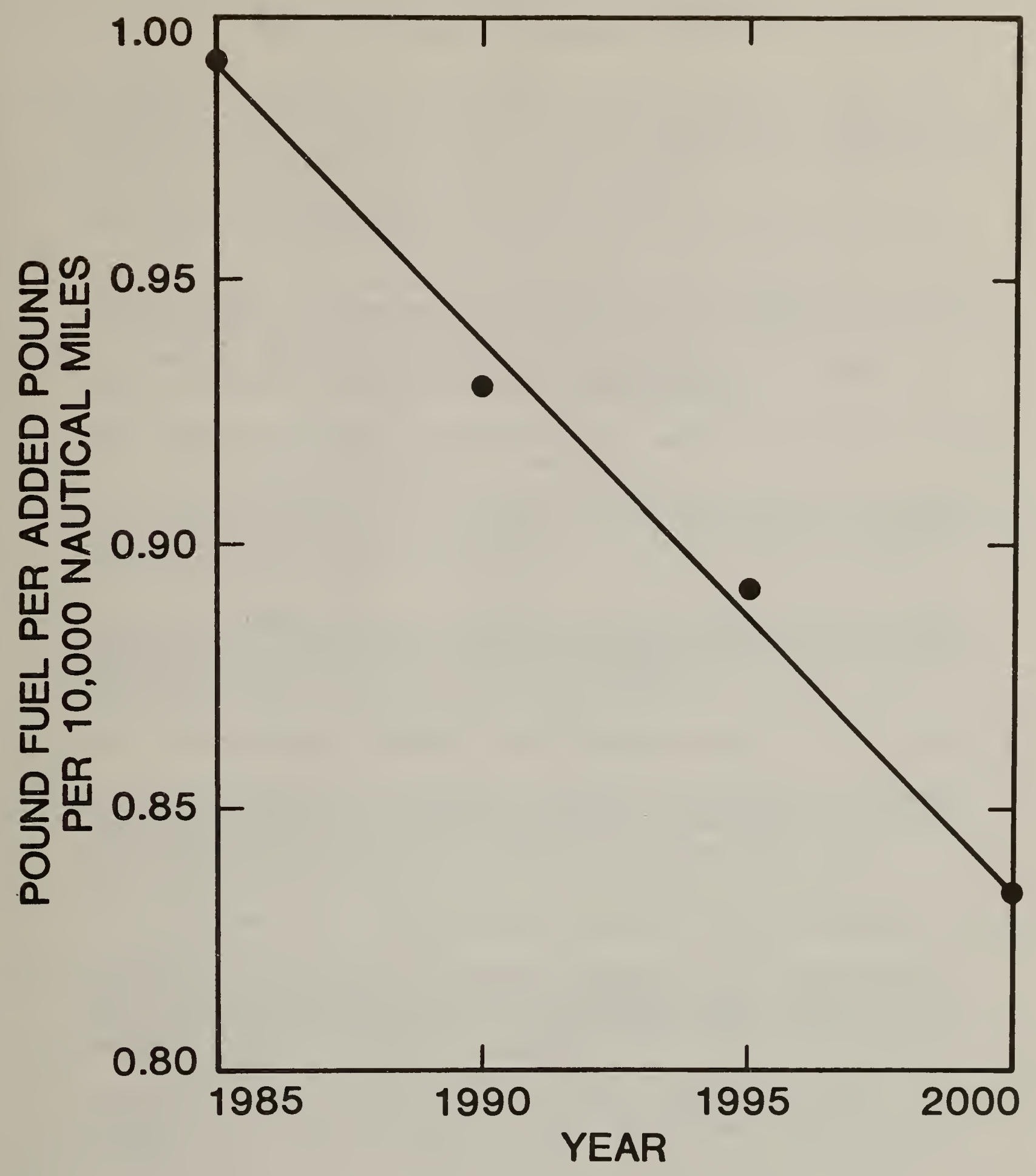

Figure E-1. Sensitivity of Incremental Fuel Consumption to Increased Weight, 1985-2000 

Annotated Listing of Literature Reviewed

[1] Acumenics, Assessment of the Impact of an ICAO Annex 16, Chapter II, Non-Addition Rule, Study Report to the Federal Aviation Administration, July 2, 1981, 220 pages.

Source of the Global Aviation Forecast (GAF) Model, used to project fuel costs for future years.

[2] Aerospace Industries Association of America, Inc., Aerospace Facts and Figures 1982/83, Washington, DC, August 1982, 168 pages.

[3] Air Registry Board, World Airline Accident Summary, Cheltenham, England, 1965-1982 examined, about 25 pages per year.

Most inclusive accident listing available. Each accident receives from one line to several paragraphs of description.

[4] Air Transport Association of America, Air Transport Facts and Figures, Washington, DC, Volumes 27-30 published in 1966-69 were examined, approximately 50 pages per volume.

[5] Aircraft Accident Report: Air Manila, Incorporated, Lockheed L-188A, Republic of the Philippines Registry RP-C1061, Guam, Marianas Islands, June 4, 1976, NTSB-AAR-77-6, National Transportation Safety Board, Washington, DC, September 26, 1977, 25 pages.

Also corresponding unpublished report from Human Factors Division of NTSB.

[6] Aircraft Accident Report: Alaska Airlines, Inc., Boeing 727, N2969G, Near Juneau, Alaska, September 4, 1971, Report Nos. NTSB-AAR-72-28 and SA-429, National Transportation Safety Board, Washington, DC, October 13, 1972, 86 pages.

Also corresponding unpublished report from Human Factors Division of NTSB.

[7] Aircraft Accident Report: Allegheny Airlines, Inc., Allison Prop Jet Convair 340/440, N5832, New Haven, Connecticut, June 7, 1971, Report Nos. SA-427 and NTSB-AAR-72-20, National Transporation Safety Board, Washington, DC, June 1, 1972, 68 pages.

According to other sources, this was really a CV560 turboprop. Also examined corresponding unpublished report from Human Factors Division of NTSB.

[8] Aircraft Accident Report: American Airlines, Inc., Boeing 727, N1996, Near the Greater Cincinnati Airport, Constance, Kentucky, November 8, 1965 , SA-387, Civil Aeronautics Board, Washington, DC, October 7, 1966, 27 pages plus attachment. 
[9] Aircraft Accident Report: American Airlines, Inc., Boeing 727-95, N1963, St. Thomas, Virgin Islands, April 27, 1976, Report No. NTSB-AAR-77-1, National Transportation Safety Board, Washington, DC, December 16, 1976, 69 pages.

Also corresponding unpublished report from Human Factors Division of NTSB.

[10] Aircraft Accident Report: American Airlines, Inc., DC-10-10, N110AA, Chicago-0'Hare International Airport, Chicago, Illino1s, May 25, 1979, Report No. NTSB-AAR-79-17, National Transportation Safety Board, Washington, DC, December $21,1979,104$ pages.

Also corresponding unpublished report from Human Factors Division of NTSB.

[11] Aircraft Accident Report: American Flyers Airline Corporation, L-188C, N183H, Near Ardmore Municipal Airport, Ardmore, Oklahoma, April 22, 1966 , Report No. SA-392, Civil Aeronautics Board, Washington, DC, Apri1 4, 1967, 23 pages plus attachments.

Also corresponding unpublished report from Human Factors Division of NTSB.

[12] Aircraft Accident Report: Capitol International Airways, Inc. DC-8-63F, N4909C, Anchorage, Alaska, November 27, 1970, Report No. NTSB-AAR-72-12, National Transportation Safety Board, Washington, DC, March 29, 1972, 47 pages.

Also corresponding unpublished report from Human Factors Division of NTSB.

[13] Aircraft Accident Report: Continental Airlines, Inc., McDonnell Douglas DC-10-10, N68045, Los Angeles, California, March 1, 1978, Report No. NTSB-AAR-79-1, National Transportation Safety Board, Washington, DC, January $25,1979,51$ pages.

Also corresponding unpublished report from Human Factors Division of NTSB.

[14] Aircraft Accident Report: Delta Airlines, Inc., Douglas DC-9-31, N975NE, Boston, Massachusetts, July 31, 1973, Report Nos. SA-439 and NTSB-AAR-74-3, National Transportation Safety Board, Washington, DC, March 7, 1974, 80 pages.

Also corresponding unpublished report from Human Factors Division of NTSB.

[15] Aircraft Accident Report: Eastern Airlines, Inc., Boeing 727-225, N8845E, John F. Kennedy International Airport, Jamaica, New York, June 24, 1975, Report No. NTSB-AAR-76-8, National Transportation Safety Board, Washington, DC, March 12, 1976, 59 pages.

Also corresponding unpublished report from Human Factors Division of NTSB. 
[16] Aircraft Accident Report: Eastern Airlines, Inc., Douglas DC-9-31, N8984E, Charlotte, North Carolina, September 11, 1974, Report No. NTSB-AAR-75-9, National Transportation Safety Board, Washington, DC, May 23, 1975, 40 pages.

Also corresponding unpublished report from Human Factors Division of NTSB.

[17] Aircraft Accident Report: Eastern Airlines, Inc., L-1011, N310EA, Miami, Florida, December 29, 1972, Report No. NTSB-AAR-73-14, National

Transportation Safety Board, Washington, DC, June 14, 1973, 51 pages.

Also corresponding unpublished report from Human Factors Division of NTSB.

[18] Aircraft Accident Report: Mohawk Airlines, Inc., BACl-11, N1116J, Near Blossburg, Pennsylvania, June 23, 1967, National Transportation Safety Board, Washington, DC, 1967, 65 pages.

Also corresponding unpublished report from Human Factors Division of NTSB.

[19] Aircraft Accident Report: North Central Airlines, Inc., Convair 580, N2045, O'Hare International Airport, Chicago, Illinois, December 27, 1968 , Report Nos. SA-409 and NTSB-AAR-70-27, National Transportation Safety Board, Washington, DC, November 12, 1970, 54 pages.

Also corresponding unpublished report from Human Factors Division of NTSB.

[20] Aircraft Accident Report: North Central Airlines, Inc., McDonnell Douglas DC-9-31, N954N and Delta Airlines, Inc., Convair CV-880, N8807E, O'Hare International Airport, Chicago, Illinois, Decemier 20, 1972, Report No. NTSB-AAR-73-15, National Transportation Safety Board, Washington, DC, July 5, 1973, 44 pages.

Also corresponding unpublished report from Human Factors Division of NTSB.

[21] Aircraft Accident Report: Northeast Airlines, Inc., Fairchild Hiller FH-227C, N380NE, Near Hanover, New Hampshire, October 25, 1968, Report No. SA-408, National Transportation Safety Board, Washington, DC, April 1, 1970, 63 pages.

Also corresponding unpublished report from Human Factors Division of NTSB.

[22] Aircraft Accident Report: Pan American World Airways, Inc., Boeing 707-321B, N454PA, Pago Pago, American Samoa, January 30, 1974, Report No. NTSB-AAR-74-15, National Transportation Safety Board, Washington, DC, November $8,1974,32$ pages.

Also corresponding unpublished report from Human Factors Division of NTSB.

[23] Aircraft Accident Report: Saudi Arabian Airlines, Lockheed L-1011, HZ-AHK, Riyadh, Saudi Arabia, August 19, 1980, Presidency of Civil Aviation, Jeddah, Saudi Arabia, January 16, 1982, 188 pages. 
[24] Aircraft Accident Report: Trans Caribbean Airways, Inc., Boeing 727-200, N8790R, Harry S. Truman Alrport, Charlotte Amalie, St. Thomas, Virgin Islands, December 28, 1970 , Report No. NTSB-AAR-72-8, National

Transportation Safety Board, Washington, DC, December 29, 1971, 56 pages.

Also corresponding unpublished report from Human Factors Division of NTSB.

[25] Aircraft Accident Report: Trans World Airlines, Inc., B707, N742TW, The Greater Cincinnati Airport, Erlanger, Kentucky, November 6, 1967, Report No. SA-401, National Transportation Safety Board, Washington, DC, September $11,1968,56$ pages.

Also corresponding unpublished report from Human Factors Division of NTSB.

[26] Aircraft Accident Report: Trans World Airlines, Inc., Convair 880, N821 TW, Constance, Kentucky, November 20, 1967, Report No. SA-402, National Transportation Safety Board, Washington, DC, August 27, 1969, 58 pages.

Also corresponding unpublished report from Human Factors Division of NTSB.

[27] Aircraft Accident Report: United Airlines, Inc., Boeing 727, N7030U, Salt Lake City, Utah, November 11, 1965, Report No. SA-388, Civil Aeronautics Board, Washington, DC, June $7,1966,15$ pages plus attachments.

Also corresponding unpublished report from Human Factors Division of NTSB.

[28] Aircraft Accident Report: United Airlines, Inc., Boeing 737, N9031U, Chicago-Midway Airport, Chicago, Illinols, December 8, 1972, Report No. NTSB-AAR-73-16, National Transportation Safety Board, Washington, DC, August 29, 1973, 67 pages.

Also corresponding unpublished report from Human Factors Division of NTSB.

[29] Aircraft Fire Safety, AGARD Conference Proceedings, AGARD-CP-166, Advisory Group for Aerospace Research and Development, North Atlantic Treaty Organization, Neuilly sur Seine, France, October 1975, 28 papers.

Includes paper by A.F. Taylor with estimates of accidents involving fatalities attributable to fire. Also includes paper by W.D. Weatherford, $\mathrm{Jr}$. and B.R. Wright on research and antimist engine fuels.

[30] Aircraft manufacturers warned of hazard from burning plastic, Aviation Daily, Vol. 205, No. 17, January 24, 1973, p. 134.

Quotes Cook County coroner as saying cyanide levels were lethal in three victims of December 20, 1972 accident in Chicago and seven victims of December 8, 1972 accident in Chicago.

[31] Aircraft Operating Cost and Performance Report, Vol. XIV, Civil Aeronautics Board, Washington, DC, July 1980, 130 pages. 
[32] Airport Crash/Fire/Rescue (CFR) Service Cost and Benefit Analysis, NASA-LS-39422, Vo1. 1, U.S. Department of Transportation, Washington, DC, October 1978,142 pages.

[33] Alia (The Royal Jordanian Airlines), Dart Herald, JY-ACQ, accident on Kanisa Mountain, Syrian Arab Republic, on April 10, 1965, Report (undated) released by the Directorate of Aviation Safety, Directorate General of Civil Aviation, Ministry of Defence, Syrian Arab Republic, Airline Accident Digest, Circular 88-AN/74, No. 17, Vol. 1, International Civil Aviation Organization, Montreal, Quebec, Canada, 1968, pp. 72-76.

[34] R.L. Alpert, M.K. Mathews and A.T. Modak, Modeling of Ceiling Fire Spread and Thermal Radiation, Report No. DOT/FAA/CT-81/70, Final Report, U.S. Department of Transportation, Washington, DC, October 1981, 105 pages.

[35] Avmark, Inc., Transport Aircraft Values, 1970-1984, Miami, FL, 1976, 142 pages.

Forecasts of used aircraft prices. This report was not available to be examined but includes a formula for prices. Note that actual prices have been extremely volatile, year-to-year, since the mid-1970's.

[36] Avmark, Inc., Used Aircraft: Who They Came From - Where They Went, Miami, FL, December 22, 1975, 52 pages.

Source of information on used aircraft prices for 1970-75, overall and by year, by selling airline and by receiving airline, for U.S. airlines.

[37] Bimonthly fire record, Fire Journal, Vo1. 68, Ncrember 1974, pp. 63 ff.

[38] Bimonthly fire record, Fire Journal, Vol. 74, March 1980, pp. 17 ff.

[39] H.C. Black, Jet airplanes - a summary of accident experience with particular reference to crash fires, Paper given to Conference on Transport Category Airplane Post-Crash Fuel Systems Fire and Explosion Hazard Reduction, Washington, DC, June 13-17, 1977.

Cited in personal communication by Wayne Smoot, Federal Aviation Administration, as a source of information on fatal accidents with post-impact fires. It has not been examined in this project. According to Smoot's listing of incidents, Black's report does not add incidents or information on incidents beyond what was available in the references examined in this report.

[40] Boeing Company, Current Market Outlook, Boeing Company, Seattle, WA, March 1983, 30 pages.

[41] Boeing Company, Dimensions of Airline Growth, Boeing Company, Seattle, WA, March 1983, 76 pages.

Historical and forecast statistics on aircraft usage for jet aircraft models. 
[42] Boeing Commercial Airplane Company, World Jet Alrplane Inventory at Year-End 1982, Boeing Company, Seattle, WA, 1983, 76 pages.

Particularly of interest for the tables showing year-end jet airplane inventories for U.S. versus non-U.S. owners and operators for every year from 1960 to 1982 .

[43] British European Alrways, Vanguard, G-APEE, accident at London (Heathrow) on 27 October 1965, Report (undated) released by the Board of Trade, United Kingdom, C.A.P. 270, Airline Accident Digest, Circular 88-AN/74, No. 17, Vol. III, International Civil Aviation Organization, Montreal, Quebec, Canada, 1969, pp. 77-82.

[44] British Overseas Airways Corporation, Boeing 707-465, G-ARWE, accident at Heathrow Airport, London, England, on 8 April 1968, Report No. EW/C/0203 (dated April 1969) released by the Board of Trade, United Kingdom as C.A.P. 324, Airline Accident Digest, circular 96-AN/79, No. 18, Vol. II, International Civil Aviation Organization, Montreal, Quebec, Canada, 1971, pp. 79-120.

[45] Louis J. Brown, Jr., Cabin Hazards From a Large External Fuel Fire Adjacent to an Aircraft Fuselage, Final Report No. FAA-RD-79-65, Federal Aviation Administration, Washington, DC, August 1979, 50 pages.

[46] Louis J. Brown, Jr. and Richard M. Johnson, Correlation of LaboratoryScale Fire Test Methods for Seat Blocking Layer Materials with LargeScale Test Results, Final Report DOT/FAA/CT-83/29, Federal Aviation Administration, Atlantic City, NJ, June 1983, 65 pages.

[47] Canadian Pacific Airlines Ltd., Douglas DC-8, CF-CPK, accident at Tokyo International Airport, Tokyo, Japan, on 4 March 1966, Report released by the Civil Aviation Bureau, Ministry of Transport, Japan on 4 March 1968, Airline Accident Digest, Circular 96-AN/79, No. 18, Vol. I, International Civil Aviation Organization, Montreal, Quebec, Canada, 1970, pp. 37-50.

[48] Civil Aeronautics Board, Reports to Congress: Fiscal Year 1971, Washington, DC, 1971,128 pages.

[49] Civil Air Transport, Boeing 727-92C, B-1018, accident at Linkuo, near Taipei, Taiwan, on 16 February 1968, Report (not dated) released by the Civil Aeronautics Administration, Republic of China, Airline Accident Digest, Circular 96-AN/79, No. 18, Vol. II, International Civil Aviation Organization, Montreal, Quebec, Canada, pp. 56-62.

[50] Collision Aeronaves - Boeing 747 PH-BUF de KLM y Boeing N737PA de Pan Am en los rodeos (Tenerife) el 27 Marzo de 1977, Joint Accident Report by KLM and Pan American Alrways, 12.7.1978.

Description of the two-aircraft accident and fire at the Canary Islands on March 27, 1977. 
[51] A. Cominsky et al, Study of Aircraft Crashworthiness for Fire Protection, NASA CR-166159, prepared by McDonnell Douglas Corporation for the National Aeronautics and Space Administration, Long Beach, CA, January 1981,121 pages.

A brief overview of crash scenarios and crash fire safety concepts is joined to the most thorough listing and description of post-crash fires to this date. This report covers incidents from 1961 through mid-1978 and has the most credible estimates available in overview reports of the split between fire and crash-trauma fatalities.

[52] Coordinating Research Council, Aviation Fuel Safety - 1975, Report No. 482, Atlanta, GA, November 1975, 129 pages.

Includes numerous analyses of survivability with worldwide data base, but information on individual incidents generally is limited to one line each.

[53] Crash Survival Design Guide, USAAMRDL Technical Report 71-22, U.S. Army, Fort Eustis, VA, October 1971,373 pages.

[54] M.A. Delichatsios, et al, Computer Modeling of Aircraft Cabin Fire Phenomena, First Year Report, Factory Mutual Research, Norwood, MA, no date, 68 pages.

[55] James Demaree, Examination of Aircraft Interior Emergency Lighting in a Postcrash Fire Environment, Final Report DOT/FAA/CT-82/55, Federal Aviation Administration, Atlantic City, NJ, June 1982, 50 pages.

[56] Development of an Algorithm and Data Gathering for Aircraft Seats, Unpublished Final Report to National Aeronautics and Space Administration, Econ, Inc., San Jose, CA, August 31, 1981, pages not numbered.

[57] J.A. Donoghue, Airframers enter a new arena, buying and selling used airplanes, Air Transport World, Vol. 20, No. 7, July 1983, pp. 25-28.

Discussion includes reference to the average price of used DC-10s as $\$ 18$ million.

[58] Douglas Aircraft Company, 1983-1997 Outlook for Commercial Aircraft, Long Beach, CA, July 1983, 61 pages.

[59] Won Dukko and Kumar Ramohalli, Application of Thermochemical Modeling to Aircraft Interior Polymeric Materials, Final Report DOT/FAA/CT-82/83, Federal Aviation Administration, Atlantic City, NJ, June 1982, 64 pages.

[60] Carolyn Edwards, An Analysis of Aviation Safety Information, U.S. Department of Transportation, Washington, DC, 1975, 41 pages.

Analyses limited to U.S. aircraft and airlines, no information on individual accidents. 
[61] Thor I. Eklund and Joseph A. Wright, Fuel Fire Hazard Penetration into a Model Fuselage as a Function of Circumferential Door Location and Fuel Bed Heights, NAFEC Report No. FAA-NA-80-9, Federal Aviation Administration, Atlantic City, NJ, May 1980, 38 pages.

[62] Howard W. Emmons, The Ingestion of Flames and Fire Gases into a Hole in an Aircraft Cabin for Small Tilt Angles and Low Wind Speeds, Home Fire Project Technical Report No. 49, Harvard University, Cambridge, MA, October 1981 , 19 pages.

[63] J.H. Enders and E.C. Wood, Final Report of the Special Aviation Fire and Explosion Reduction Advisory Committee, prepared by the SAFER Advisory Committee for the U.S. Department of Transportation, Washington, DC, June 26, 1980, 82 pages.

A major consensus document on technical options for improving airline fire survivability.

[64] FAA Aviation Forecasts - Fiscal Years 1983-1994, Report No. FAA-APO-83-l, Federal Aviation Administration, Washington, DC, February 1983, 72 pages.

[65] Fire Resistant Seat Cushions, Unpublished Final Report by Aerospace Industries Association of America, Transport Airworthiness Requirements Committee, Washington, DC, June 14, 1983, 68 pages.

[66] P.N. Garuda Indonesian Airways, Lockheed Electra L-188C, PK-GLB, accident at Mapanget Airport, Menado, Indonesia, on 16 February 1967 , Report (not dated) released by the Civil Air Transport Board, Ministry of Communications, Indonesia, Airline Accident Digest, Circular 107-AN/81, No. 19, International Civil Aviation Organization, Montreal, Quebec, Canada, 1973, pp. 108-116.

[67] John K. Graham and James W. Vaupel, Value of a life: what difference does it make?, Risk Analysis, Vol. I, No. 1, March 1981, pp. 89-95.

Overview of values attributed, explicitly or implicitly, to a statistical life saved in a large number of governmental actions.

[68] Lauren Graham, Research into post-crash fires, SAFE Journal, Vol. VII, No. 4, Winter 1977 , pp. 26-29.

[69] Roy J. Harris, Jr. and Norman Thorpe, Commercial-jet makers are trying to cut big stockpile of used planes, Wall Street Journal, Vol. CCII, No. 1l, July 18, 1983, p. 23.

Cites used aircraft prices of "less than $\$ 2$ million" for B727s and \$15-20 million for L-10lls.

[70] Richard Hill, Paul N. Boris and George R. Johnson, Aircraft Cabin Compartmentation Concepts for Improving Postcrash Fire Safety, Final Report FAA-RD-76-131, Federal Aviation Administration, Atlantic City, NJ, October 1976,74 pages. 
[71] Richard G. Hill, George R. Johnson and Constantine P. Sarkos, Postcrash Fuel Fire Hazard Measurements in a Wide-Body Aircraft Cabin, Final Report FAA-NA-79-42, Federal Aviation Administration, Atlantic City, NJ, December 1979 , 95 pages.

[72] Stefan N. Hoffer, Economic Analysis of Investment and Regulatory Decisions - A Guide, Report No. FAA-APO-82-1, Federal Aviation Administration, January 15, 1982, 139 pages.

Includes formulas for cost-benefit analyses of regulatory decisions, including references to OPM's official discount rate of 10 percent.

[73] Thomas G. Horeff, A Crashworthiness Analysis with Emphasis on the Fire Hazard: U.S. and Selected Foreign Turbine Aircraft Accidents, 1964-1974, FAA-RD-75-156, prepared for U.S. Department of Transportation, Washington, DC, July 1976, 162 pages.

Attributes far more fatalities to fire than the Cominsky report, principally by attributing one-fourth of all fatalities to fire in all incidents with poor information.

[74] Indian Airlines Corporation, Caravelle, VT-DPP, accident at Palam Airport, India, on 15 February 1966, Report No. 1/7/66-AS, dated 5 October 1967 , released by the Director General of Civil Aviation, India, Airline Accident Digest, Circular 88-AN/74, No. 17, Vol. II, International Civil Aviation Organization, Montreal, Quebec, Canada, 1969, pp. 64-74.

[75] International Civil Aviation Organization, Aircraft Accident Digest, Montreal, Quebec, Canada, 1965-present examined, Vol. 24 released in 1982 is the latest volume in print, about 200-250 pages per volume.

Digests of national accident reports for selected international aircraft accidents. See citations for individual accidents examined.

[76] International Civil Aviation Organization, Annual Report to the Council, Montreal, Quebec, Canada, volumes for 1965-1981 examined, about 200 pages per volume.

One of two major ICAO reports giving summary information on finances, activities, equipment and personnel of the world's airlines.

[77] International Civil Aviation Organization, Civil Aviation Statistics of the World, Document 9180 series, Montreal, Quebec, Canada, 1st edition (1975) through 6 th edition (1980) examined, $132-164$ pages.

One of the two major ICAO reports giving summary information on finances, activities, equipment and personnel of the world's airlines. 
[78] International Civil Aviation Organization, Fleet-Personnel, Series FP, Montreal, Quebec, Canada, 1980 and 1981 editions examined, approximately 200 pages per volume.

Statistics, by country, airline and aircraft type, on fleet inventory, numbers of seats per aircraft, departures and hours flown. There are numerous missing entries, and individual entries are not always consistent with totals, but this is the best avallable source for information on actual numbers of seats used in practice, by aircraft type.

[79] Japan Airlines, DC-8-62, JA-8040, accident at Moskva/Sheremetievo, USSR, on 28 November 1972, Report (not dated) released by the Deputy Minister of Civil Aviation of the USSR, Airline Accident Digest, Circular 132-AN/93, No. 21, International Civil Aviation Organization, Montreal, Quebec, Canada, 1977, pp. 22-26.

[80] N.B. Johnson and S.H. Robertson, Aircraft Crash Survival Design Guide, Volume V - Aircraft Postcrash Survival, Report No. USARTL-TR-79-22E, Final Report, U.S. Army Research and Technology Laboratories, Fort Eustis, VA, January 1980,224 pages.

An overview of provisions and how they operate.

[81] Jordan A. Greene and Associates, Jordan Greene's Aircraft Marketletter: Commercial Jet Transports, Avmark Services, Inc., Miami, FL, July and August 1983 examined.

Source of current information on market values of used aircraft.

[82] Ward L. Keech, Economic Values for Evaluation of Federal Aviation Administration Investment and Regulatory Programs, Report No. FAA-AP0-81-3, Federal Aviation Administration, Washington, DC, September 1981,79 pages.

Includes recommended values for loss of life $(\$ 530,000)$, serious injury $(\$ 38,000)$, minor injury $(\$ 15,000)$, and costs of replacement or restoration of eight types of turbine powered air carriers. Replacement costs are roughly comparable with used aircraft prices cited by Rek (1979) and Rek (1980).

[83] KLM, B-747, PH-BUF and Pan Am, B-747, N736, collision at Tenerife Airport, Spain, on 27 March 1977, Report (dated October 1978) released by the Subsecretaria de Aviacion Civil, Spain, Airline Accident Digest, Circular 153-AN/56, No. 23, International Civil Aviation Organization, Montreal, Quebec, Canada, 1980, pp. 22-68.

[84] D.A. Kourtides et al, Optimization of Aircraft Seat Cushion Fire Blocking Layers, Final Report DOT/FAA/CT-82-132, prepared by the National Aeronautics and Space Administration for the U.S. Department of Transportation, Moffett Field, CA, March 1983, 209 pages.

Cost/weight effectiveness model and algorithm are presented. Several new results on various blocking materials and configuration also are presented. 
[85] L.M. Krasner, Study of Hand-Held Fire Extinguishers Aboard Civil Aviation Aircraft, DOT/FAA/CT-82/42, prepared by Factory Mutual Research

Corporation for U.S. Department of Transportation, Norwood, MA, June 1982, 57 pages.

[86] Letter to John Hall, Center for Fire Research, National Bureau of Standards from R.L. Sears, Product Safety, Boeing Commercial Airplane Company, August 29, 1983, 14 pages.

This letter provided additional information on eight post-crash fire accidents and cited six previously unknown ramp fires. None of the latter appeared to be susceptible to prevention by seat blocking.

[87] Letters to Wayne Stiefel, Center for Fire Research, National Bureau of Standards, from John N. Feren, Manager of Tactical Analysis, Douglas Aircraft Company, July 18, 1983 and August 18, 1983, 25 and 7 pages.

[88] Letter to William J. Sullivan, Federal Aviation Administration, from William R. Kirkham and Delbert R. Lacefield, Civil Aeromedical Institute, November 28, 1977 .

Includes their proposed formulas for lethal and incapacitating combinations of cyanide and carboxyhemoglobin in blood. Since cyanide is taken as evidence of involvement of interior materials, the formulas can be used to infer which fatalities had lethal levels that would have been non-lethal or non-incapacitating if there had been no cyanide.

[89] Simon F. Lister and Gordon Raisbeck, An Approach to the Establishment of Practical Air Traffic Control Safety Goals, Report No. FAA-RD-71-36, Interim Report, U.S. Department of Transportation, Washington, DC, May 1971, 64 pages.

Includes a listing of mortality risk levels for selected activities, all expressed per 10 million exposure hours. Scheduled domestic airline passenger service is 16.0 . The others range from 0.45 (factory worker) to 290.0 (general aviation - passenger and crew).

[90] G.V. Lucha, M.A. Robertson and F.A. Schooley, An Analysis of Aircraft Accidents Involving Fires, NASA CR-137690, prepared by Stanford Research Institute for the National Aeronautics and Space Administration, Stanford, CA, May 1975,147 pages.

One of the first efforts to develop a baseline data base on post-crash fires, this report provides table-entry documentation on individual incidents from 1963-1974 U.S. airline experience. It also develops statistics and formulas (now ten years old) for aircraft costs and depreciation, based primarily on take-off weight, which the authors state accounted for 96 percent of the variation in cost. Unlike later reports, this does not present a detailed discussion of risk-reducing systems and their costs and benefits, but it provides a great deal of information useful in preparing an initial data base of fire-related losses. 
[91] Lufthansa, Boeing 747, D-ABYD, accident at Nairobi, Kenya, on 20 November 1974, Report No. CAV/ACC/26/74 (dated July 1976) released by the Accident Investigation Branch, East African Community, Airline Accident Digest, Circular 132-AN/93, No. 21, International Civil Aviation Organization, Montreal, Quebec, Canada, 1977, pp. 181-194.

[92] Charles D. MacArthur, Dayton Aircraft Cabin Fire Mode1, Version 3, Volumes I and II - Physical Description and Program User's Guide and Appendices, DOT/FAA/CT-81/69-I and II, Federal Aviation Administration, Atlantic City, NJ, June 1982, 52 and 204 pages.

[93] Major Aircraft Fires, Proceedings of a Symposium by the Ministry of Technology and Fire officers' Committee Joint Fire Research Organization, Borehamwood, Herts, United Kingdom, December 9, 1966, Her Majesty's Stationary Office, London, England, 1967, 101 pages.

[94] Mitre Corporation, Preliminary Analys is of Civil Aviation Accidents, January 1964 - December 1972, FAA-AVP-75-2, prepared for the U.S. Department of Transportation, Washington, DC, April 1975, 140 pages.

Listings of accidents and analyses are limited to U.S.-site accidents. Detailed descriptions (1-2 paragraphs) are limited to accidents involving five or more fatalities.

[95] K.R. Mniszewski et al, Fire Management/Suppression Systems/Concepts Relating to Aircraft Cabin Fire Safety, Final Report, prepared by IIT Research Institute and Gage Babcock \& Associates for the U.S. Department of Transportation, Chicago, IL, July 1982, 134 pages plus appendices.

This report examines a variety of systems for reducing losses occurring in post-crash, in-flight, and ground fires. Systems are divided into suppression-oriented, smoke control, thermal hardening and emergency evacuation. Of particular interest is an assessment of the likely impact of each system on deaths, injuries and losses, for each accident and overall. Their historical data base covers 1967 through 1978. The alternative defined as reduced "flammability of interior finish and combustibility of seating" was found to have an estimated cost per fatality prevented of $\$ 2.8 \mathrm{million}$ and an overall cost-to-benefit ratio of 5.58. The data base is primarily confined to accidents occurring on or near the territory of the U.S.A. or its possessions, but there are two exceptions. Their cumulative assessment of the likely impact of seat blocking on fatalities is roughly equal to our Medium-Save estimates, although the estimates for individual accidents vary considerably.

[96] National Research Council/National Academy of Sciences, Fire Safety Aspects of Polymeric Materials: Volume 6: Aircraft: Civil and Military, Report of the Committee on Fire Safety Aspects of Polymeric Materials to the National Materials Advisory Board, Commission on Soclotechnical Systems, Washington, DC, 1977, 257 pages.

Includes listings of fire-related incidents, including one of the more complete, better documented lists of ground fire incidents. 
[97] 1974 large-1oss fires in the United States, Fire Journal, Vo1. 69, September 1975, pp. $13 \mathrm{ff}$.

[98] W.J. Parker, An Assessment of Correlations Between Laboratory and Ful1 Scale Experiments for FAA Aircraft Fire Safety Program, Part 3: ASTM E 84, NBSIR 82-2564, National Bureau of Standards, Washington, DC, January 1983, 52 pages.

[99] W.J. Parker, An Assessment of Correlations Between Laboratory and Fu11Scale Experiments for the FAA Aircraft Fire Safety Program, Part 6: Reduced-Scale Modeling of Compartments at Atmospheric Pressure, NBSIR 82-2598, National Bureau of Standards, Washington, DC, March 1983, 50 pages.

[100] Randa11 Pozdena, Forecasts of Aircraft Activity by Altitude, World Region and Aircraft Type, Report No. FAA-AVP-76-18, Federal Aviation Administration, Washington, DC, November 1976, 132 pages.

[101] James G. Quintiere, An Assessment of Correlations Between Laboratory and Ful1-Scale Experiments for the FAA Aircraft Fire Safety Program: Parts 1 (Smoke), 2 (Rate of Energy Release in Fire) and 4 (Flammability Tests), NBSIR 82-2508, 82-2536, and 82-2525, National Bureau of Standards, Washington, DC, July $1982,53,24$ and 27 pages.

[102] James G. Quintiere and Takeyoshi Tanaka, An Assessment of Correlations Between Laboratory and Full-Scale Experiments for the FAA Aircraft Fire Safety Program, Part 5: Some Analyses of the Post Crash, NBSIR 82-2537, National Bureau of Standards, July 1982, 25 pages.

[103] Bron Rek, Airliner price guide, Flight International, Vol. 118, No. 3725, September 27,1980 , pp. 1272-1273.

A follow-up survey of new and used aircraft prices for major aircraft models.

[104] Bron Rek, Would you buy a second-hand jet?, Flight International, Vol. 115, No. 3653, March 24, 1979, pp. 910-912.

Results of a survey of new and used aircraft prices for major aircraft models.

[105] Safety record of short/medium-haul jets better than wide-bodies, Air Transport World, Vol. 17, No. 8, August 1980, pp. $57 \mathrm{ff}$.

[106] Constantine P. Sarkos, Comments on Subgroup 1, Appendix A, Aircraft Accident/Incident Fire Experience, T. Horeff Trip Report, May 22-27, 1978, Memorandum to AFS140, July $10,1978$.

Includes Sarkos' proposed formula for estimating when interior materials were involved in a fire fatality, based on blood cyanide levels. 
[107] Constantine P. Sarkos and Richard G. Hill, Effectiveness of Seat Cushion Blocking Layer Materials Against Cabin Fire, SAE Technical Paper Series 821484 , Warrendale, PA, 1982, 9 pages.

Summary descriptions of results of tests on seat blocking materials. Extra escape times, relative to unprotected cushion, are provided for Norfab, Vonar and non-combustible foam. Photographs also are included.

[108] Constantine P. Sarkos, Richard G. Hill and Wayne D. Howell, The Development and Application of a Full-Scale Wide-Body Test Article to Study the Behavior of Interior Materials During a Post Crash Fuel Fire, Journal of Fire and Flammability, Vol. 13, July 1982, pp. 172-202.

[109] Constantine P. Sarkos, Richard G. Hill and Wayne D. Howell, The Development and Application of a Full-Scale Wide-Body Test Article to Study the Behavior of Interior Materials During a Post Crash Fuel Fire, Paper reprinted from Lecture Series No. 123 on Aircraft Fire Safety, North Atlantic Treaty Organization Advisory Group for Aerospace Research and Development, Neuilly sur Seine, France, June 1982, 21 pages.

A report similar to the Agard paper by Sarkos and Hill but giving more attention to the test methods as opposed to the system being tested. It cites an FAA study of 1964-74 accidents that found $39 \%$ of fatalities in survivable accidents were attributable to fire.

[110] John J. Smith, Regulatory Evaluation - Regulatory Flexibility Analysis and Trade Impact Assessment: Flammability Requirements for Aircraft Seat Cushions, Unpublished Report, Federal Aviation Administration, Washington, DC, July 1983, 28 pages.

[111] Clyde C. Snow, John J. Carroll and Mackie A. Allgood, Survival in Emergency Escape from Passenger Aircraft, AM 70-16, Federal Aviation Administration, Washington, DC, October 1970, 61 pages.

The most thorough examination found of factors affecting ability to use extra escape time, time required to escape, and related matters, studied through analysis of three accidents, the 1965 Salt Lake City accident and two pre-1965 accidents.

[112] R.G. Snyder, Advanced Techniques in Crash Impact Protection and Emergency Egress from Air Transport Aircraft, AGARD-AG-221, Advisory Group for Aerospace Research and Development, North Atlantic Treaty Organization, Neuilly sur Seine, France, June 1976, 320 pages.

Analysis of 1964-75 air transport accidents in NATO-member countries; very limited information on individual accidents.

[113] A Study of U.S Air Carrier Accidents, 1964-1969, NTSB-AAS-72-5, National Transportation Safety Board, Washington, DC, May 10, 1972, 383 pages. 
[114] A.F. Taylor, Fire, Fuel and Survival: A Study of Transport Aircraft Accidents, 1955-1974, Aircraft Fire Safety, AGARD Conference Proceedings, AGARD-CP-166, Paper 非6, Advisory Group for Aerospace Research and Development, North Atlantic Treaty Organization, Neuilly sur Seine, France, October 1975.

Covers fatal fire incidents through 1974 with little detail listed per incident and tends to estimate fire fatalities higher than other sources, such as Cominsky (1981).

[115] Linda Gay Thompson, Seat Cushion Design User's Manual, Unpublished Report by Informatics, Inc., Palo Alto, CA, May 22, 1982, pages not numbered.

[116] Turkish Airlines, F-28, TC-JAO, accident at Izmir/Cumaovasi, Turkey, on 26 January 1974, Report No. T-5-199 (not dated) released by the Ministry of Communications, Turkey, Airline Accident Digest, Circular 132-AN/93, No. 21, International Civil Aviation Organization, Montreal, Quebec, Canada, 1977, pp. 109-115.

[117] U.S. Air Carrier Accidents Involving Fire, 1965 Through 1974, and Factors Affecting the Statistics, NTSB Special Study NTSB-AAS-77-1, National Transportation Safety Board, 1977, 62 pages.

[118] Varig Airlines, DC-8, PP-PEA, accident at Roberts International Airport, Charlesville, Marshall Territory, Liberia, on 5 March 1967, Summary of Aircraft Report dated 13 September 1967, released by the Commission of Inquiry, Department of Commerce and Industry, Republic of Liberia, Airline Accident Digest, Circular 88-AN/74, No. 17, Volume II, International Civil Aviation Organization, Montreal, Quebec, Canada, 1969, pp. 142-150.

[119] Varig, Boeing 707, PP-VJ2, accident near Paris/or1y, France, on 11 July 1973, Report (dated December 1975) released by Secretariat d'Etat aux Transports, France, Airline Accident Digest, Circular 132-AN/93, No. 21, International Civil Aviation Organization, Montreal, Quebec, Canada, 1977, pp. 68-78.

[120] Wharton Econometrics, Extension to the Year 2002, Philadelphia, PA, August 1983.

[121] Wharton Econometrics, The Wharton Long-Term Mode1, Philadelphia, PA, June 1983. 

Data Sources and Calculations for Sample Application of Models to Fire-Blocking of Aircraft Seats

Tables G-1 through G-3 indicate the expected lives saved as a function of the extra escape time provided, for each fatal accident listed in tables 1-3. The evidence supporting these functions is contained in the detailed accident descriptions in appendix $A$. The savings functions for the individual accidents are combined together in table G-4, and table G-5 converts these totals to savings functions appropriate for 1982 exposure levels, using the conversion factors given in section 2.2 .2 .

Table G-6 provides actual savings for the escape time values considered in the analysis. Note that 20 seconds is less than half the lower of the escape time values obtained in testing and probably is less than the time that would be provided by any blocking material that would be approved by FAA. Note that 180 seconds is the upper limit of interest; at that point, everyone who could have been saved would have been saved. Note that the lives saved using U.S. airlines and/or U.S. aircraft are consistently within two percent of the savings for the world airline case, regardless of the actual escape time provided. The two cases are so similar that it is not useful to pursue the analysis of the U.S./U.S. case any further. Table G-7 provides further comparisons of the relative savings for different escape-time values.

Table G-8 describes the design characteristics of the three existing materials considered in the analysis. Manufacturer $B$ stated that the cotton/muslin scrim was unnecessary for both materials 2 and 4 , permitting additional cost and weight reduction.

Table G-9 gives the data collected on incremental materials, installation, and fabrication costs and weight penalties. Manufacturers $A$ and $B$ were asked to assume a high production situation in computing these costs. Table G-10 converts that data into high, middle and low estimates of the cost per seat, not including operating costs, and the incremental weight-per-seat.

These calculations, combined with the formulas given in sections 2.4.2 and 2.4 .3 , do not yet suffice to produce high, middle and low estimates of year-by-year costs of creating and maintaining a seat-blocked fleet and of operating such a fleet. The missing elements are the number of seats per aircraft, by aircraft type (given in appendix E) and the phase-in and refurbishment cycles. A fixed three-year refurbishment cycle was used, based upon discussions with seat manufacturers. In practice, refurbishment cycles are determined by marketing considerations and vary from carrier to carrier. Also, seat backs are less prone to soiling and wear than seat bottoms. A three-year cycle was used because no information was available to support a more complicated formula.

On the basis of discussions with FAA and seat manufacturers, we assume that seat blocking would be phased in during a normal three-year refurbishment cycle and that replacement or refurbishment of the blocker will cost as much as the initial cost of creating and installing it. Manufacturer A said time studies might show savings in refurbishment, but until such studies were made no adequate estimate could be made. Manufacturer B raised the possibility 
that blockers might last through two seat refurbishment cycles. Tables G-11 and G-12 show the schedules of new seat blocking (initially for new and existing alrcraft, later only for new aircraft) and seat blocker refurbishment for U.S. and world airlines, respectively, assuming blocker refurbishment will follow the same schedule as normal seat refurbishment. Table G-13 examines the effects if blockers are durable enough to last six years between refurbishments. Questions remain concerning the potential for deterioration of material 2 or its fire blocking properties if it is kept in use through two refurbishment cycles. 
Table G-1. Estimated Fire Fatalities Prevented by Seat Blocking, 1965-82

\section{U.S. Airlines}

Note: $T$ is the number of extra seconds of escape time provided by seat blocking. It 1 s assumed that any version of seat blocking will provide at least 20 extra seconds.

\begin{tabular}{|c|c|c|c|c|c|c|}
\hline & & & Estimated & Estimate & Number of Pers & ns Saved \\
\hline & & & Fire & High & Middle & Low \\
\hline & Date & Description & Fatalities & Estimate & Estimate & Estimate \\
\hline 1. & $11 / 8 / 65$ & $\begin{array}{l}\text { American, B727, Jet } \\
\text { Near Constance, KY }\end{array}$ & 36 & 0 & 0 & 0 \\
\hline 2. & $11 / 11 / 65$ & $\begin{array}{l}\text { United, B727, Jet } \\
\text { Salt Lake City, UT }\end{array}$ & 43 & $\begin{array}{l}11+T, \text { if } T<29 \\
40, \text { if } T \geq 29\end{array}$ & $\begin{array}{l}11+T, \text { if } T \leq 27 \\
38, \text { if } T \geq 27\end{array}$ & $\begin{array}{l}7+T, \text { if } T \leq 23 \\
30, \text { if } T \geq 23\end{array}$ \\
\hline 3. & $4 / 22 / 66$ & $\begin{array}{l}\text { American Flyers, L- } 188 \text {, } \\
\text { Turboprop, Ardmore, OK }\end{array}$ & 15 & 15 & 15 & 0 \\
\hline 4. & $6 / 23 / 67$ & $\begin{array}{l}\text { Mohawk, BAC-111, Jet } \\
\text { Blossburg, PA }\end{array}$ & 34 & 0 & 0 & 0 \\
\hline 5. & $6 / 12 / 68$ & $\begin{array}{l}\text { Pan American, B707, Jet } \\
\text { India }\end{array}$ & 6 & 0 & 0 & 0 \\
\hline 6. & $11 / 27 / 70$ & $\begin{array}{l}\text { Capitol International, } \\
\text { DC8, Jet, Anchorage, AK }\end{array}$ & 47 & 47 & 15 & 10 \\
\hline 7. & $12 / 28 / 70$ & $\begin{array}{l}\text { Trans-Car1bbean, } B 727 \text {, } \\
\text { Jet, St. Thomas, Virgin } \\
\text { Islands }\end{array}$ & 2 & 0 & 0 & 0 \\
\hline 8. & $6 / 7 / 71$ & $\begin{array}{l}\text { Allegheny, CV } 580 \text {, } \\
\text { Turboprop, New Haven, CT }\end{array}$ & 27 & $\begin{array}{l}T / 2, \text { if } T \leq 54 \\
27, \text { if } T \geq 54\end{array}$ & 5 & 1 \\
\hline 9. & $12 / 8 / 72$ & $\begin{array}{l}\text { United, B737, Jet } \\
\text { Chicago, IL }\end{array}$ & 30 & 7 & 7 & 0 \\
\hline 10. & $12 / 20 / 72$ & $\begin{array}{l}\text { North Central, DC9, } \\
\text { Jet, Chicago, IL }\end{array}$ & 10 & 9 & 7 & 3 \\
\hline 11. & $7 / 22 / 73$ & $\begin{array}{l}\text { Pan American, B707, } \\
\text { Jet, Tah1t1 }\end{array}$ & 79 & 0 & 0 & 0 \\
\hline 12. & $1 / 30 / 74$ & $\begin{array}{l}\text { Pan American, B707, } \\
\text { Jet, Pago Pago, } \\
\text { American Samoa }\end{array}$ & 95 & $\begin{array}{l}6+T, \text { if } T \leq 88 \\
94, \text { if } T \geq 88\end{array}$ & $\begin{array}{l}6+T, \text { if } T<41 \\
47, \text { if } T \geq 41\end{array}$ & 0 \\
\hline 13. & $9 / 11 / 74$ & $\begin{array}{l}\text { Eastern, DC9, Jet } \\
\text { Charlotte, NC }\end{array}$ & 36 & 0 & 0 & 0 \\
\hline 14. & $4 / 27 / 76$ & $\begin{array}{l}\text { American, } B 727 \text {, Jet } \\
\text { St. Thomas, V1rgin } \\
\text { Islands }\end{array}$ & 36 & $\begin{array}{l}T / 2, \text { if } T \leq 22 \\
11, \text { if } T \geq 22\end{array}$ & 0 & 0 \\
\hline 15. & $3 / 27 / 77$ & $\begin{array}{l}\text { Pan American, B747, } \\
\text { Jet, Canary Islands }\end{array}$ & 192 & 0 & 0 & 0 \\
\hline 16. & $4 / 4 / 77$ & $\begin{array}{l}\text { Southern, DC9, Jet } \\
\text { Near New Hope, GA }\end{array}$ & 20 & 3 & 3 & 3 \\
\hline 17. & $3 / 1 / 78$ & $\begin{array}{l}\text { Continental, } \mathrm{DC} 10 \text {, Jet } \\
\text { Los Angeles, CA }\end{array}$ & 4 & 0 & 0 & 0 \\
\hline
\end{tabular}




\section{Non-U.S. Airlines Using U.S.-Built Aircraft}

Note: $T$ is the number of extra seconds of escape time provided by seat blocking. It 1 s assumed that any version of seat blocking w1ll provide at least 20 extra seconds.

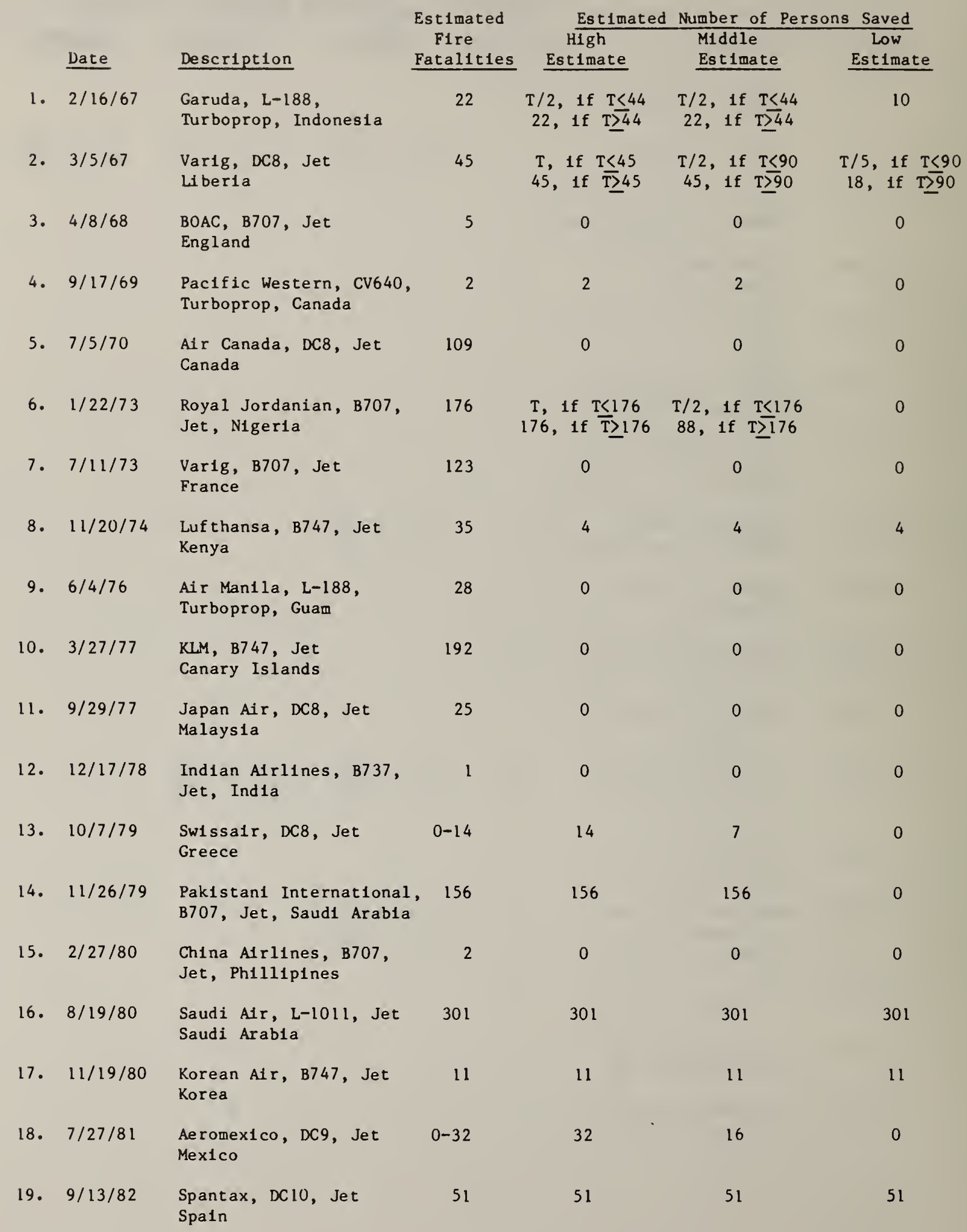


Table G-3. Estimated Fire Fatalities Prevented by Seat Blocking, 1965-82

Non-U.S. Airlines Using Non-U.S.-Built Aircraft

Note: $\mathrm{T}$ is the number of extra seconds of escape time provided by seat blocking. It is assumed that any version of seat blocking will provide at least 20 extra seconds.

\section{Date Description}

1. $2 / 15 / 66$

Indian Airlines, Caravelle, Jet, India

2. 9/11/68 Air France, Caravelle, Jet, France

3. 7/26/69 Air Algerie, Caravelle, Jet, Algeria

4. $5 / 6 / 70$

Somali, Viscount, Turboprop, Somalia

5. 3/15/74 Sterling, Caravelle, Jet, Iran

\section{Estimated}

Fire

Fatalities

$0-2$

95

33

0

0

0

$0-5$

0

0

0

15

$\frac{\text { Estimated Number of Persons Saved }}{\text { High }}$

Estimate

2

0

0

0

0

0

0

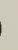

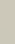

15

15

0 
These tables represent summations of the savings figures in tables G-l, G-2 and G-3. $T$ is the number of extra seconds of escape time and is assumed to be at least 20 if seat blocking is present.

\section{Lives Saved by Seat Blocking}

Total Fire

Fatalities

U.S. Airlines Only

712

$$
\begin{aligned}
& 98+3 \mathrm{~T} \text { if } 20 \leq \mathrm{T}<22 \\
& 109+2.5 \mathrm{~T} \text { if } 22 \leq \mathrm{T}<29 \\
& 138+1.5 \mathrm{~T} \text { if } 29 \leq \mathrm{T} \leq 54 \\
& 165+\mathrm{T} \text { if } 54 \leq \mathrm{T} \leq 88 \\
& 253 \text { if } \mathrm{T}>88
\end{aligned}
$$

U.S. Airlines and/or Aircraft

$$
\begin{array}{ll}
1,996-2,042 \quad & 665+5.5 \mathrm{~T} \text { if } 20 \leq \mathrm{T}<22 \\
& 676+5 \mathrm{~T} \text { if } 22 \leq \mathrm{T}<29 \\
& 705+4 \mathrm{~T} \text { if } 29 \leq \mathrm{T}<44 \\
& 772+2.5 \mathrm{~T} \text { if } 45 \leq \mathrm{T}<54 \\
& 799+2 \mathrm{~T} \text { if } 54 \leq \mathrm{T}<88 \\
& 887+\mathrm{T} \text { if } 88 \leq \mathrm{T}<176 \\
& 1,063 \text { if } \mathrm{T} \geq 17 \overline{6}
\end{array}
$$

Wor1d Airlines

$$
\begin{array}{ll}
2,139-2,192 \quad & 682+5.5 \mathrm{~T} \text { if } 20<\mathrm{T}<22 \\
& 693+5 \mathrm{~T} \text { if } 22<\mathrm{T}<29 \\
& 722+4 \mathrm{~T} \text { if } 29<\mathrm{T}<44 \\
& 789+2.5 \mathrm{~T} \text { if } 45<\mathrm{T}<54 \\
& 816+2 \mathrm{~T} \text { if } 54 \leq \mathrm{T}<88 \\
& 904+\mathrm{T} \text { if } 88<\mathrm{T}<176 \\
& 1,080 \text { if } \mathrm{T} \geq 17 \overline{6}
\end{array}
$$

$69+2 \mathrm{~T}$ if $20<\mathrm{T}<27$

$96+\mathrm{T}$ if $27<\overline{\mathrm{T}}<41$

137 if $\mathrm{T}>4 \mathrm{l}$

$613+4 \mathrm{~T}$ if $20<\mathrm{T}<27$

$640+3 \mathrm{~T}$ if $27 \overline{<\mathrm{T}<4 \mathrm{l}}$

$681+2 \mathrm{~T}$ if $41<\mathrm{T}<44$

$748+0.5 \mathrm{~T}$ if $45 \leq \mathrm{T} \leq 176$

836 if $T \geq 176$

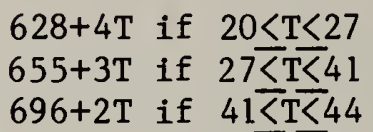

Low Estimate

851 if $T \geq 176$ 
Table G-5. Estimated Annual Savings From Seat Blocking Given 1982 Exposure Levels

\section{High Estimate \\ Middle Estimate}

U.S. Airlines Only
$5.56+0.16 \mathrm{~T}$ if $20<\mathrm{T}<27$

$7.73+0.08 \mathrm{~T}$ if $27 \leq \mathrm{T}<41$

11.04 if $\mathrm{T}>41$

$13.30+0.08 \mathrm{~T}$ if $54<\mathrm{T}<88$

20.39 if $\mathrm{T} \geq 88$

Damage

Avoided

\section{$\$ 1.79$ Million}

\author{
$57.88+0.38 \mathrm{~T}$ if $20<\mathrm{T}<27$ \\ $60.43+0.28 \mathrm{~T}$ if $27<\mathrm{T}<41$ \\ $64.31+0.19 \mathrm{~T}$ if $41<\mathrm{T}<44$ \\ $70.63+0.05 \mathrm{~T}$ if $45 \leq \mathrm{T} \leq 176$ \\ 78.94 if $\mathrm{T} \geq 176$
}

$\$ 7.87$ million

$58 \cdot 26+0.37 \mathrm{~T}$ if $20<\mathrm{T}<27$ $60.76+0.28 \mathrm{~T}$ if $27 \leq \mathrm{T}<41$ $64.56+0.19$ if $41<\bar{T}<44$ $70.78+0.05 \mathrm{~T}$ if $4 \overline{5} \leq \mathrm{T}<176$ 78.94 if $\mathrm{T} \geq 176$
$1.93+0.08 \mathrm{~T}$ if $20 \leq \mathrm{T}<23$ 3.79 if $\mathrm{T} \geq 23$

$\$ 1.43$ million

$37.87+0.11 \mathrm{~T}$ if $20<\mathrm{T}<23$ $40.04+0.02 \mathrm{~T}$ if $23 \leq \mathrm{T}<90$ 41.74 if $\mathrm{T} \geq 90$
Damage

Avoided

World Airlines

Lives Saved

$$
\begin{aligned}
& 63 \cdot 27+0.51 \mathrm{~T} \text { if } 20 \leq \mathrm{T} \leq 22 \\
& 64 \cdot 29+0.46 \mathrm{~T} \text { if } 22 \leq \mathrm{T}<29 \\
& 66.98+0.37 \mathrm{~T} \text { if } 29 \overline{\mathrm{T}} \mathrm{L} 44 \\
& 73.19+0.23 \mathrm{~T} \text { if } 45 \leq \mathrm{T}<54 \\
& 75.70+0.19 \mathrm{~T} \text { if } 54 \leq \mathrm{T}<88 \\
& 83.86+0.09 \mathrm{~T} \text { if } 88 \leq \mathrm{T} \leq 176 \\
& 100.19 \text { if } \mathrm{T} \geq 176
\end{aligned}
$$

Low Estimate

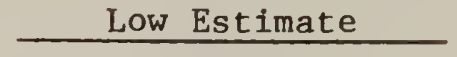

\section{U.S. Airlines and/or Aircraft}


Table G-6. Estimated Annual Savings Given Five Values of Added Escape Time and 1982 Exposure Levels

\section{High Estimate}

Middle Estimate

Low Estimate

U.S. Airlines Only
20 seconds
43 seconds
60 seconds
90 seconds
180 seconds

Property damage savings

for all cases

U.S. Airlines and/or Aircraft

$\begin{array}{ll}13.70 & \text { lives } \\ 16.28 & \text { lives } \\ 18.10 & \text { lives } \\ 20.39 & \text { lives } \\ 20.39 & \text { lives }\end{array}$

$\$ 3.14$ million

$$
\begin{aligned}
8.76 & \text { lives } \\
11.04 & \text { lives } \\
11.04 & \text { lives } \\
11.04 & \text { lives } \\
11.04 & \text { lives }
\end{aligned}
$$

$\$ 1.79$ million

65.48 lives

72.48 lives

73.63 lives

75.13 lives

78.94 lives

$\$ 13.91$ million
73.20 lives
82.91 lives
86.85 lives
91.86 lives
100.38 lives

savings

for all cases

World Airlines
73.47 lives
82.89 lives
87.10 lives
91.96 lives
100.19 lives

$\$ 13.67$ million

\subsection{6 lives \\ 72.73 lives \\ 73.78 lives \\ 75.28 lives \\ 78.94 lives}

$\$ 7.78$ million

3.53 lives

3.79 lives

3.79 lives

3.79 lives

3.79 lives

$\$ 1.43$ million

Property damage savings

for all cases

$\$ 13.67$ mi11ion
40.07 lives
40.90 lives
41.24 lives
41.74 1ives
41.74 lives

$\$ 3.47$ million
39.40 lives
40.19 lives
40.53 lives
41.00 lives
41.00 lives

$\$ 3.41$ million 
Table G-7. Additions to or Reductions in Savings at Limits of Expected Values of Added Escape Time

(All loss values are in millions of dollars)

High Estimate Middle Estimate Low Estimate

U.S. Airlines Only

Material 1 (20 secs) vs.

Material 2 ( 43 secs)

Lives saved

Total savings @ $\$ 500 \mathrm{~K}$ per life

$\begin{array}{llll}-2.58(-16 \%) & -2.28(-21 \%) & -0.26(-7 \%) \\ -1.29(-11 \%) & -1.14(-16 \%) & -0.13(-4 \%)\end{array}$

Material 5 (90 secs) vs.

Material 4 (60 secs)

Lives saved

Total savings @ $\$ 500 \mathrm{~K}$ per life

$+2.29(+13 \%)$

0

0

$+1.15(+9 \%)$

0

Material 6 (180 secs) vs.

Material 4 (60 secs)

Lives saved

Total savings @\$500 K per life

$+2.29(+13 \%)$

0

0

$+1.15(+9 \%)$

0

0

World Airlines

Material 1 (20 secs) vs.

Material 2 (43 secs)

Lives saved

Total savings @ $\$ 500 \mathrm{~K}$

$-9.42(-11 \%) \quad-7.07(-10 \%) \quad-0.79(-2 \%)$

per life

$-4.71(-9 \%) \quad-3.54(-8 \%) \quad-0.40(-2 \%)$

Material 5 ( 90 secs) vs.

Material 4 (60 secs)

Lives saved

Total savings @ $\$ 500 \mathrm{~K}$ per life

$\begin{array}{llll}+4.86(+6 \%) & +1.50(+2 \%) & +0.47(+1 \%) \\ +2.43(+4 \%) & +0.75(+2 \%) & +0.24(+1 \%)\end{array}$

Material 6 (180 secs) vs.

Material 4 (60 secs)

Lives saved

Total savings @ $\$ 500 \mathrm{~K}$

per life

$\begin{array}{lll}+13.09(+15 \%) & +5.16(+7 \%) & +0.47(+1 \%) \\ +6.55(+11 \%) & +2.58(+6 \%) & +0.24(+1 \%)\end{array}$


Table G-8. Design Characteristics of Seat Blocking Alternatives

\author{
Current Design - "Typical" Cushion (similar to below) \\ Cover - Wool/Nylon \\ Scrim - Cotton/Muslin \\ Urethane - Fire-Retarded Urethane
}

Design for Material 2 - Blocking Material Sewn Around Urethane

Cover - Wool/Nylon

Scrim - Cotton/Muslin

Fire Blocker - Weave Structure 1 x 1 Plain,

Aluminized One Side,

$25 \%$ Nomex, $70 \%$ Kevlar, 5\% Kynol

Design for Material 3 - Blocking Material Sewn Around Urethane

Cover and Scrim Assumed to be Same as

for Material 2

Fire Blocker - loosely woven fiberglass scrim and light weight fiberglass paper bonded with non-halogenated fire-retarded adhesive system.

Design for Material 4 - Blocking Material Bonded to Urethane

Cover - Wool/Nylon

Scrim - Cotton/Muslin

Fire Blocker - 3/16" Neoprene Foam

NOTE: The blocking materials tested by FAA were as follows:

Version of Material 2 - Norfab 11HT-26-A1 fabric, a registered

trademark of the Norfab Corporation. Version of Material 3 -

Insul-Fab, a registered trademark of Facile Technologies, Inc. Version of Material 4 - Vonar No. 3, a registered trademark of E.I. duPont de Nemours Company, Inc.

Each material was analyzed in combination with conventional fireretarded urethane and with the less expensive lighter non-fire-retarded urethane. 


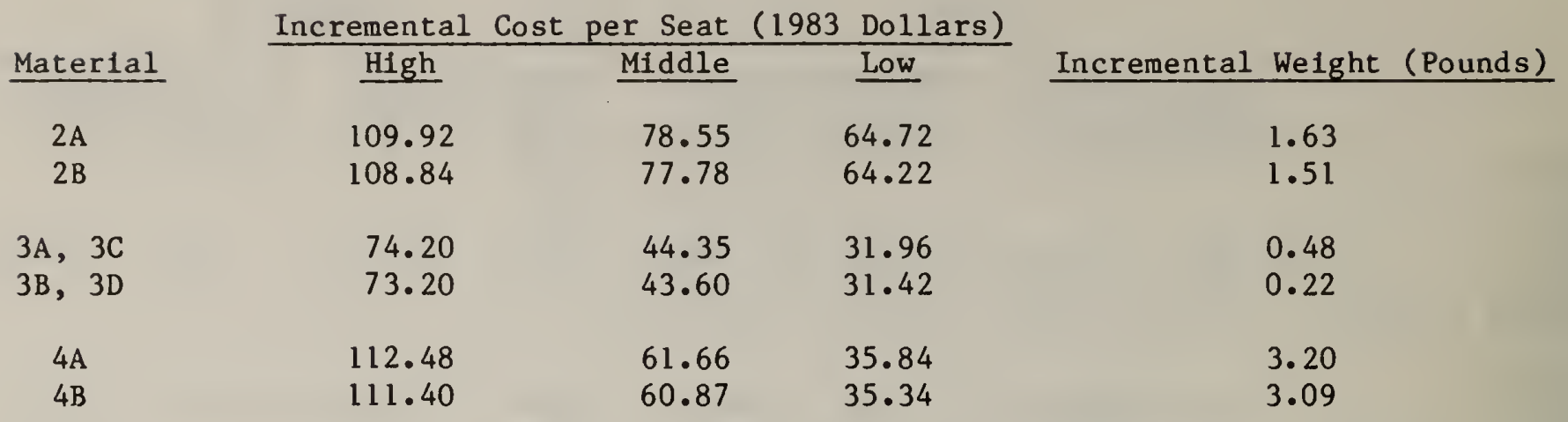

Note: The high cost estimates are the upper bounds of manufacturer $B$ 's range of estimates. The middle estimates are averages of manufacturer $A^{\prime}$ 's estimates and the midpoints of manufacturer B's ranges of estimates. The low estimates are manufacturer A's estimates. The weight estimates are averages of the two manufacturer's estimates. All estimates assume a fleet mix of 92 percent coach seats and eight percent first-class seats.

Table G-11. Schedule of Seats Blocked for U.S. Fleet Using Three-Year Cycles for Phase-In and Refurbishment

Number of Seats Newly Blocked or Reblocked

Year

1984

1985

1986

1987

1988

1989

1990

1991

1992

1993

1994

1995

1996

1997
Added

15,622

31,954

32,260

34,242

37,585

22,831

35,291

37,201

42,524

41,056

37,547

35,326

31,118

24,389
Refurbished

107,231

93,951

117,075

106,014

103,949

137,191

114,204

116,374

135,743

118,849

132,691

160,535

146,194

163,330
Combined

122,853

125,905

149,335

140,256

141,534

160,022

149,495

153,575

178,268

159,905

170,238

195,861

177,312

187,719 
Table G-12. Schedule of Seats Blocked for World Fleet Using a Three-Year Refurbishment Cycle

\section{Number of Seats Newly Blocked or Reblocked}

$\underline{\text { Year }}$

1984

1985

1986

1987

1988

1989

1990

1991

1992

1993

1994

1995

1996

1997

\section{Added}

57,556

74,334

75,127

78,839

91,863

82,480

89,210

101,709

103,147

102,891

100,376

98,391

92,238

86,851 $\underline{\text { Refurbished }}$

244,617

234,411

299,976

265,340

261,107

330,810

292,189

295,890

364,088

327,736

355,491

434,128

403,226

438,997
Combined

302,173

308,745

375,103

344,179

352,971

413,290

381,399

397,599

467,236

430,627

455,867

532,519

495,464

525,848

Table G-13. Schedule of Seats Blocked for U.S. Fleet Using a Three-Year Phase-In and Six-Year Reblocking Cycle

Year

1984

1985

1986

1987

1988

1989

1990

1991

1992

1993

1994

1995

1996

1997
Refurbished

34,242

37,585

22,831

35,291

37,201

42,524

41,056

37,547

35,326

31,118

24,389
107,231

93,951

117,075

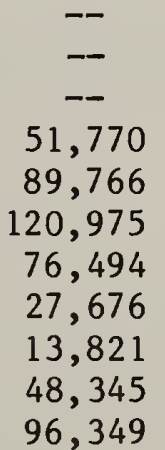

Combined

122,853

117,075

149,335

34,242

37,585

22,831

87,061

126,967

163,499

117,550

65,223

49,147

79,463

120,738 

Formulas for Additional Sensitivity Analyses

In addition to the sensitivity analyses performed in this report, readers may wish to evaluate the effect of alternative assumptions regarding fue 1 price, incremental weight per seat or incremental cost per seat. The tabulated fuel-cost present values for each year have been summed and rearranged to facilitate the evaluation of these influences on fuel cost. To compute the annualized cost of fuel to fly a specified incremental weight per seat at a 10 percent discount rate for the 1984 through 1997 study period and a three-year phase-in, use the following:

$\left.\begin{array}{l}\text { U.S. Fleet Annualized } \\ \text { Fuel Cost in Millions } \\ \text { of } 1983 \text { Dollars }\end{array}\right\}=6.67 \times\left[\begin{array}{l}\text { Incremental Weight } \\ \text { per Seat in Pounds }\end{array}\right] \times\left[\begin{array}{l}1983 \text { Price per Gallon } \\ \text { of Fuel in Dollars }\end{array}\right]$

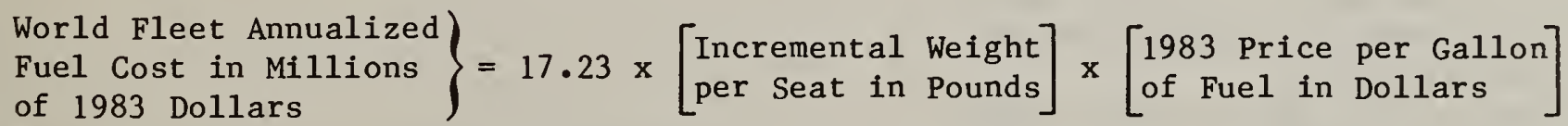

A similar formulation can be applied to evaluate the effect of changes in incremental cost per seat on total seat costs. To compute the annualized seat costs for a specific incremental cost per seat, using a 10 percent discount rate for the 1984 through 1997 study and a three-year phase-in and reblocking schedule, use the following:

$\left.\begin{array}{l}\text { U.S. Fleet Annualized } \\ \begin{array}{l}\text { Seat Cost in Millions } \\ \text { of } 1983 \text { Dollars }\end{array}\end{array}\right\}=0.1506 \times\left[\begin{array}{l}\text { Incremental Cost per } \\ \text { Seat in Dollars }\end{array}\right]$

$\left.\begin{array}{l}\text { World Fleet Annualized } \\ \text { Seat Cost in Millions } \\ \text { of } 1983 \text { Dollars }\end{array}\right\}=0.3875 \times\left[\begin{array}{l}\text { Incremental Cost per } \\ \text { Seat in Dollars }\end{array}\right]$

Similar computations for a three-year phase-in and a six-year reblocking schedule would use the following:

$\left.\begin{array}{l}\text { U.S. Fleet Annualized } \\ \begin{array}{l}\text { Seat Cost in Millions } \\ \text { of } 1983 \text { Dollars }\end{array}\end{array}\right\}=0.0814 \times\left[\begin{array}{l}\text { Incremental Cost per } \\ \text { Seat in Dollars }\end{array}\right]$ 
NBS-114A (REV. 2-8C)

U.S. DEPT. OF COMM.

BIBLIOGRAPHIC DATA

SHEET (See instructions)

4. TITLE AND SUBTITLE

\begin{tabular}{l|l}
\hline $\begin{array}{l}\text { 1. PUBLICATION OR } \\
\text { REPORT NO. } \\
\text { NBSIR } 84-2817\end{array}$ & 2. Performing Organ. Report No \\
\end{tabular}

3. Publication Date

March 1984

DECISION ANALYSIS MODEL FOR PASSENGER-AIRCRAFT FIRE SAFETY WITH APPLICATION TO FIRE-BLOCKING OF SEATS

5. AUTHOR(S)

John R. Hall, Jr. and S. Wayne Stiefel

6. PERFORMING ORGANIZATION (If joint or other than NBS, see instructions)

NATIONAL BUREAU OF STANDARDS

DEPARTMENT OF COMMERCE

WASHINGTON, D.C. 20234

7. ContracU Grant No. DTFA30-83-A-0034

8. Type of Report \& Period Covered Interim

Nov. 1982-Dec. 1983

9. SPONSORINC ORGANIZATION NAME AND COMPLETE ADDRESS (SUreet, Cily, State, ZIP)

U.S. Department of Transportation

Federal Aviation Administration

Technical Center

Atlantic City, New Jersey 08405

10. SUPPLEMENTARY NOTES

Document describes a computer program; SF-185, FIPS Software Summary, is attached.

11. ABSTRACT (A 200-word or less factual summary of most significant information. If document includes a significant bibliography or literature survey, mention it here)

This report develops a generic model for analysis of the costs and benefits of fire-risk reducing strategies related to passenger airlines. The model calculates incremental costs for installing and operating these options. It also calculates estimated lives saved and property damage avoided, and it provides rules for combining costs and benefits into a single measure of attractiveness for an alternative. This model is then applied to the strategy of fire-blocking seats on passenger airlines, either on U.S. airlines or on all world airlines.

12. KEY WORDS (Six to twelve entries; alphabetical order; capltallze only proper names; and separate key words by semicolons) Aircraft accidents; aircraft fires; aircraft safety; decision analysis; fire safety risk analysis; seats; statistics; upholstery

13. AVAILABILITY

Unlimited

$\square$ For Official Distribution. Do Not Release to NTIS

L_ Order From Superintendent of Documents, U.S. Government Printing Office, Washington, D.C. 20402.

[X] Order From National Technical Information Service (NTIS), Springfield, VA. 2216I
14. NO. OF PRINTED PAGES 103

15. Price 

